Portland State University

PDXScholar

$1-1-1983$

\title{
A computer decision support system to assist in providing equality of educational opportunity
}

Porter Sexton

Portland State University

Follow this and additional works at: https://pdxscholar.library.pdx.edu/open_access_etds Let us know how access to this document benefits you.

\section{Recommended Citation}

Sexton, Porter, "A computer decision support system to assist in providing equality of educational opportunity" (1983). Dissertations and Theses. Paper 795.

https://doi.org/10.15760/etd.795

This Dissertation is brought to you for free and open access. It has been accepted for inclusion in Dissertations and Theses by an authorized administrator of PDXScholar. Please contact us if we can make this document more accessible: pdxscholar@pdx.edu. 


\author{
A \\ COMPUTER DECISION SUPPORT SYSTEM \\ TO ASSIST IN PROVIDING \\ EQUALITY OF EDUCATIONAL OPPORTUNITY
}

by

PORTER SEXTON

A dissertation submitted in partial fulfillment of the requirements for the degree of

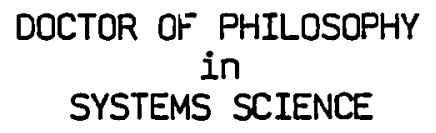

Portland State University

1983 
TO THE OFF ICE OF GRADUATE STUDIES AND RESEARCH:

The members of the Committee approve the dissertation of Porter W. Sexton presentedjon February 10, 1983.

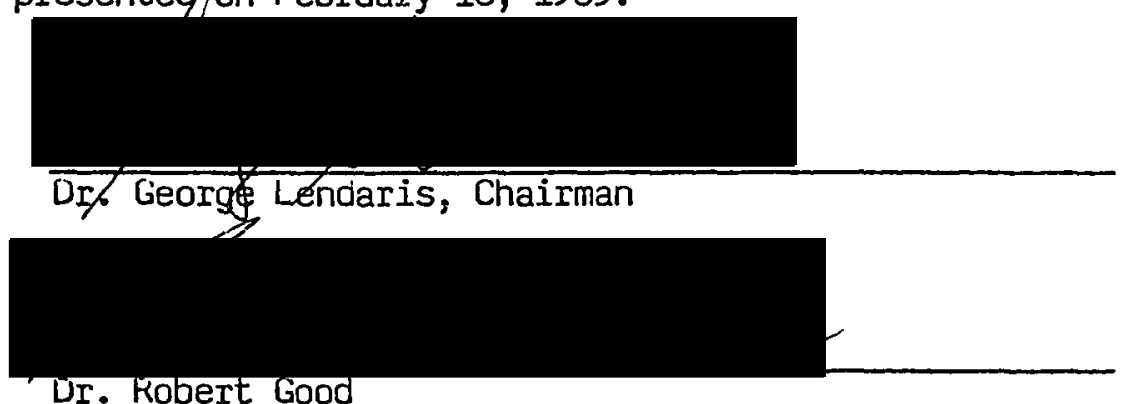

Dr. Robert Good

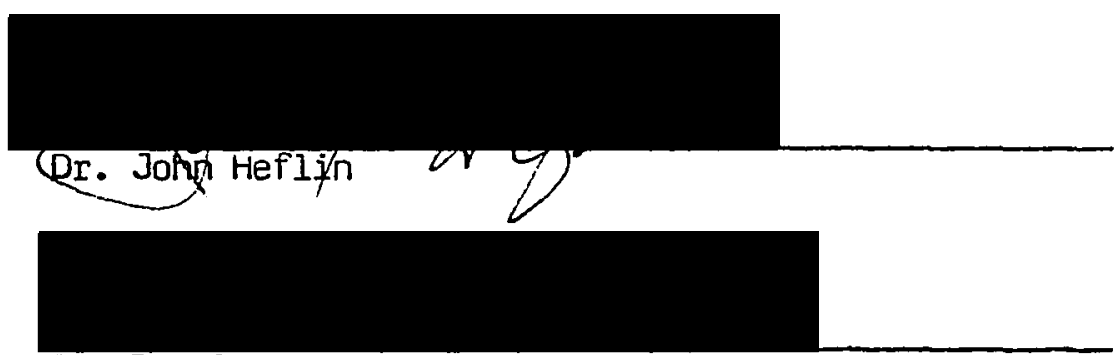

Dr. Ronald Houser
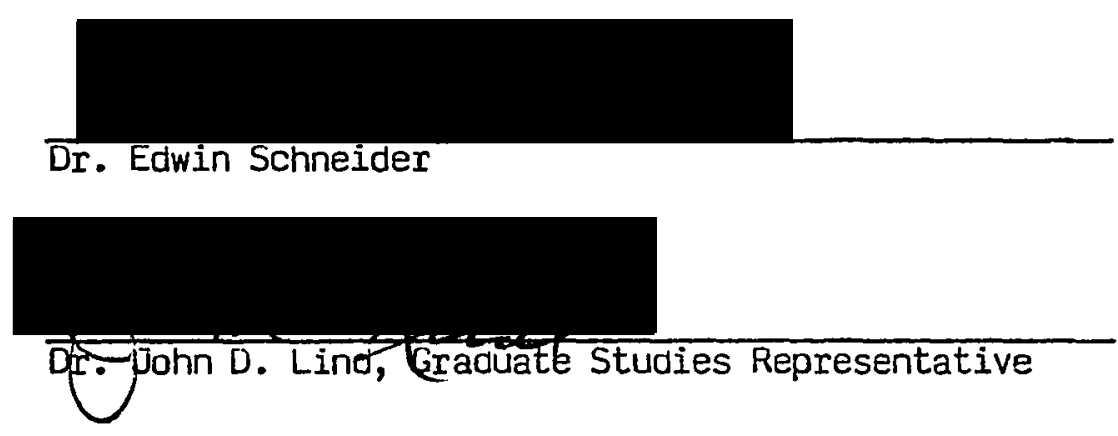

APPRUVED:

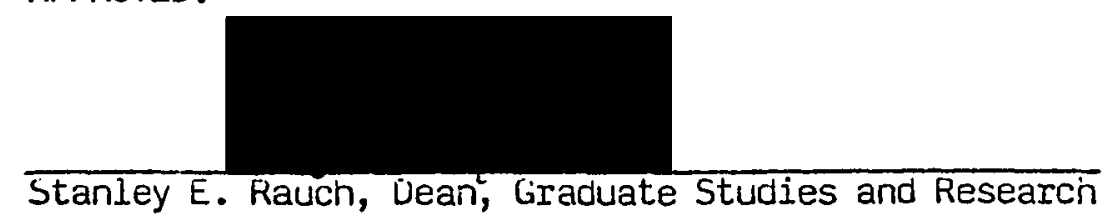


AN ABSTRACT OF THE DISSERTATION OF Porter $W$. Sexton for the Doctor of Philosophy in Systems Science presented February 10, 1983.

Title: A Computer Decision Support System to Assist in Providing Equality of Educational Opportunity

APPROVED BY MEMBERS OF THE DISSERTATION COMMITTEE:

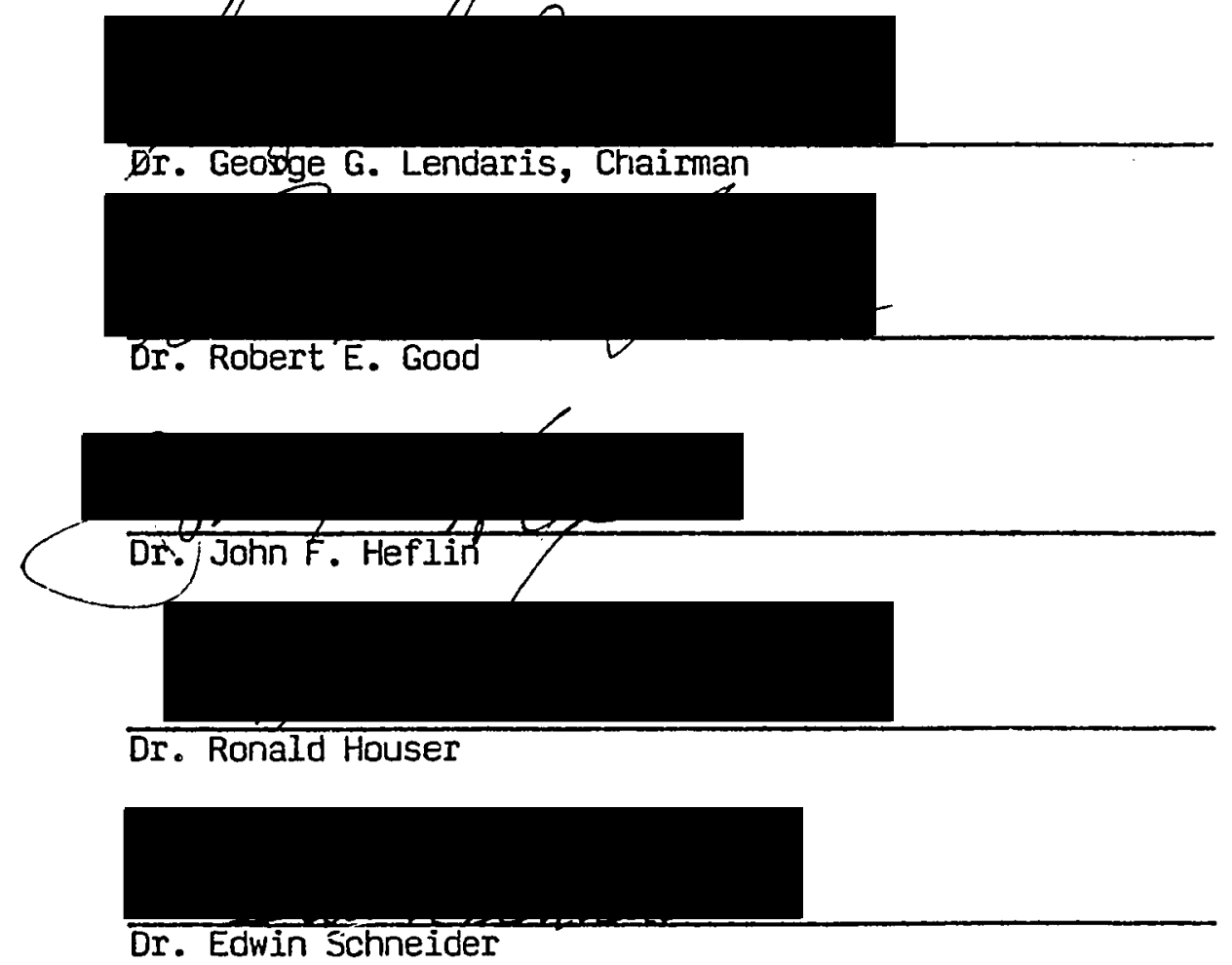

This dissertation presented research conducted by the author in the development of a computer Decision Support System (DSS) for determining equality of educational opportunity in a public school district. 
The research process consisted of five major phases:

Phase 1: The support of a local school district was obtained, and, with the assistance of the superintencient, a task group of concerned administrators was assembled to assist in defining the needs and goals for the DSS.

Phase 2: Working with the task group, the author developed a list of key variables to be included in the support system and gathered and stored the data for a preliminary version of the DSS.

Phase 3: A thorough review of the literature was undertaken in order to reach an understanding of the concepts of Equality of Educational Opportunity (EEO) sufficient to provide a model to be included in the DSS. The literature review led to the identification of four conceptual (subjective) models of EEO.

Phase 4: The four subjective models of EEO identified from the literature were proposed as hypothetical models for inclusion in the DSS. Four analytical techniques were then undertaken to determine which model, if any, best represented reality as determined by the data gathered in Phase 2. The analytical techniques used were correlation analysis, subgroup analysis, graphic analysis, and phenomena explanation. The results of these analyses showed that one model, identified as the EEO Achievement Aspects Subjective Model, best fitted the data examined. 
Phase 5: In the final phase of the research, the model was incorporated into a Decision Support System in such a way that the DSS was able to calculate a single value, termed an EEO Accountability Index, for a given set of data. The potential uses of such an inciex and of such a DSS was then further explained.

There were two important functions which could be accomplished by the design and implementation of this computerized decision support system. They were:

1. The DSS could provide analyses based upon a statistically derived model of reality which, in some cases, could be more accurate than the decision maker's heuristically derived subjective model, and in some cases could be less accurate. In either case, differences between conclusions based upon the statistically derived model and those based upon the subjective model could be important decision support tp the decision maker.

2. The process of determining (building) the statistically derived model could add new insights to one's understanding which may alter one's mentally held subjective model. In this way, one's subjective model could come to better reflect reality.

The research reported here was meant to serve both of the above functions. Accordingly, the audience for this dissertation might be (1) information specialists responsible for the design of Decision Support Systems, (2) school district board members, superintendents, and decision makers, and (3) other academicians interested in developing a better understanding of the concepts of EEO and the implications of those concepts for educational decision maxing. 
ACKNOWLEDGEMENT

This dissertation presents research by the author on the development of a Computer Decision Support System for determining equality of educational opportunity in a public school system.

The researcher gratefully acknowledges the contributions made to this research by the Portland Public School District, Portland, Oregon. Although the findings herein are not a product of the School District's Research and Evaluation Department's efforts, a great deal of the support for this research was supplied by Portland Public Schools. Since the only data used in this study are for ninth grade students, during the 1980-8I school year, the findings of this report do not reflect overall findings for the School District.

The author wishes to express his gratitude to Dr. George Lendaris, chairman of the dissertation committee, Dr. Robert Good and Dr. John Heflin of Portland State University, and Dr. Ronald Houser and Dr. Edwin Schneider of Portland Public Schools for their continued support and guidance. A special debt of gratitude is due to Dr. Ethel Simon-McWilliams who served as expert consultant to this dissertation.

Finally, the author dedicates this work to his wife, Mary, who has been both his inspiration and his comfort, and to the children in the public schools of America in the hope that this work may prove to be of benefit to them. 
ACKNOWLEDGEMENT .............................

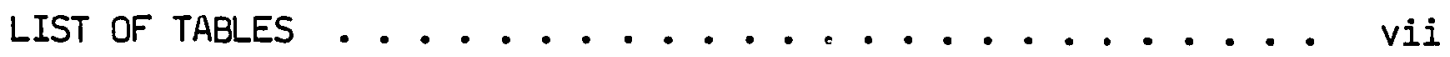

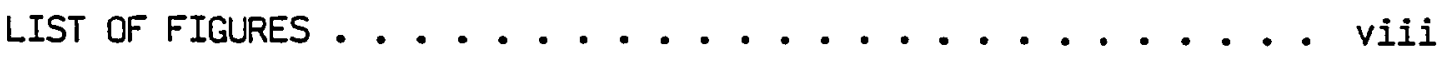

CHAPTER

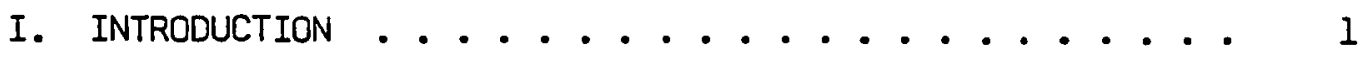

Background ..................... I

Intended Audience .............. 4

Research Paradigm .............. 5

Overview of Dissertation Organization ..... 8

Preview of Results ............. 9

II. DECISION SUPPORT SYSTEM DESIGN ........... II

General Model of an Information System . . . . . Il

Management Information Systems and Decision Support

Systems ................... 16

Design Process for this Research . . . . . . . 18

III. IDENTIFICATION OF KEY VARIABLES .......... 22

The Concept of Equality of Educational Opportunity . 22

Identification of EEO Variables ........ 31

Tangible Aspects of EEO .......... 33

Intangible Aspects of EEO . . . . . . . 37

Effectiveness Aspects of EEO . . . . . . . . 42

Achievement Aspects of EEO .......... 46

Ability Aspects of EEO ............ 51

Computer Collection of Variable Values . . . . . 52 
CHAPTER

PAGE

IV. BUILDING SUBJECTIVE MODELS . . . . . . . . 58

Subjective Models . . . . . . . . . 58

EEO Tangible Aspects Subjective Model ...... 61

EEO Tangible/Intangible Aspects Subjective Model . . 67

EEO Effectiveness Aspects Subjective Model . . . . 71

EEO Achievement Aspects Subjective Model . . . . . 87

V. COMPUTER SIMULATION OF SUBJECTIVE MODELS . . . . . . 97

Computer Simulation and Analysis . . . . . . 97

Correlation Analysis . . . . . . . . 98

Sub-group Analysis . . . . . . . . . . 109

Graphic Analysis ............ 112

Phenomena Explanation . . . . . . . . II5

Suggestions for Further Research . . . . . . . 117

VI. PRODUCT OF THIS RESEARCH: AN EEO ACCOUNTABILITY INDEX • 119

Need for an EEO Accountability Model . . . . . . 119

Suggested EEO Accountability Model . . . . . . 121

Suggested EEO Accountability Index . . . . . . 124

Use of the Suggested EEO Accountability Index . . . 126

VII. SUMMARY AND CONCLUSIONS . . . . . . . . . . 129

Summary . . . . . . . . . . . 129

Conclusions . . . . . . . . . . 137

Afterword ........................... 140

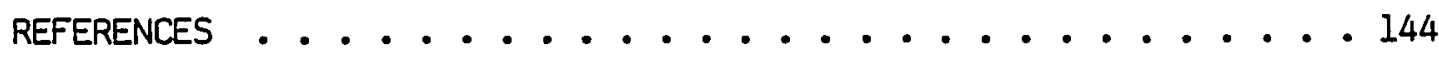

APPENDIX A CORRELATION ANALYSES . . . . . . . . . . 151 
APPENDIX B SIMPLIFIED REPRESENTATIONS OF CORRELATION

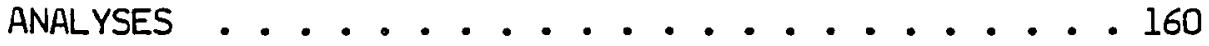

APPENDIX C GLOSSARY OF ABBREVIATIONS AND ACRONYMS . . . . . 166

APPENDIX D CONSTITUTION OF. THE UNITED STATES

AMENDMENTS V, XIII, XIV, XV ........... 169 


\section{LIST OF TABLES}

TABLE

PAGE

I. Summary of Significant Correlations Found . . . . . . 102

A-I. Pearson Correlation Coefficients for Selected Variables - All Groups . . . . . . . . 152

A-II. Pearson Correlation Coefficients for Selected Variables - Ethnic Group 1 . . . . . . . 153

A-III. Pearson Correlation Coefficients for Selected Variables - Ethnic Group 2......... 154

A-IV. Pearson Correlation Coefficients for Selected Variables - Ethnic Group 3... . . . . . 155

A-V. Pearson Correlation Coefficients for Selected Variables - Ethnic Group 4........ 156

A-VI. Pearson Correlation Coerficients for Selected Variables - Ethnic Group 5 . . . . . . . 157

A-VII. Pearson Correlation Coefficients for Selected Variables - Female . . . . . . . . 158

A-VIII. Pearson Correlation Coefficients for Selected Variables - Male . . . . . . . . . 159

B-I. Simplified Correlation Matrix - All Groups . . . . . 161

B-II. Simplified Correlation Matrix - Ethnic Group 2 . . • 162

B-III. Simplified Correlation Matrix - Ethnic Group 3 . . . 163

B-IV. Simplified Correlation Matrix - Ethnic Group 4 . . . . 164

B-V. Simplified Correlation Matrix - Female . . . . . . 165

B-VI. Simplified Correlation Matrix - Male . . . . . . 166 


\section{LIST OF FIGURES}

FIGURE

1. Generalized Model of an Information System. . . . . . . 12

2. "Schematic of an Idealized Accountability System for the Education Sector" (Levin, 1972) . . . . . 29

3. Cost Per Student ................ 34

4. FTE Per Student .................... 35

5. Non-FTE Cost Per Student . . . . . . . . . 36

6. Minority Percentage ............. 39

7. Minority Faculty Percentage ........... 40 40

8. Voter Support ................. 41

9. Reading RIT Gain .. . . . . . . . . . . . 44

10. Math RIT Gain . . . . . . . . . . . . 45

11. Language Arts RIT Gain . . . . . . . . . . . 46

12. Reading RIT Score . . . . . . . . . . . . 47

13. Grade Point Average Per Student . . . . . . . . . . 48

14. Attendance Per Student . . . . . . . . . . . 49

15. Suspensions Per Student . . . . . . . . . . . 50

16. Flowchart of Research Method Used . . . . . . . . 57

17. Diagram of the EEO Tangible Aspects Subjective Model. . . . 66

18. Diagram of the EEO Tangible/Intangible Aspects Subjective Model ............ 70

19. Diagram of the EEO Effectiveness Aspects Subjective Model - 82

20. Diagram of the EEO Achievement Aspects Subjective Model . - 94

21. Diayram of EEO Variable Relationships Determined by Correlation Analysis . . . . . . . . . . . 104

22. Preliminary Statistical Model of EEO Accountability . . . 108

23. Suggested EEO Accountability Model . . . . . . . . 122 


\section{CHAPTER I}

INTRODUCTION

\section{Background}

How can school districts attempt to provide a more equal opportunity for educational achievement to all their students?

The Federal Elementary and Secondary Education Acts of 1965 and 1972 established definitions, guidelines, statutory requirements, and funding aimed at Equality of Educational Opportunity (EEO). A myriad of programs to improve, monitor, and evaluate educational opportunity have been developed since that time. Associated with this development has been an increasing burden on school districts to effectively meet the attendant information requirements, such as program monitoring, evaluating, and reporting.

The acquisition of technically adequate and useful information in public schools has been a particularly difficult task (Mellor, 1977). In fact, in the past, public school district efforts to obtain a range of decision-making information have been largely inadequate (Nevo and Stufflebean, 1976). More recently, however, the case has been made that computerized management information systems can help to more effectively provide the information needed for supporting decisionmaking in an educational environment (Maher, 1979). Indeed, the past few years have seen the implementation of data-based management information systems in a number of school districts around the country with the goal of meeting the increased information requirements. 
And yet, as pointed out in Clemson (1978), "management information systems are almost always expensive failures." Clemson describes the conventional approach to developing management information systems as follows (summarized):

1. The decision needs of the organization are analyzed.

2. The information requirements are determined.

3. A major programming effort is undertaken to process the data specified in step two. The project usually bogs down at this stage because the care and feeding of the massive data banks require all available resources.

4. The rest of the system's history is spent trying to keep it current. The very size and complexity of the system militates against the effort to update it rapidly.

Indeed, most proposals for computerized models for decision support in the area of EEO have been large-scale, sociological models subject to just such a fate (See Dyer, 1972, Beshers, 1972, or Smith, 1972, for example). There have been large scale surveys and computer analyses of EEO factors such as the Coleman Report (1966), the U.S. Office of Civil Right's Report (1972), and annual Title I ESEA Reports (1965 et. seq.). However, these large-scale computer assisted studies have not led to small computerized information systems useful to individual school districts concerned with ensuring equality of educational opportunity. 
An outgrowth of the problems associated with such large scale efforts has been a thrust to develop smaller, more dedicated Decision Support Systems (DSS) aimed at specific groups of decisions and based on specific models of the context in which the decisions are to be made. The steps suggested by Clemson in building such a special purpose computerized DSS include:

1) identification of key variables;

2) subjective model building;

3) computer simulation of models; and

4) continuous management involvement.

Clemson seemed also to suggest that a computerized DSS could be designed and implemented to assist decision makers with questions specifically related to equality of educational opportunity. If so, such a system could provide a great deal of support to the school district in meeting its EEO information needs.

This investigation picked up on this implied suggestion of Clemson, and set out to develop some groundwork for the design of such a DSS. Along with this task selection, the author chose the process suggested by Clemson as the organizational schema for the research itself. Namely, 1) a clear notion of information systems and the EEO context was established (Chapter II), 2) key EEO variables were identified (Chapter III), and then 3) a computer model was built which relates these variables in a manner which adequately represents the EEO "reality" for the pertinent decision makers (Chapters IV and V). 
There are two aspects of the chosen task which made it particularly difficult, and which changed it from one simply of design to one of research. Those aspects were a) there was no theoretical agreement about the basic concepts of EEO, and $b$ ) therefore the decision makers and ultimate users of the DSS were not able to identify key components or relationships from which to construct a basic model. Thus, the design of such a DSS required not only the construction of a new model, but, in addition, it required the development of a methodology for the construction of such a model.

\section{Intended Audience}

Two important functions normally stand to be accomplished by the design and implementation of a computerized decision support system. They are:

1. As one of its functions, DSS could provide analyses based upon a statistically derived model of reality. In some cases, this analysis could be more accurate than one based on the decision maker's heuristically derived subjective model; and in some cases, it could be less accurate. In either case, differences between conclusions based upon the statistically derived model and those based upon the subjective model could be important decision support to the decision maker.

2. The process of determining (building) the statistically derived model could add new insights to one's under- 
standing which may alter one's mentally held subjective model. In this way one's subjective model could come to better reflect reality.

This study was meant to serve both of the above functions. Accordingly, the audience for this Dissertation might be (1) information specialists responsible for the design of Decision Support Systems; and, (2) school district board members, superintendents, and decision makers, and (3) other academicians interested in developing a better understanding of the concepts of EEO and the implications of those concepts for educational decision making.

\section{Research Paradigm}

This dissertation is being offered in partial fulfillment of the requirements for the Doctor of Philosophy Degree in Systems Science at Portland State University. Since "Systems Science" is a relatively new and still developing academic area, some definition may be useful. Ludwig von Bertalanffy (1968), in his classic, General System Theory, introduced "Systems Science" this way:

'Systems Science,' or one of its many synonyms, is rapidly becoming part of the established university curriculum. This is predominantly a developinent in engineering science in the broad sense, necessitated by the complexity of 'systems' in modern technology, man-machine relations, programming and similar considerations which were not felt in yesteryear's technology but which have become imperative in the complex technological and social structures of the modern world. Systems theory, in this sense, is preeminently a mathematical field, offering partly novel and highly sophisticated techniques, closely linked with computer science, and essentially determined by the requirement to cope with a new sort of problem that has been appearing. 
What may be obscured in these developments-important as they are--is the fact that systems theory is a broad view which far transcends technological problems and demands, a reorientation that has become necessary in science in general and in the gamut of disciplines from physics and biology to the behavioral and social sciences and to phiiosophy. It is operative, with varying degrees of success and exactitude, in various realms, and heralds a new world view of considerable impact. (p. vii)

There are three ways in which the present research falls within the System Science paradigm which has growin from the above. First, the selected task of developing a computerized DSS is within the technical domain of Systems Science; second, the context within which the DSS is being developed, namely for aiding public school systems in their fundamental goal of ensuring equal educational opportunity, is precisely the type of application--complex, interdisciplinary, funcamentally important, technically denanding--which necessitates the "systems approach"; and third, since the output of this research was not only a specific model, but in addition includes suggested improvements to the model-building process in the problem context area, the research took the systems approach into yet another application area. For these reasons, the paradigm of systems science (as it has come to exist) serves as the governing framework which defines and legitimizes the endeavor reported here.

There are a number of ways in which the paradigm influences research. Kuhn (1962) has suggested several areas of paradigm influence (elaborated upon for this study by Heflin in consultation): 
1. The paradigm assists in selecting the problems which are critical.

- For the research presented here, the critical problem selected was the development of a DSS for a complex, poorly defined task.

2. The paradigm provides a theoretical framework for addressing the vital problems.

- The framework for addressing the associated problems was the methodology for computer system design suggested by Clemson (1978) as expanded by the author.

3. The paradigm selects certain types of instrumentation as valid and appropriate, thus providing the methodological arms for studying the conceptual and theoretical issues.

- In this research, identification of key variables, building of subjective models, and computer simulation and analysis of models served as these methodological arms.

4. The paradigm defines legitimate proof and specifies the type of experiences that will be accepted as empirical evidence. 
- For the present context, the problem-solving and design processes as encompassed under the name "systems approach" serve as the governing process for determining the legitimacy of this research.

In the above ways, Systems Science provides the general paradigm which governs this research.

\section{Overview of Dissertation Organization}

In order to implement a basic tenet of the systems approach, the cooperation and support of the superintendent of the participating school district was obtained, and a task-group of key administrators involved in EEO policy and practice was established. This task-group was used to assist in defining the needs associated with the envisioned DSS, and in outlining the research required to accomplish the research and design process as described previously.

The major first task of the author was an extensive literature search. The results are given in the next three chapters: Chapter II, wherein key concepts underlying information systems are presented; Chapter III, where key EEO variables are defined; and Chapter IV, where subjective models are designed which reflect EEO concepts and legal developments.

The model-building part of the process is discussed in Chapter $V$, which contains the underlying research, analysis, results, and an interpretation of the results. Several general relationships that may help in building models in such contexts do emerge. Validation of the 
Iesults is undertaken, and a graphic technique of pattern recognition is used to clarify some of these relationships. The results of the statistical analysis and of the subjective model building process are compared. In Chapter VI a preliminary model is then derived, and the EEO accountability index developed. Finally, Chapter VII contains a review of the key ideas presented, conclusions based on this study, and some recommendations for further research.

\section{Preview of Results}

The purpose of this research has been to lay the groundwork for building a computerized model of Equal Educational Opportunity to be used in a Decision Support System. This research has led to the development of a preliminary EEO model and a resultant index which can be used as a measure of school district system equity.

The methodology which emerged during the course of the research reported here was a) subjective models are developed based on a literature review of the field of EEO, b) models are statistically derived from empirical data, and c) these separately derived models are checked against one another. This methodology for checking theory against reality in order to specify a computer system model was developed here as a necessary extension of previous DSS design methodologies. A first-order approximation model, based on very limited data, was developed in this research by this methodology. Since no such model existed before, nor was there an apparent method for developing one, this research can be said to have been successful. 
The computer model reported here is used to calculate an overall EEO accountability index for a school district. This index can be used as a measure to compare a school system's educational equity at various points in time, and to determirie the effect on equity of specific proposed decisions by a school district. Thus, the model provides decision support to school district decision makers concerned with improving educational equity.

The further development and implementation of the computer system used to gather and analyze the data for this research, additional refinement of the first-order model derived in this study, and incorporation of the ability to calculate directly the EEO accountability index, will contribute to the ongoing process of developing EEO decision support systems.

The data used for the research reported in this Dissertation were specific to one school district at one point in time. Further research and further development of such Decision Support Systems should help to show whether the relationships discovered were applicable generally in the area of public education EED, or were merely specific characteristics of the school district and time of this study. This research lays the groundwork for such work, and the ideas and results presented herein should indeed prove useful to the general educational community concerned with determining the degree of equality of educational opportunity within a school system. 
CHAPTER II

\section{DECISION SUPPORT SYSTEM DESIGN}

Historically, development of computerized information systems has been a large and expensive undertaking in most situations. However, now, with the availability of more and more sophisticated hardware and software at lower and lower costs, management decision support systems individualized to specific contexts can be developed more easily and more cost effectively. Such systems can be designed to provide the manager in a given decision-making context with support in tasks such as monitoring, query, evaluation, and forecasting. What is needed in each context is an appropriate understanding of the foundational ideas, and a means of representing that understanding in a form (called a model) usable by the computer. The research for this dissertation has focused on developing an appropriately formatted understanding of the issues underlying EEO, and deveioping a methodology for constructing a model usable by a decision maker in the EEO context.

\section{General Model of an Information System}

This chapter gives an overview of a portion of the literature about information systems. Its purpose is to examine the successes and failures in this field in order to gain insights useful for DSS design.

Perhaps a good starting point is a generalized conceptual model for an information system. An understanding of the basics of such a general model is useful as an overall guide to the design of more specific systems, such as decision support systems. 
Professor George Lendaris, in his class "Information Systems" at Portland State University, presented the following generalized model of an information system.

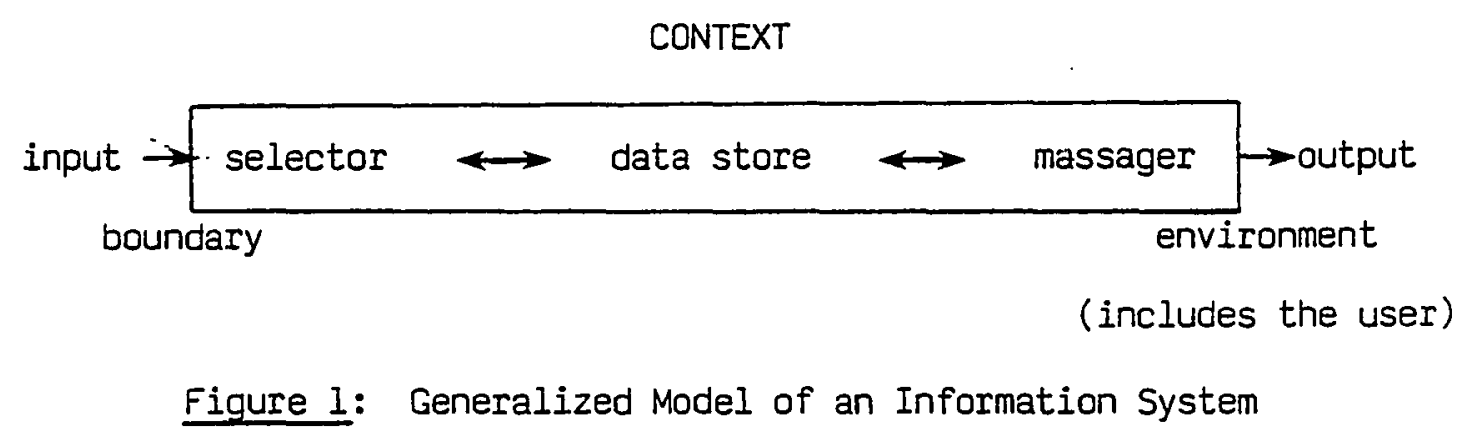

The model consists of seven elements: input data, selector, data store, massager, output, boundary and environment. The model asserts that the problem context directly affects the definition of all seven elements, and thus insists that the context be explicitly considered. This model distinguishes between "data," which are the values of selected attributes, and "information," which is defined as a pattern of the data that has some particular significance to the user.

1. Input Data: A variety of data exists in the world-atlarge which may be related to any given information system. In our case, a number of files related to the concept of EEO may already exist in the school district computer system. Further, there may also be a large 
amount of data in offices throughout the district. Additionally, there may exist a great deal of data outside the district which relates directly to the problem and can be collected if needed.

2. Selector: The selector selects from the large universe of possible and available data that data to be placed in the DSS data store. In many cases, "raw" or disaggregated data would be stored. In other cases, simply an address or a process for obtaining the data which is needed might be stored. The design of the selector and the design of the data store are thus interdependent and are generally developed simultaneously.

3. Data Store: The data is stored in files organized by a "schema," an organizational principle for relating the various data items and files. There may be several independent data stores within the overall data store of the system.

4. Massager: The "massager" is the operational unit of the system. The massager manipulates the data in the data store, performing such operations necessary to produce the output desired by the user of the system. Several distinct functions may be performed by the massager: (a) Query: query is the ability of the 
system to respond to specific questions and requests. For example, a user may want to ask the system for a particular statistical breakout of the performance of some group of students on some indicator. The massager would have to be able to access specific items in the data store, perform statistical operations, and arrange the results in a format useful to the user. (b) Monitoring: Monitoring is an on-going function of some systems. Data is periodically examined by the system, and, when conditions are found which meet or exceed some predefined conditions, appropriate output is generated to inform users of this condition. An example of this is exception reporting. Exception reporting draws management's attention to pre-described exceptional phenomena. (c) Evaluation: The massager unit can access data and perform statistical operations useful in evaluation procedures. The massager can also be used to bring the results of multiple evaluations together in ways which may be useful to the user. (d) Forecasting: Forecasting consists of applying models, such as trend extrapolation, growth and substitution models, analogies, etc., to the data and running the models under various assumptions or conditions. A particular value of forecasting in decision support systems is that forecasting allows the user to ask "what if" questions and examine possible impacts of decisions being considered. 
5. Output: The function of the system is to present the data to the user in such a way that the user perceives a pattern and this becomes useful information. One of the interesting considerations in designing the output format is to match the format of the output to the tasks and preferences of the user. Some applications may require large batch-printed tables of data while others might be better served by instantaneous graphic representation on an interactive graphics screen.

6. Boundary: The boundary defines the limits of the system and distinguishes the system from its environment.

7. Environment: The environment of an information system is usually considered to consist of the users of the system and their particular information needs. This is the environment of direct concern to the system most of the time. Of course, the environment of all systems includes everything that is outside of the boundary, and seemingly uninvolved components of it, such as the financial environment of the suprasystem supporting the information system, often have a way of making their presence felt. On such occasions, these elements of environment come into the context in which the system functions. 
Management Information Systems and Decision Support Systems

McLeod (1979), in Management Information Systems, traced the development of today's more sophisticated systems from their origins in the first computerized systems of twenty years ago. Earlier, Martin (1976), in Principals of Data-Base Management, had established the basics of managerial procedures for developing, maintaining, operating, and revising this type of data-based information system.

Two aspects of design and performance evaluation of information systems are considered by Arnovick (1978): (1) initiation, planning, development, and testing of new systems, to include modification of existing structures; and (2) appraisals and measurement of operational systems and components. Arnovick develops a taxonomy of information systems which provides a basis for organized evaluation of system performance.

McPherson-Turner and Eisele (1979) described the design of a management information system that has demonstrated efficacy in the operation of a research project in an educational environment. The four states in the design of this system were information collection, information organization, information analysis, and information reporting.

Over the past decade, these Data-Based Management Systems (DBMS), as they have come to be called, have been developed and implemented at huge expense at a large number of major public and private educational institutions. Computerized information systems, based upon data-based management systems, have become a modern, expensive, way of life. A key question is whether the results have been worth the expense. In a 
classic study, the long-term cost effectiveness of DBMS at over two dozen major corporations were examined (Wiorkowski and Wiorkowski, 1978). The finding was that for large corporations data-based management systems are often cost effective over a relatively short period of time (three to five years). However, for small corporations, this was not found to be the case. For small corporations, as Clemson put it, "management information systems are almost always expensive failures," and therefore better DSS design methods are needed.

This is not to say that there were no successes. In 1974, Hayman published "Educational Management Information Systems for the Seventies" which optimistically outlined the potential such systems could fulfill for educational management. Many of these potentials have been realized. The work of Pugh and Krasnakevich (1971) and others has led to computer assisted reassignment systems now available. Charles Maher (1979) documented some successes with special education management information systems. Maurice Elias (1979) and others wrote of "The Use of Computerized Management Information in Evaluation."

It has been suggested that the ability of an information system to respond to questions posed by managers may be the best determination of the effectiveness of the management information system (Brown, 1979). And it has been shown that a management information system can be successfully used for instructional as well as administrative support in higher education (Bess, 1979). One researcher who has done a great deal to document the successes of computerized decision support systems over the past decade has been Stephen Alter. He has described a broad range of successful and not so successful decision support systems and 
has discussed the various challenges and risks the implementation of such systems pose to managers (1976, 1980).

Design Process for this Research

What can be seen, from both the successes and the failures, is that the field has developed a great deal of expertise over the past decade in the design and implementation of management information systems suited to particular environments. To a large degree, this expertise has been built upon the foundation established by Arthur Hall (1969) in his classic piece, "Three-Dimensional Morphology of Systems Engineering." Hall analyzed a large number of systems engineering projects and found characteristics common among successful projects and characteristics common among unsuccessful projects. Based on these common characteristics, Hall proposed his morphology for successful systems engineering. The different aspects of this morphology have been further developed since that time. For example, Arnovick (1978) stressed the phases of initiation, planning, development, and testing. Axelrod (1970) stressed involvement and communication between users, top management, and designers. Robert Holland (1980) wrote of the importance of tailoring the system to the specific needs of the clients. Ein-Dor (1978) stressed the importance of planning for the development process, as did James Penrod (1978) in his account of the planning, design, and implementation of an information system at Pepperdine University. The literature abounds with advice for the information system designer.

One of the most influential writers in the field of computerized information sytems has been Peter Keen. In 1976, Keen suggested 
employing intermediary personnel, who are skilled in mathematical programming and are managerially trained, to support strategic decision-making by upper-level executives. What a relief to managers who had been reading with dread that the managers of tomorrow would need to be skilled computer programmers as well! In Keen's book with Michael Scott-Morton, Decision Support Systems: An Organizational Perspective, the practical and the pragmatic was emphasized. Their advice to the would-be designers of decision support systems was simple: keep it simple, keep it cost effective, and base the design on a model which is built upon a good understanding of the context. This last recommendation clarifies why Keen recommended intermediary personnel skilled in both computer programming and managerial matters. In order to build an appropriate model for a decision support system, an understanding of both the computer function and of the managerial function must be built into its design.

This combination of needs for both technical and application considerations in systems design represents one of the most pressing and potentially rewarding areas of applied research open today. The design of a decision support system for managerial support in the area of ensuring equality of educational opportunity in a public school system involves such a two-fold task: (1) key variables which are pertinent to EEO considerations and for which data is available must be identified and selected, and data for them placed in the data store, and (2) relationships between the variables must be discovered and defined precisely enough that the relationships can be used to determine and evaluate the outcomes of specific events. A goal of this research 
is to provide some groundwork to assist school systems and other concerned agencies with designing such a computerized information system, and perhaps, in the process, to also provide some basic understanding of the key variables and relationships in the complex area of Equal Educational Opportunity.

The general methodology recommended in the literature and used by most analysts in designing information systems has been to work with the decision makers who ultimately were to be the users of the system in determining the specifications of the system. Some reference to other systems and to the normative requirements of such a system were also generally required. Basically, it was assumed that "upper management," or the "decision maker," would be the expert in determining the requirements of the system.

Clemson (1978) outlined this basic approach to the design of a Decision Support System:

1. identification of key variables;

2. subjective model building;

3. computer simulation of models; and

4. continuous management involvement.

With this methodology in mind, an EEO Information System Task Group of assistant superintendents and department directors was assembled for this project. After a few meetings, it became clear that there were no "experts" in determining EEO Decision Support specifications (i.e., variables and models). The discussions of the group, and a quick review of the literature, revealed why this was the 
case. The concepts involved in EEO were simply too complex, and the differing opinions, values, and assumptions implicit and explicit in EEO concepts too diverse, to readily yield specifications for a generally acceptable EEO decision support system. The task-group therefore was used to help the author to define the need for such a DSS, and to outline the research required to complete the steps necessary for its design.

Additional research was called for, and the approach of the author was to undertake an extensive review of the philosophical, sociological, and legal underpinnings of the concepts of EEO for the specific purpose of determining the key variables and relationships necessary for the specifications of an EEO decision support system. The next two chapters are a brief summary of that review. 
CHAPTER III

IDENTIFICATION OF KEY VARIABLES

As stated earlier, development of a Decision Support System requires that an appropriately formatted understanding of the fundamental ideas be developed, and a means for representing that understanding be created. Using the Clemson outline presented previously in this dissertation, the first step in such a process is the identification of key variables. This chapter reviews some of the variables which have been identified by the leading researchers in the field of EEO. Using a review of the relevant literature as a base, the author here identifies key variables that can be both attainable and useful to the participating school district in the design of a Decision Support System.

The Concept of Equality of Educational Opportunity

In an influential report entitled "The Concept of Equality of Educational Opportunity" (1967), James Coleman defined four different aspects of inequality.

One type of inequality may be defined in terms of differences of the community's input to the schools, such as per-pupil expenditure . . . 
A (second) type of inequality would include various intangible characteristics of the school as well as the factors directly traceable to the community inputs to the school (see Sweatt vs. Painter 330 US 629 [1950]). Yet such a definition gives no suggestion of where to stop, or just how relevant these factors might be for school quality.

Consequently, a (third) type of inequality may be defined in terms of consequences of the school for individuals with equal backgrounds and abilities. In this definition, equality of educational opportunity is equality of results, given the same individual input. With such a definition, inequality might come about from differences in the school inputs and/or racial composition and/or from more intangible things....

A (fourth) type of inequality may be defined in terms of consequences of the school for individuals of unequal backgrounds and abilities. In this definition, equality of educational opportunity is equality of results, given different individual inputs. The most striking examples of inequality here would be children from households in which a language other than English . . . is spoken ....

Such a definition taken in the extreme would imply that educational equality is reached only when the results of schooling (achievement and attitudes) are the same for racial and religious minorities as for the dominant group. (pg. 18-19)

Based on the understanding reached from a review of the EEO literature, the auti.or felt this typology of Coleman's covered the EEO concerns well. Since each of these types of inequality refer to different aspects of educational equity, each could potentially require different variables to represent it. Accordingly, these four types of inequality were chosen to be used in the present research as an organizational basis for identifying key variables to incorporate in a Decision Support System for EEO. 
Much recent research in education has focused on "school effectiveness" measures. Such studies as George Madaus' (1978) Schooling Effectiveness: A Reassessment of the Evidence and Michael Rutter's (1979) Fifteen Thousand Hours have led the way, addressing the issues of school system accountability and potential school impact on, and responsibility for, educational outcomes.

In the study by Michael Rutter, Barbara Maughan, Peter Mortimore, and Janet Ouston (Rutter et al. [1979]) ten-year-old children in twenty London elementary schools were tested with standardized nonverbal and reading tests in 1970. Teachers were surveyed with a questionnaire on student behavior, and student delinquency rates were tabulated. In 1974, two-thirds of those children were retested and similar surveys completed. An analysis of variance was then done to determine differences between the groups of students then at twelve London secondary schools. Later research on these dozen secondary schools would then be adjusted to account for the differences in entering students. Four types of measures were used in this analysis of the secondary schools:

1) Intake measures: verbal reasoning, parent occupation, behavior as described by the questionnaire;

2) Process measures: interviews with staff, pupil questionnaire, observations;

3) Outcomes measures: delinquency figures, teacher ratings of behavior, attendance, examination success; and 
4) Ecological measures: geographical area, balance of intake, parental choice of student placement.

Significant statistical variance between schools was shown for attendance, behavior, delinquency, and exam results; and these four outcome measures were shown to correlate highly for each school $(.68$ to .77 correlation coefficients in pairwise comparisons). Factor analysis was used to isolate relative correlation of outcome measures with:

1) physical and administrative features;

2) social organization of schools; and

3) ecological variables.

Then a correlation of variables with outcomes was done (Spearman's rank correlation at .05 level), as was a one-way analysis of variance for "groups of schools" (schools clustered around variables for which they had similar measures). This combined process led to identification of grouped variables, or "global variables," and to identification of schools with groups of similar variables.

A final composite analysis consisted of two stages:

1) A log-linear modeling procedure for composite analysis based on proportions of children who were members of particular sets (categories); and

2) Multiple linear regression, to assess the relative effect of correlated variables. 
The following were some of the main conclusions drawn by Rutter

et al. (1979) (condensed by the author):

First, secondary schools in inner London differed markedly in the behavior and attainments shown by their pupils.

Second, although schools differed in the proportion of behaviorally difficult or low achieving children they admitted, these differences did not wholly account for the variations between schools in their pupils' later behaviour and attainment.

Third, the variations between schools in different forms of "outcome" for their pupils were reasonably stable over periods of at least four or five years.

Fourth, in general, schools performed fairly similarly on all the various measures of outcome.

Fifth, the differences in outcome between schools were not due to such physical factors as the size of the school, the age of the buildings or the space available; nor were they due to broad differences in administrative status or organization.

Sixth, the differences between schools in outcome were systematically related to their characteristics as social institutions.

Seventh, outcomes were also influenced by factors outside teachers' immediate control.

Eighth, the effect of balance in the intake was most marked with respect to delinquency, and least important in the case of the children's observed behavior in the classroom and elsewhere about the school.

Ninth, the association between the combined measure of overall school process and each of the measures of outcome was much stronger than any of the associations with individual process variabies. This suggests that the cumulative effect of these various social factors was considerably greater than the effect of any of the individual factors on their own. The implication is that the individual actions or measures may combine to create a particular ethos, or set of values, attitudes and behaviours which will become characteristic of the school as a whole.

Tenth, the total pattern of findings indicates the strong probability that the associations between school 
process and outcome reflect in part a causal process. In other words, to an appreciable extent children's behaviour and attitudes are shaped and influenced by their experiences at school and, in particular, by the qualities of the school as a social institution.

Such research, as it relates to educational equity, has been hampered by the lack of consensus by scholars and practitioners on a definition of educational equity. There have been contradictory equity-related theories:

1) Equity defined in terms of access to quality programs, and

2) Equity defined in terms of the beneficiaries of educational rewards and outcomes.

These have been the polar extremes - and usually researchers have not bridged this gap with a uniformly accepted theory. The consequence of this lack of agreement on a theoretical basis of educational equity has been the appearance of discrepancy in the results of researchers whose work was based on differing concepts of equity. For example, in many ways, the findings of Rutter and other "school effectiveness" researchers appeared to contradict some of the earlier studies, such as those cited by Coleman (1966) and Jencks (1972), which examined school outcomes as compared to the backgrounds of students. In the course of this research, this contradiction was noted by the author when Rutter's results were compared to the findings of Coleman et al. (1966). Coleman's results are summarized here (condensed by the author): 
Of the many implications of this study of school effects on achievement, one appears to be of overriding importance. This is the implication that stems from the following results taken together:

1. The great importance of family background for achievement;

2. The fact that the relation of family background to achievement does not diminish over the years of school;

3. The relatively small amount of school-to-school variation that is not accounted for by differences in family background, indicating the small independent effect of variations in school facilities, curriculum, and staff upon achievement;

4. The small amount of variance in achievement explicitly accounted for by variations in facilities and curriculum;

5. Given the fact that no school factors account for much variation in achievement, teachers' characteristics account for more than any other - taken together with the results from section 2.3, which show that teachers tend to be socially and racially similar to the students they teach;

6. The fact that the social composition of the student body is more highly related to achievement, independently of the student's own social background, than is any school factor;

7. The fact that attitudes such as a sense of control of the environment, or a belief in the responsiveness of the environment, are extremely highly related to achievement, but appear to be little influenced by variations in school characteristics.

Taking all these results together, one implication stands out above all: That schools bring little influence to bear on a child's achievement that is independent of his background and general social cortext; and that this very lack of an independent effect means that the inequalities imposed on children by their home, neighborhood, and peer environment are carried along to become the inequalities with which they confront adult life at the end of school.

For equality of educational opportunity through the schools must imply a strong effect of schools that is independent of the child's immediate social environment, and that strong independent effect is not present in American schools. 
The schematic model of public education put forth by Levin (1972) is of particular relevance when considering the differences between the Coleman findings and the Rutter findings.

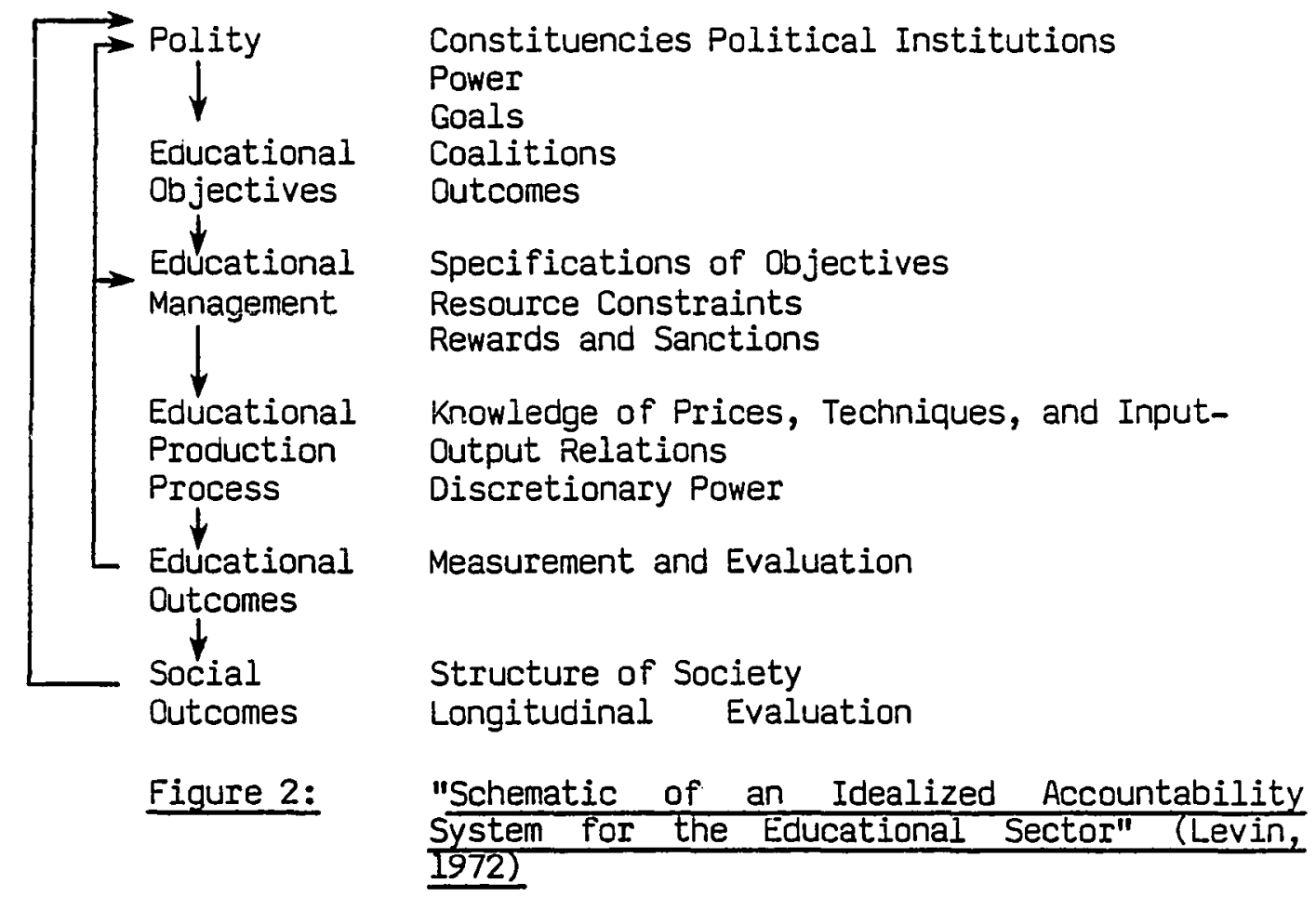

Within the framework of this schematic model, Jencks, Coleman, and others had found that factors in the Polity sector correlated highly with factors in the Societal Outcomes sector, and that factors in the Educational Management sector correlated very little, if at all, with factors in the Societal Outcomes sector. These researchers were defining educational outcomes in terms of the beneficiaries of educational rewards and outcomes, and were thus identifying key variables in this area. On the other hand, Rutter conceded these previous findings and concentrated on the relationship, between the 
Educational Management sector and the Educational Outcomes sector:

If the effects of schooling are to be judged in terms of the strength of associations between particular school variables and measures of attainment, it is essential that the school variables should be the right ones (meaning that they reflect those aspects of school life which do in fact have an impact). (pg. 5)

By thus restricting his investigation to the Educational Management/Educational Outcomes sectors of the Levin model, Rutter was able to show that some factors in the Educational Management sector did correlate with factors in the Educational Outcomes sector for the data under study. Researchers such as Rutter in the "school effectiveness" movement tended to define equity in terms of access to quality programs, and thus to identify key variables in this area.

Applied at the Societal Outcomes/Polity area, the studies of Coleman and others tended to emphasize the concept of inequality in the beneficiaries of educational rewards and outcomes. Applied at the Educational Management/Educational Outcomes area, the studies of Rutter and others tended to emphasize the concept of inequality in access to quality programs. Such differing research approaches, based upon differing concepts of EEO, led researchers to identify differing sets of key variables. Consistent with the purpose of this Dissertation to unify such prior research in selecting key variables for the DSS model, an attempt was made to make the selected variables consistent with a variety of existing definitions of EEO. As mentioned earlier, the conceptual framework attributed to James Coleman was used as the organizing principle for selecting the variables. 


\section{Identification of EEO Variables}

In his introduction to the Report on Equality of Educational Opportunity, U.S. Commissioner of Education Harold Howe (1966) introduced the variables contained in the national survey on EEO (Coleman Report) as follows:

The second question is whether the schools offer equal education opportunities in terms of a number of other criteria which are regarded as good injicators of educational quality. The attempt to answer this elusive question involves describing many characteristics of the schools.

Some of these are tangible, such as numbers of laboratories, textbooks, libraries, and the like. Some have to do with the curriculums offered - academic, commercial, vocational - and with academic practices such as the administering of aptitude and achievement tests and "tracking" by presumed ability. Other of these aspects are less tangible. They include the characteristics of the teachers found in the schools - such things as their education, amount of teaching experience, salary level, verbal ability, and indications of attitudes. The characteristics of the student bodies are also assessed, so far as is possible within the framework of the study, so that some rough descriptions can be made of the socioeconomic backgrounds of the students, the education of their parents, and the attitudes the pupils have toward themselves and their ability to affect their own destinies, as well as their academic aspirations.

Only partial information about equality or inequality of opportunity for education can be obtained by looking at the above characteristics, which might be termed the schools' input. It is necessary to look also at their output - the results they produce. The third major question, then, is addressed to how much the students learn as measured by their performance on standardized achievement tests. (p. iii-iv)

The literature review undertaken for this research and outlined thus far helped to identify many candidate variables in the area of EEO. A number of the variables were concerned with the degree of 
segregation of students and faculty by such factors as race, ethnicity, language background, handicapping condition, socioeconomic background and sex. Certain of the variables related to the distribution of tangible resources within a school system. Also considered were intangible measures of school system input such as teacher expectations, student morale, school atmosphere, etc. Still other variables dealt with student achievement and effectiveness of resources. Student achievement indicators, such as test scores, grades, attendance and suspension data, were variables which can be used in program and activity evaluations to help determine resource effectiveness within the system.

After considering various organizational possibilities, Coleman's four definitions of inequality were chosen as a basis for grouping the variables to be identified for the Decision Support System.

The specific variables identified within this study, grouped according to Coleman's categories and based upon the availability of data, are given below, together with a brief description of how each variable was selected. Also shown for each identified variable is a graphic representation of the data for the ninth grade students of the participating school district. For this graphic representation, the values of the average measure of the EEO variables were calculated for each ethnic group identified by the School District. These computed average values were then normalized by determining for each value its difference from the mean (of all students) in standard deviations. The significance of the graphs thus produced is discussed later in the chapter on validation. The graphs are presented here to provide the 
reader with a feel for the key variables identified and the data collected which may form the basis for the Decision Support System.

Tangible Aspects of EEO

One type of inequality may be defined in terms of differences of the community's input to the schools, such as per-pupil expenditure. (Coleman, 1967, p. 18)

For this research, the category of variables referred to as tangible aspects included such variables as costs, often expressed as expenditure per student; staffing, expressed as Full Iime Equivalent (FTE) staff per student; and materials, such as facility, space and instructional materials. From among these variables, total cost per student (calculated on a school-by-school basis) and FTE per student (again calculated by school) were chosen for inclusion in this study as the most accessible and most often cited tangible variables. However, the major portion of the cost per student was found to be used to pay the salaries of the FTE. Thus, the total cost per student and the FTE per student were found to be interdependent variables. Therefore, a third variable, non-FTE cost per student, was introduced to measure costs in a way more independent of the FTE per student.

Cost Per Student Per School (COST)

Budget amounts were identified in school district financial files for each high school. These figures were summed by school and divided by school enrollment to determine cost per student per school. 


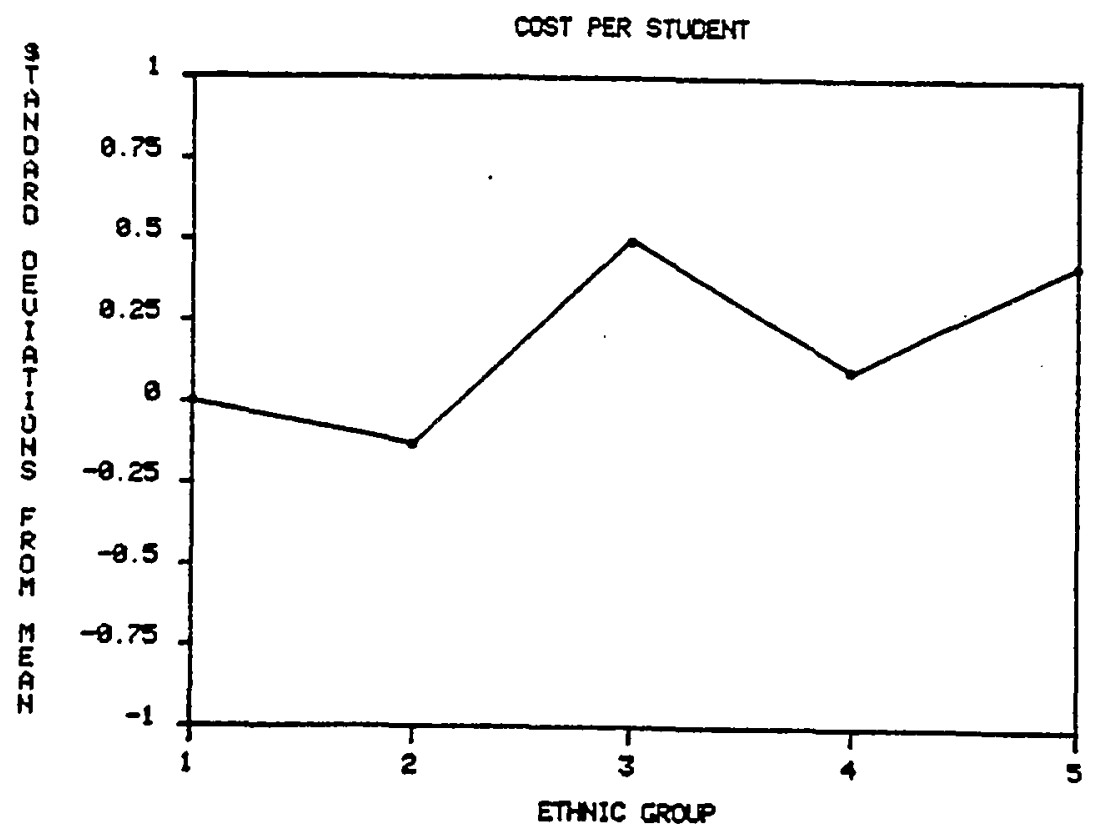

Figure 3: Cost Per Student

This graph shows the standard deviation from the mean for each ethnic category's average cost per student. The mean value for all ninth grade students was 2150; the standard deviation was 397. The mean value 2150 indicates an average in-school budgeted cost per student of $\$ 2150$ for the schools identified in this study. This graph illustrates the "W" signature, to be discussed in Chapter V. 
Full Time Equivalency Per Student Per School (FTE)

FTE (Full Time Equivalency) is a measure of the amount of time an employee spends on the job: one FTE is the equivalent of one full-time position. FTE was coded in school district personnel files for each employee; school codes were also in each employee's records. Thus, FTE was summed by school and divided by enrollment to determine FTE per student per school.

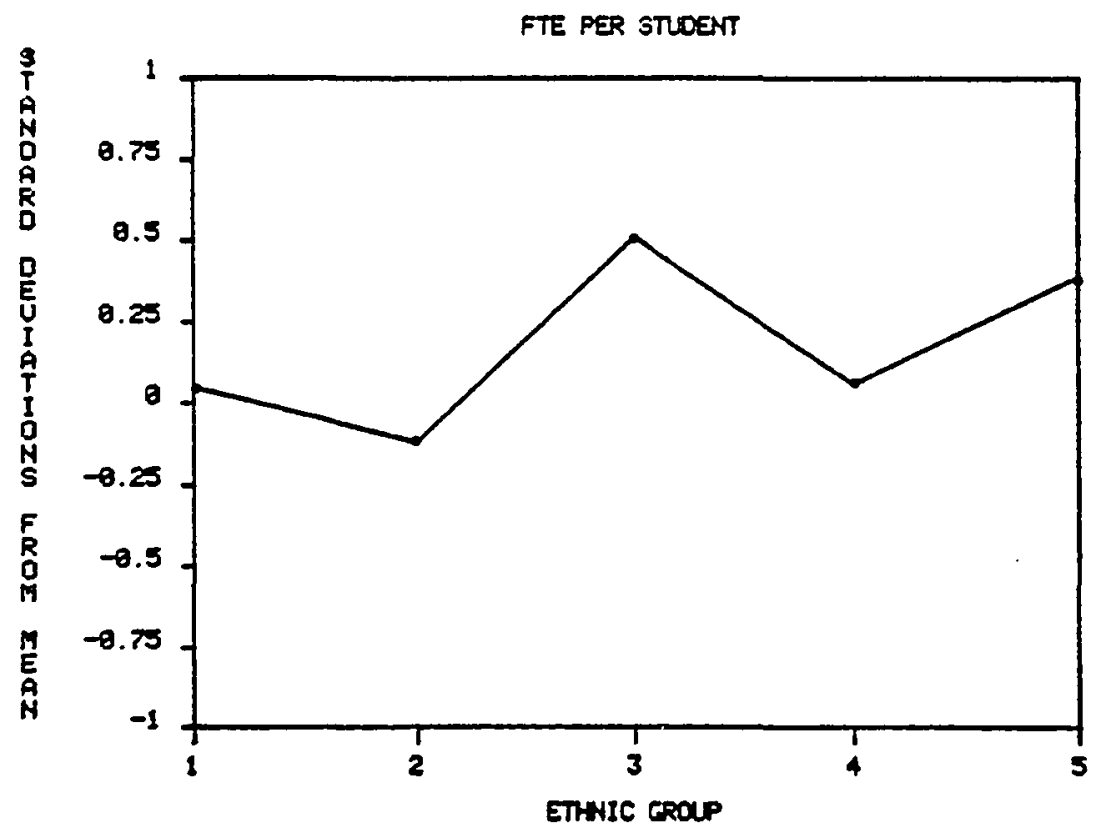

Figure 4: FTE Per Student

This graph shows the standard deviation from the mean for each ethnic category's average FTE per student. The mean value

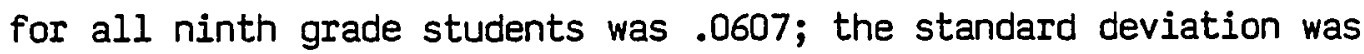
.0062 . 
A mean value of .0607 indicates .0607 FTE for each student, or approximately 1 FTE for each 16.47 students.

This graph illustrates the "W" signature, to be discussed in Chapter V.

Non-FTE Cost Per Student Per School (NCOST)

A large part of the cost per student per school was found to be spent on salaries for FTE. Thus, the first two variables, COST and FTE, were found to be interdependent. By subtracting the cost of salaries from the overall cost per school, a non-FTE cost per student per school was calculated which was not directly dependent upon either of the first two variables.

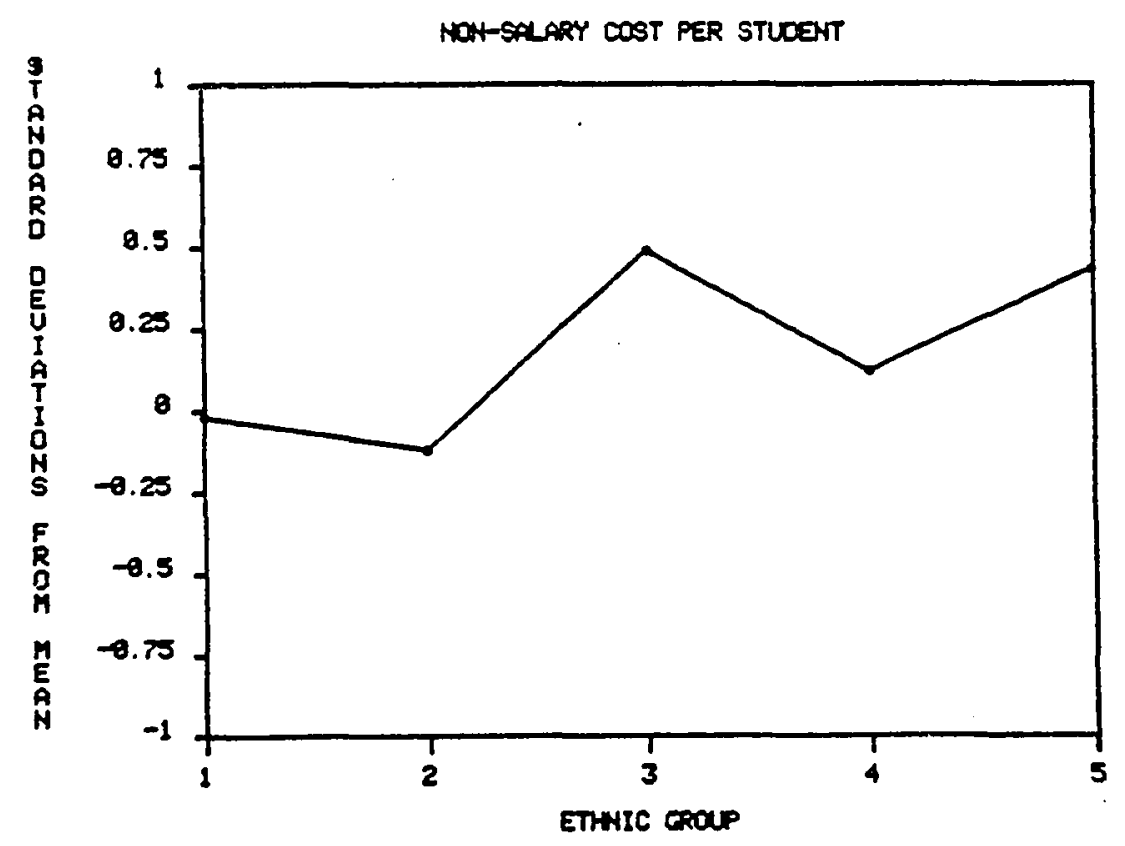

Figure 5: Non-FTE Cost Per Student 
This graph shows the standard deviation from the mean for each ethnic category's average non-salary cost per student. The mean value for all ninth grade students was 630; the standaard deviation was 249. The mean value of 630 indicates an average in-school budgeted non-salary cost per student of $\$ 630$.

This graph illustrates the "W" signature, to be discussed in Chapter V.

\section{Intangible Aspects of EEO}

A (second) type of inequality would include various intangible characteristics of the school as well as the factors directly traceable to the community inputs to the school (see Sweatt vs. Painter 330 US 629 [1949]). Yet such a definition gives no suggestion of where to stop, or just how relevant these factors might be for school quality. (Coleman, 1967, p. 18)

This definition suggested a plethora of variables under the category heading intangible aspects. Studies of factors such as teacher expectations, school atmosphere, and the leadership of the school principal have appeared more and more in a recent movement in educational research towards determining effectiveness of in-school variables. Yet these types of variables have been extremely difficult to measure and may not be readily available for a school system Decision Support System. A number of variables generally are available which may sometimes be used as a proxy for the more-difficult-tomeasure variables. Perhaps the most studied of these "proxy variables" is the percentage of ethnic minority students in a school or school system. Therefore, this proxy variable, minority percentage, has been included in this study. Several such variables, variables such as 
minority percentage of students, minority percentage of faculty, and school system desegregation index, form a subgroup of variables often referred to as desegregation variables. These variables have often been treated separately from other intangible measures. Since other intangible variables, such as program quality, community involvement, administrative style, and teacher motivation and teacher expectation, may have been equally relevant but were much more difficult to measure, they may be less available for a Decision Support System and thus they were not included in this study. An interesting variable, voter support, was here defined as the percentage of registered voters in an area who voted for the latest school tax measure. This variable, calculated by high school area, described in some way the community's relationship to the school. It was easily calculated and, therefore, included in this study as a proxy intangible measure which might simulate some of the intangible measures which had to be excluded.

Minority Percentage Per School (N\%)

Each student in the school district was registered on an official registration form. The form asked the student or the student's parent to choose from American Indian, White, Black, Oriental, and Hispanic, the race/ethnic category most closely characterizing the student. The response to this item was coded on the district's computerized record of the student's registration. Each student's record contained a code identifying the school 
of attendance. By counting the number of students by ethnic code and by school code, the minority (non-White) percentage of each school was calculated.

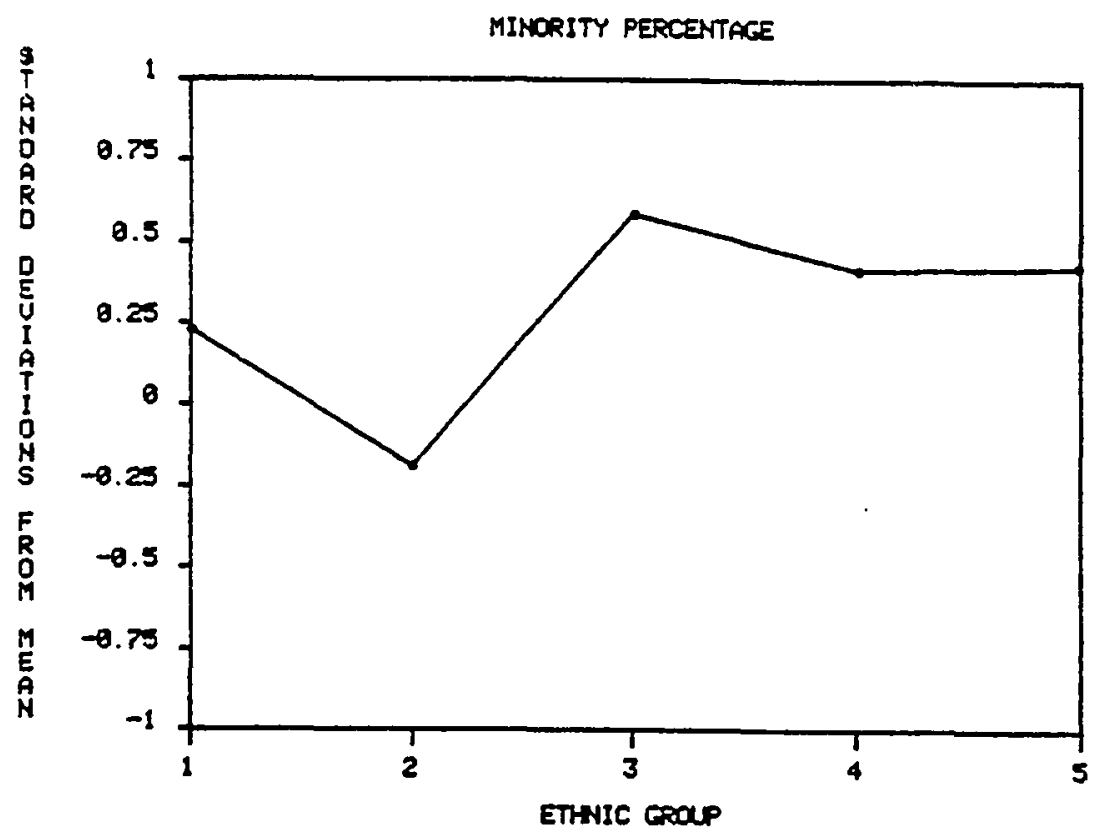

Figure 6: Minority Percentage

This graph shows the standard deviation from the mean for each ethnic category's average minority percentage per at school. The mean value for all ninth grade students was 24.9; the standard deviation was 9.9. The mean value of 24.9 indicates that the average minority percentage of students registered at the schools in this study was $24.9 \%$. 
This graph illustrates the modified "w" signature, discussed in Chapter $V$.

Minority Faculty Percentage Per School (MF\%)

Employee records also contained an ethnic code. Thus, the minority percentage of faculty (teachers, administrators, counselors, librarians, and other certified, professional staff) was easily calculated for each school.

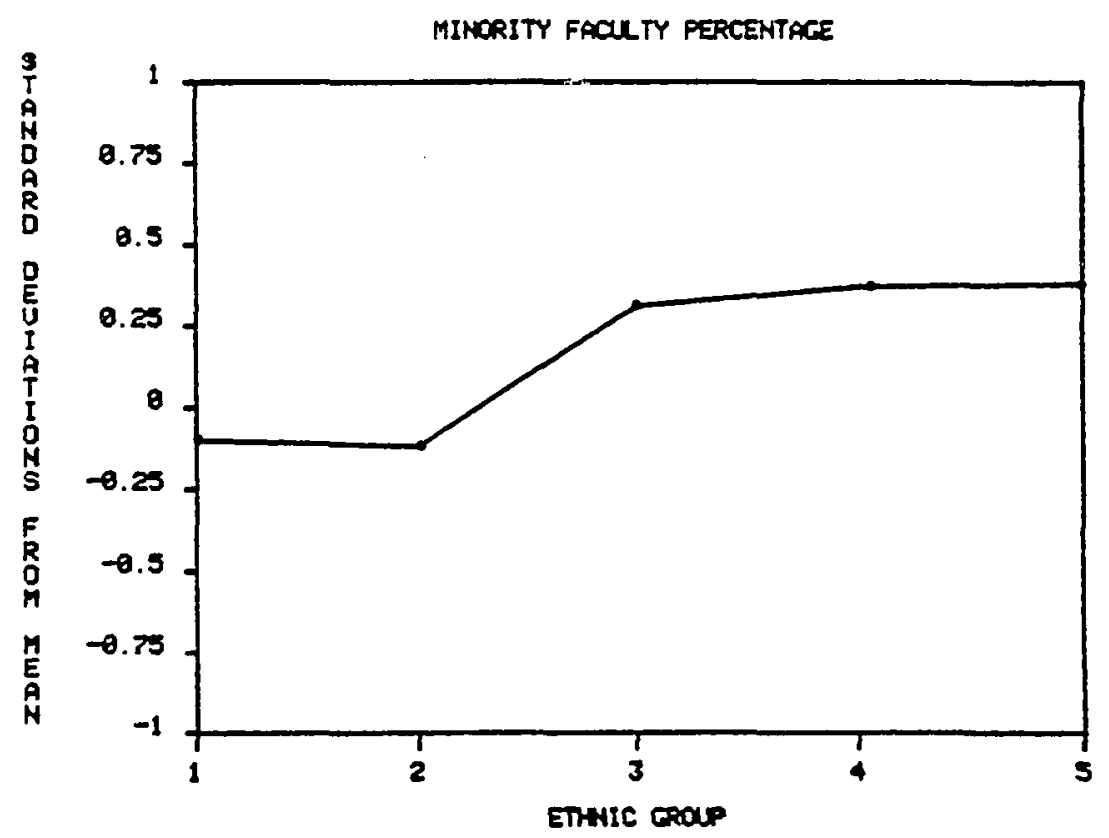

Figure 7: Minority Faculty Percentage

This graph shows the standard deviation from the mean for the minority faculty percentage the school of each student calculated 
for each ethnic group of students. The mean value for all ninth grade students was 7.7; the standard deviation was 3.06. The mean value of 7.7 indicates that the average minority faculty percentage at the high schools studied was $7.7 \%$.

This graph illustrates the modified "W" signature, discussed in Chapter V.

Voter Support (VOTE)

The percentage of registered voters who reside within the attendance area of any school and who voted in favor of the school district's latest tax measure was calculated, giving one measure of the relationship of the community to the school system.

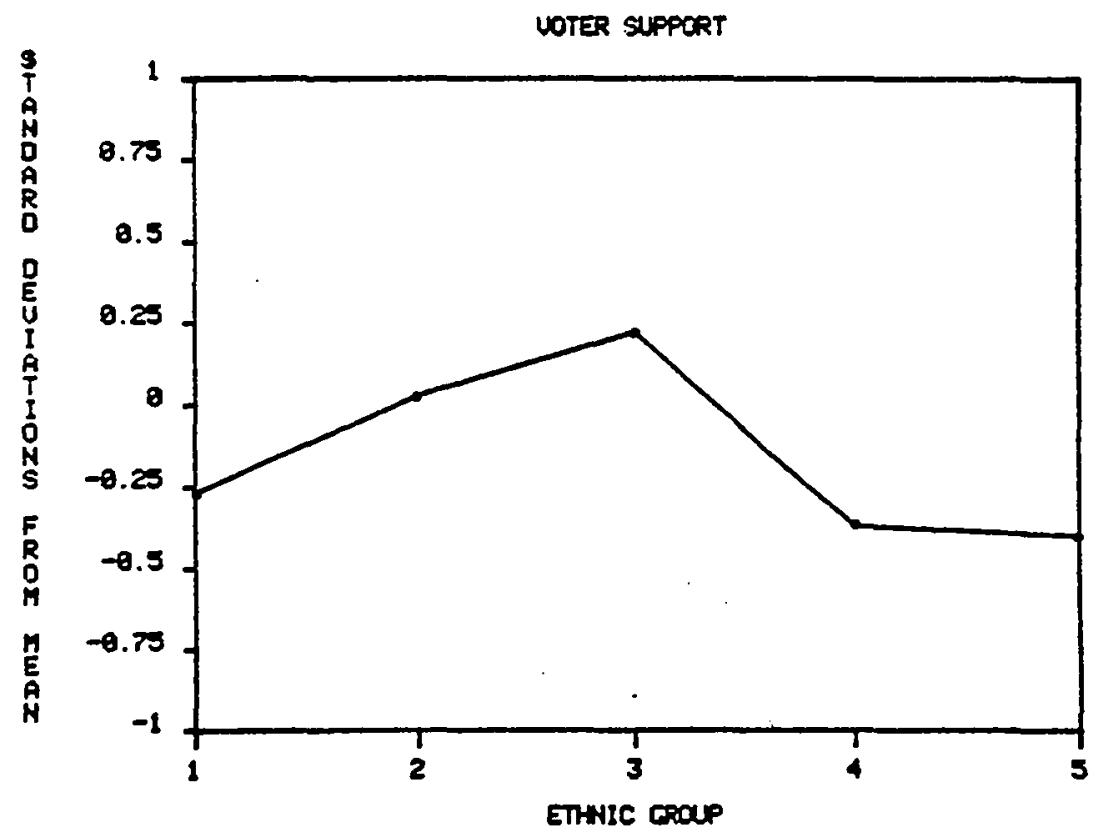

Figure 8: Voter Support 
This graph shows the standard deviation from the mean for each ethnic category's average percentage of resident voter support. The mean value for all ninth grade students was 20.7; the standard deviation was 4.6. The mean value of 20.7 indicates that $20.7 \%$ of all registered voters voted in favor of the last school levy. The percentage of voters who either voted against the levy or who did not vote would thus be 79.3\%. The point is that the percentage calculated is of registered voters, not just of those who actually voted. This graph does not illustrate a specific identified signature, as discussed in Chapter $V$.

\section{Effectiveness Aspects of EEO}

A (third) type of inequality may be defined in terms of consequences of the school for individuals with equal backgrounds and abilities. (Coleman, 1967, p. 18)

Since schools rarely deal with students with equal backgrounds and abilities, direct measures of school effectiveness were almost impossible to find. Indirect measures, which measure student progress and attempt to account for differences in background and abilities, were often termed effectiveness measures. Effectiveness measures for individual students included progress measures such as test gains and performance gains. Effectiveness measures for groups of students included change or rates of change on group behavior variables, such as graduation rate, dropout rate, absentee rate and suspension rate. These were perhaps the most widely used effectiveness measures. For this study, fall-to-spring test-score gains for individual students in 
reading, mathematics and language usage were selected as potential variables describing effectiveness aspects of EEO.

Reading RIT Gain (RGAIN)

Students were tested in reading, mathematics and language usage each fall and again each spring. The gain in each subject area was calculated for each student by subtracting the fall RIT score (score in Rasch units) from the spring score in cases where the spring score was higher. If the spring score was equal to or lower than the fall score, no gain was calculated for that student.

It should be noted that individual student test gains over a short (one-year) period of time were easily influenced by testing error and other random factors and were thus not considered reliable measures. However, average gains for groups of students could be calculated with a greater degree of reliability. 


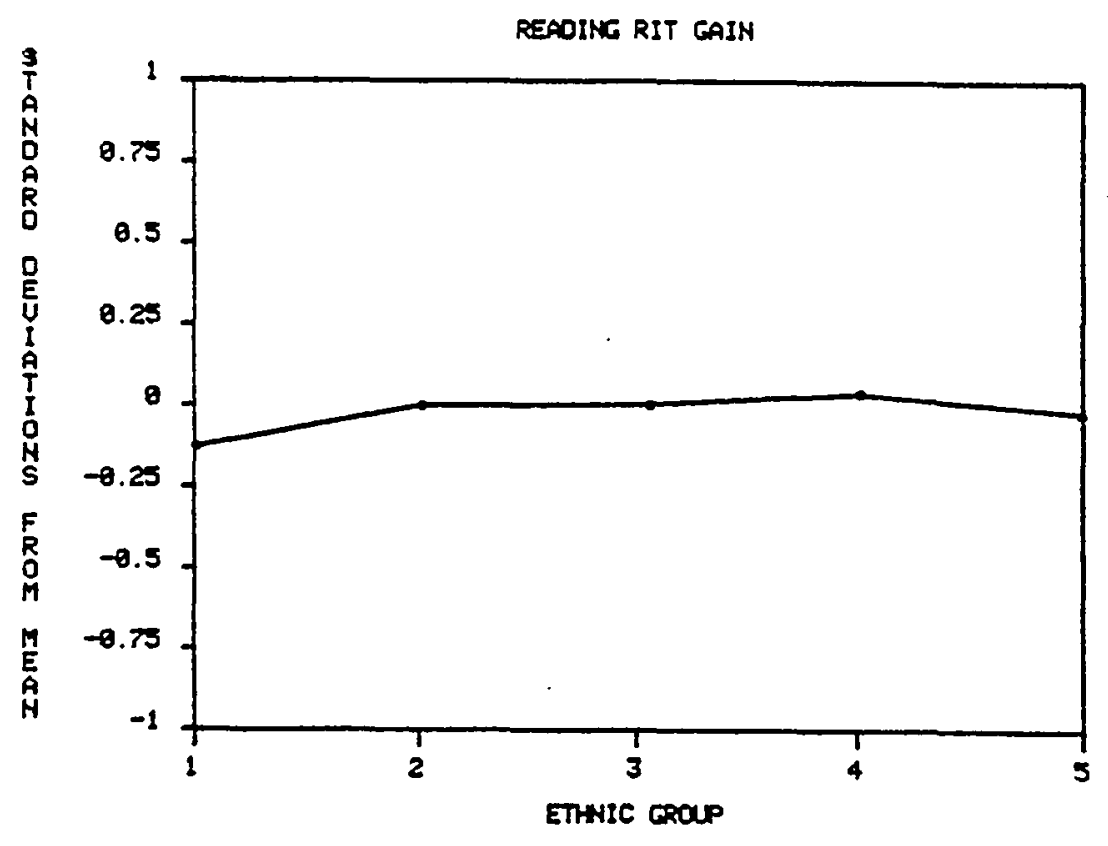

Figure 9: Reading RIT Gain

This graph shows the standard deviation from the mean for each ethnic category's average reading RIT gain. The mean value for all ninth grade students was 6.38; the standard deviation was 4.39. The mean value of 6.38 indicates that the average student in this study gained 6.38 Rasch units on reading tests from fall to spring.

This graph does not illustrate a specific identified signature, as discussed in Chapter $v$.

Math RIT Gain (MGAIN)

Same as for Reading RIT Gain. 


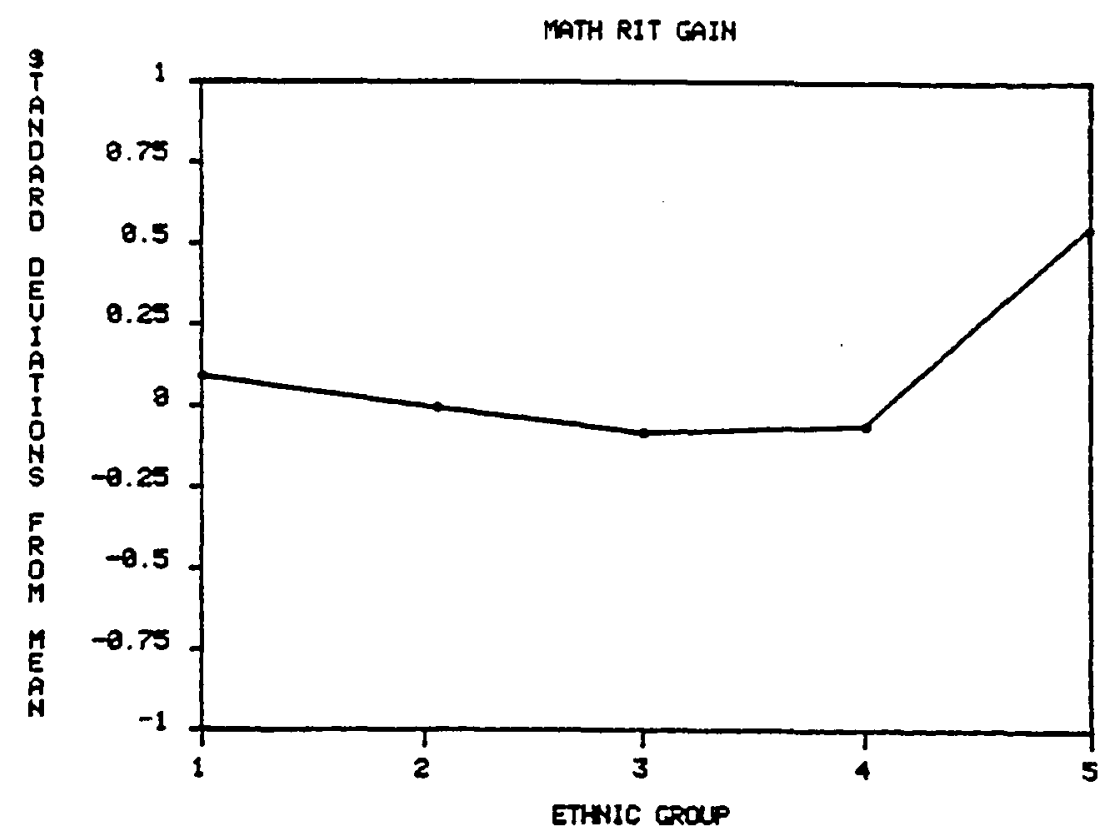

Figure 10: Math RIT Gain

This graph shows the standard deviation from the mean for each ethnic category's average math RIT gain. The mean value for all ninth grade students was 6.71 ; the standard deviation was 4.58. The mean value of 6.71 indicates that the average student in this study gained 671 Rasch units on math tests from fall to spring.

This graph does not illustrate a specific identified signature, as discussed in Chapter $v$.

Language Usage RIT Gain (LGAIN)

Same as for Reading RIT Gain. 


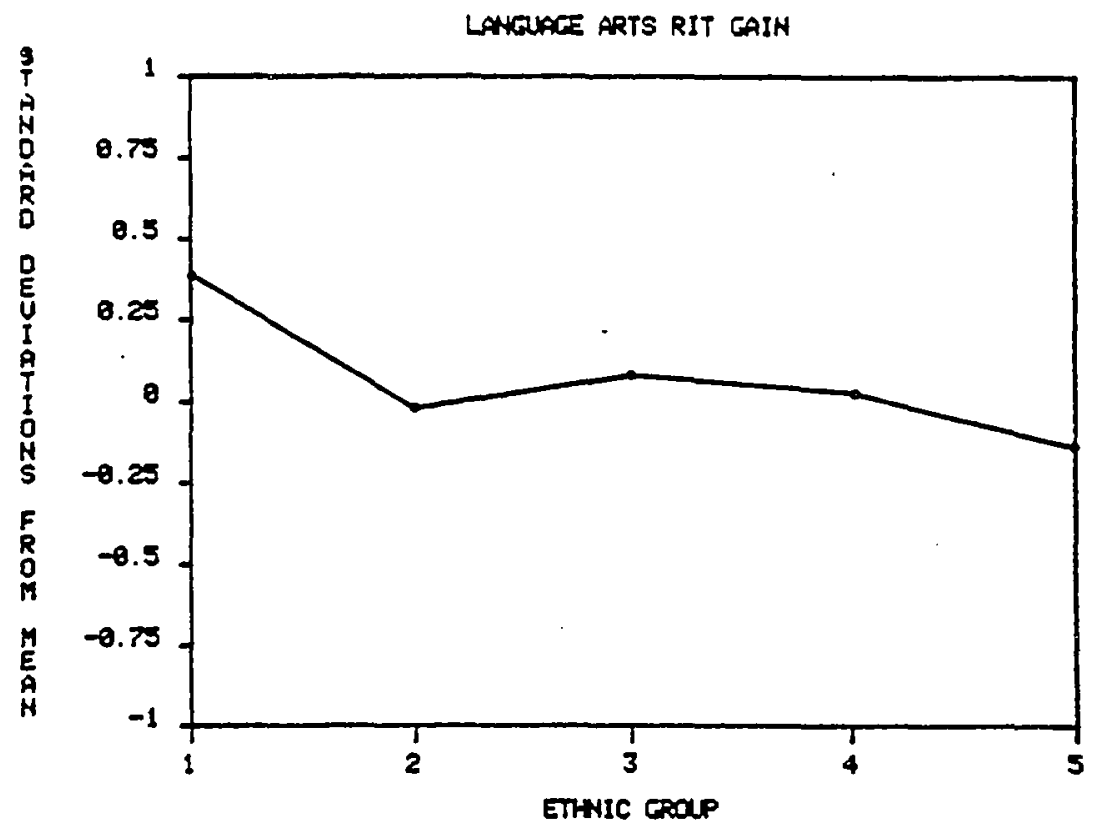

Figure 11: Language Arts RIT Gain

This graph shows the standard deviation from the mean for each ethnic category's average language arts RIT gain. The mean value for all ninth grade students was 5.75 ; the standard deviation was 4.43 . The mean value of 5.75 indicates that the average student in this study gained 5.75 Rasch units on Language Usage tests from fall to spring.

This graph does not illustrate a specific identified signature, as discussed in Chapter $V$.

Achievement Aspects of EEO

A (fourth) type of inequality may be defined in terms of consequences of the school for individuals of unequal background and abilities. (Coleman, 1976, p. 19) 
Since schools generally dealt with students of unequal background and abilities, measures of this type, termed achievement measures, abounded. Test scores, grades and performance in such areas as attendance, behavior (suspensions), school completion, etc., were data which could be obtained for most students. For this study, grade point average (GPA), reading test score (RIT), attendance, and suspension rate (SUSP) were selected as a representative sample of the achievement aspect variables of greatest interest.

Reading RIT Score (RIT)

The reading RIT score was a measure of the student's reading achievement level in units which could be compared to all other students. These data were available on the district's student test data base.

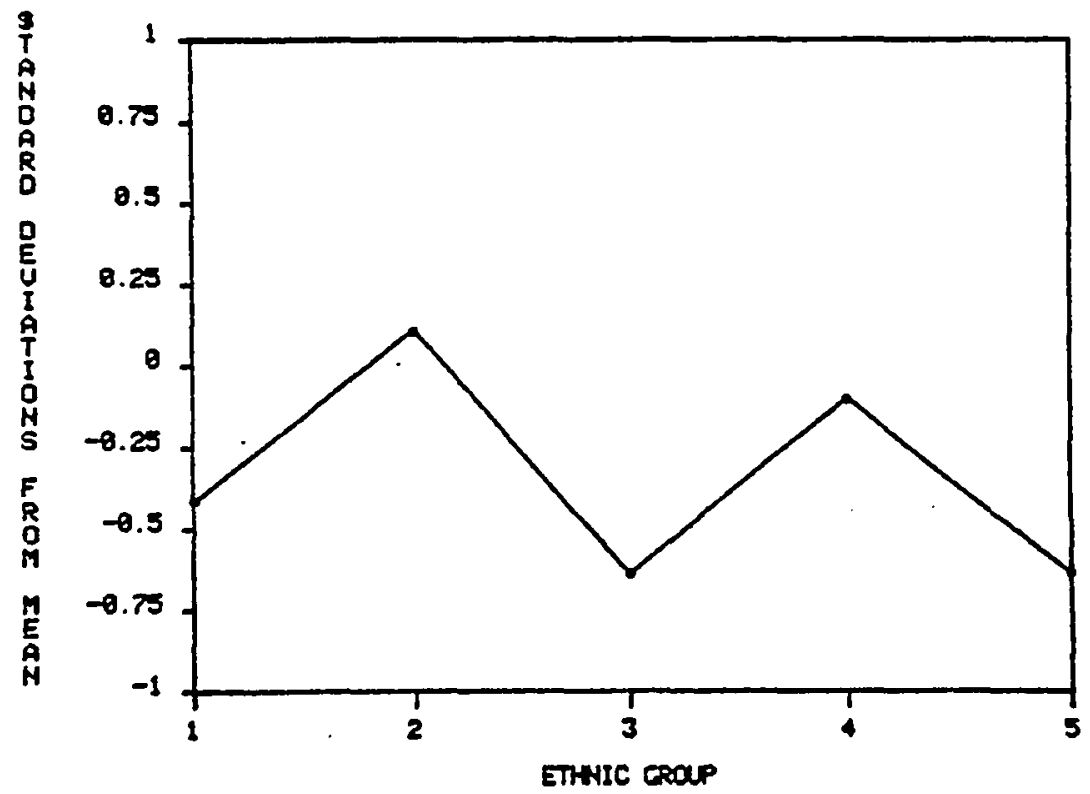

Figure 12: Reading RIT Score 
This graph shows the standard deviation from the mean for each ethnic category's average reading RIT score. The mean value for all ninth grade students was 212.6 ; the standard deviation was 10.96. The mean value of 212.6 indicates that the average student score on spring reading was 212.6 Rasch units for students in this study.

This graph illustrates the " $M$ " signature, as discussed in Chapter V.

Grade Point Average (GPA)

Students' grades were stored on computer tape. From these tapes a student's grade point average (GPA) was calculated for the year of this study.

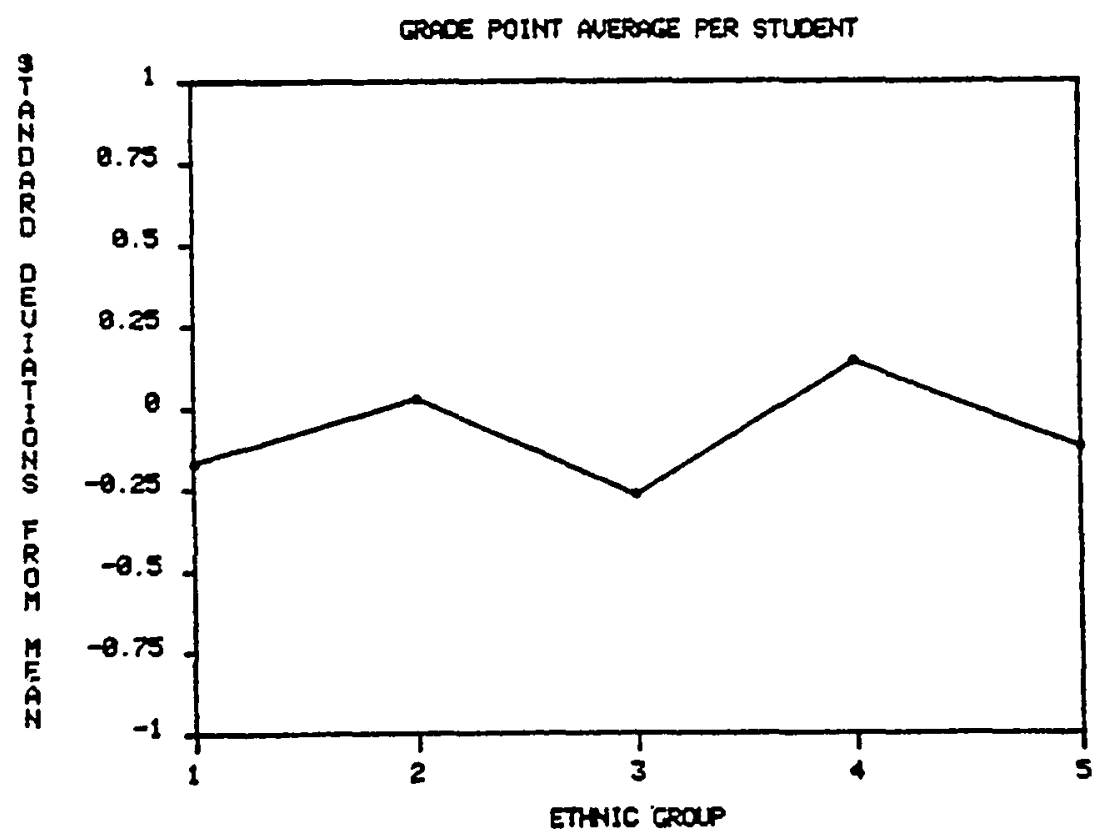

Figure 13: Grade Point Average Per Student 
This graph shows the standard deviation from the mean for each ethnic category's average GPA per student. The mean value for all ninth grade students was 2.64; the standard deviation was .699 . The mean value of 2.64 indicates an average GPA of 2.64 , or C+.

This graph illustrates the " $M$ " signature, as discussed in Chapter V.

Attendance (ATT)

Absences by class were recorded on students' records on computer tape. Total absences and, thus, total attendance figures were calculated for each student.

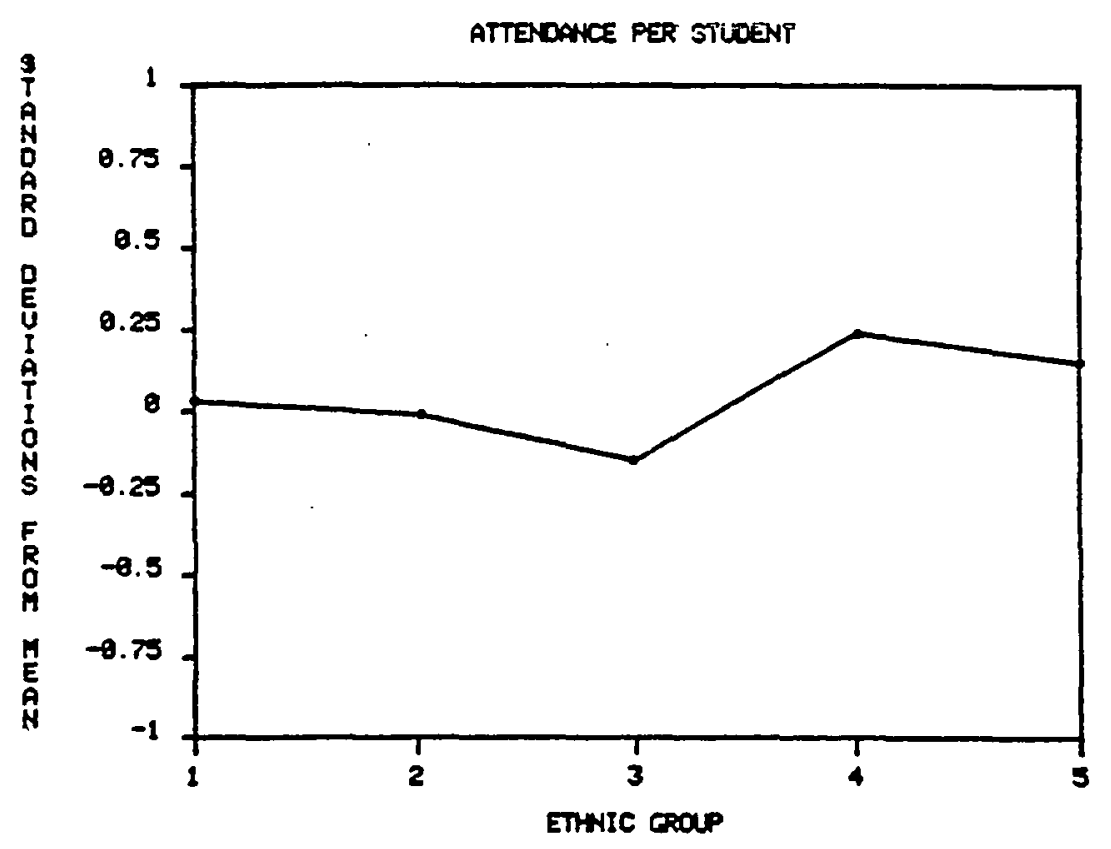

Figure 14: Attendance Per Student 
This graph shows the standard deviation from the mean for each ethnic category's average quarterly class attendance. The mean value for all ninth grade students was 279.2 ; the standard deviation was 34.9. The mean value of 279.2 indicates an average of 279.2 class periods attended per student.

This graph illustrates the modified "M" signature, discussed in Chapter $V$.

SUspensions (SUSP)

A computer file was kept which stored suspension data for each student suspended from any school in the district.

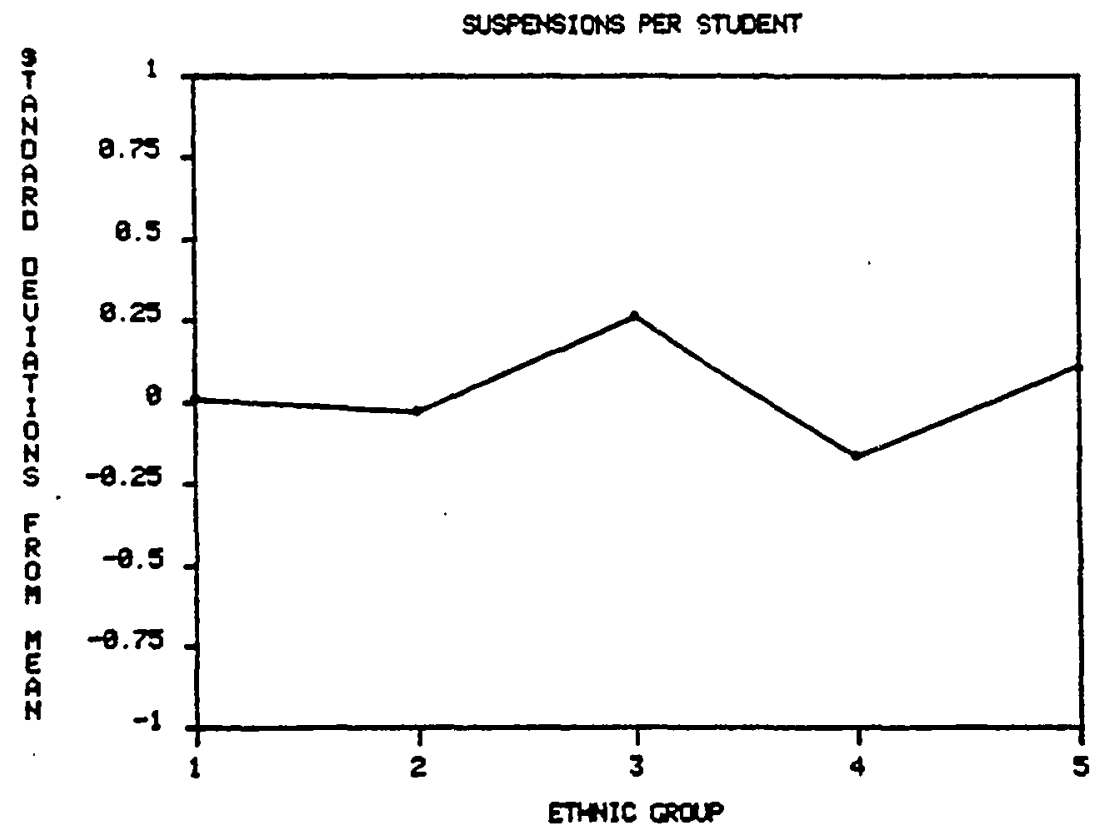

Figure 15: Suspensions Per Student 
This graph shows the standard deviation from the mean for each ethnic category's average suspensions per student. The mean value for all ninth grade students was .041; the standard deviation was .199. The mean value of .041 indicates that approximately one student in 24.4 was suspended during the period of this study.

This graph illustrates the "W" signature, discussed in Chapter V.

\section{Ability Aspects of EEO}

Both the third and fourth definitions of inequality as put forth by Coleman referred to students' "backgrounds and abilities." Variables related to students' "background and abilities" were thus necessary to determine effectiveness aspects and achievement aspects of EEO. Such variables as Intelligence Quotient (I.Q.) and Socio-economic Status (S.E.S.) were often used in this manner, even though the use of such variables has often been questioned (see Kamin, 1974). Data on such variables were not available for this study. However, in much of the literature there has been seen a high correlation between these variables and some of the variables often included as achievement measures such as reading or math test scores. In the case of this research, Reading RIT Score (RIT) was assumed to somewhat represent an ability measure, although its correct classification was as an achievement measure. In this way, it was possible to keep in mind the potential role of ability aspects without having precise data in this area. This is very similar to the technique which was used of employing "proxy variables" as "intangible aspects." 
The thirteen variables identified above served as the key variables to be used in hypothesizing and analyzing models of EEO for use in a Decision Support System.

\section{Computer Collection of Variable Values}

For the purpose of this study, data were collected for all ninth grade students in a given school district for the 1980-81 school year. The reasons for using this particular set of data were as follows:

1. The involved school district was extremely supportive of this research, making available a great wealth of computer data and resources and administrative involvement.

2. By dealing with students at only one grade level, variables which were grade-dependent, such as COST, FTE and RIT, could be compared for all students in the study without having to account for the grade-dependent differences.

3. There were only eleven schools in the district serving ninth grade students. By choosing a grade level. where there were fewer schools (with larger numbers of students and staff per school), such school-by-school data as M\% and MF\% were less likely to be significantly altered by chance fluctuations or error in a small number of computer records. In general, data from a larger sample are deemed to be more reliable than data from a smaller sample. 
4. All Ninth grade students attended high schools which used the district's computerized grade reporting system. Thus, GPA and ATT data were available for each student.

5. Each eighth grade student was tested in both the fall and the spring. Thus, previous year RIT gains as well as scores were available for most ninth grade students and were used in this research.

The general data collection and analysis method used was (1) to extract the data from each of the seven computer files where it was found to reside, (2) to create update records which would add the extracted data to each ninth grade student's computer record, (3) to extract a research data base consisting of the thirteen data items plus the ethnic code and school code for each student, and (4) to statistically examine the relationships between the variables using correlation analysis and other comparison techniques.

The flowchart in Figure 16 illustrates this method. By far the most exacting task of this portion of the research was that of gathering the data. Computer programs had to be written to read various data files and produce update records which could be used to add information to individual student records. Several months were spent on this programming task alone. Each step in the method is numbered on the flowchart (Figure 16) and described below. 
1. Extract M\%

Minority Percentage for each school was calculated from a sequential tape student masterfile, and a transaction record was written which coded the school's minority percentage on the record of each ninth grade student.

2. Extract COST and NCOST

Cost Per Student Per School and Non-FTE Cost Per Student Per School were calculated, and a transaction record was produced which coded these two items on each ninth grade student's record.

3. Extract FTE and MF\%

Full Time Equivalency and Minority Faculty Percentage were calculated for each high school, and a transaction record was produced which coded these two items on each ninth grade student's record.

4. Extract RGAIN, MGAIN, LGAIN, and RIT

Eighth grade fall and spring reading, math and language usage RIT scores were retrieved from the testing data base for each ninth grade student. Fall-to-spring gains were calculated and transaction records were generated which added RGAIN, MGAIN, LGAIN, and RIT to each ninth grade student's record. 
5. Extract $A T T$ and GPA

A program was written which read the grade tape at the end of the 1980-81 school year, calculated class attendance and GPA, and generated a transaction record for each ninth grader containing ATT and GPA.

6. Extract SUSP

A computer program was written which read the suspension tape, calculated the number of suspensions of each ninth grade student, and created a transaction record for each ninth grade student with that student's number of suspensions during the 1980-81 school year.

7. Extract VOTE

Voter Support (percentage of registered voters voting yes on latest district tax measure) was calculated for each high school attendance area. A transaction record was generated which applied the voter support figure to each ninth grader's computer record.

8. Student Masterfile Update

All of the above transactions were applied to the student masterfile, and a research data base was created which contains records for each ninth grade student in the district.

\section{Statistical Analysis}

The Statistical Package for the Social Sciences (SPSS), a computer software package from the University of Kansas, 
was used to calculate means, cross-tabulations and Pearson correlation coefficients. Relationships were sought which might lead to a usable mathematical model of EEO within a school system.

10. Graphic Analysis

Graphic analysis using Tektronix's Easy Graphing package and a technique from the research field known as pattern recognition was done to clarify and validate some of the relationships described by the statistical analysis.

11. Conclusions

Steps 1 through 10 having been accomplished, the researcher was in a position to draw inferences and make conclusions about which variables to use in the model for an EEO Decision Support System. 


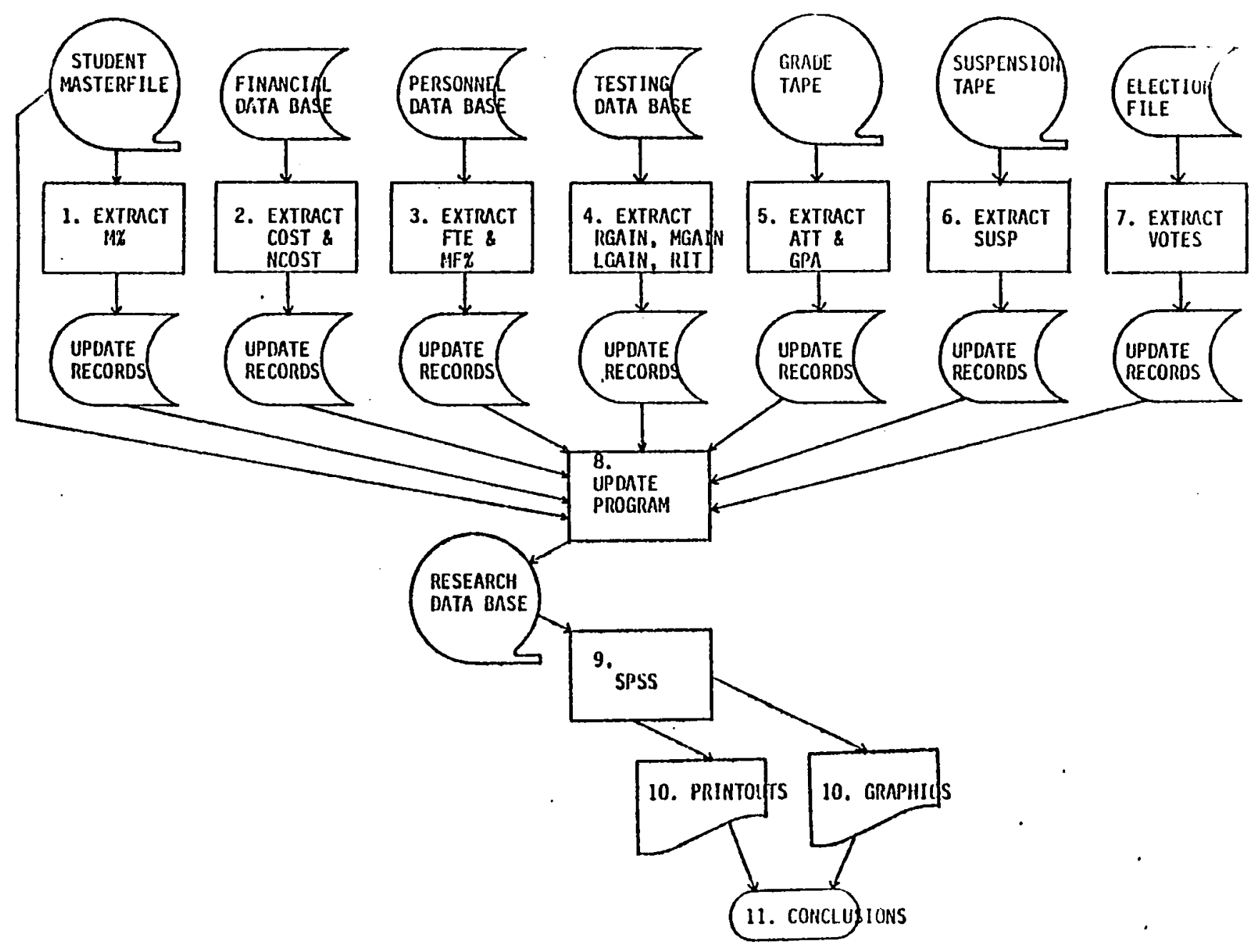

Figure 16: Flowchart of Research Method Used 
CHAPTER IV

\section{BUILDING SUBJECTIVE MODELS}

Subjective Models

The next step in the methodology adopted for the design of a DSS in this research is subjective model building. A review of the literature concerning Equality of Educational Opportunity reveals a number of philosophies and assumptions which can serve as bases for such subjective models.

In this dissertation the author interpreted the term "subjective model" to mean an abstract construct, often mentally held, which describes the relationships between key variables of a content area based upon common pitiliosüphies and assumptions.

It was found that, in many cases, the different perspectives and philosophies which people held were based on their own common sense concepts of what should happen in a given situation, e.g., If Black children are given the same instruction as white children, then they should learn the same thing or amount. Such constructions were then sometimes used as a basis for judging how a school system should function, e.g., if the school system provides remedial education at the lower grades, then it (the school system) should be able to raise the achievement level of $x \%$ of its students to the $y$ level by the second grade. These judgements about how a school system should function were sometimes adopted as goals for the system, and the constructs about how children should behave, influenced the methodologies for attaining these goals. Such subjective beliefs serve as subjective models 
which hypothetically relate variables.

The above description of people's beliefs and actions was meant as a description of one component of decision making in the public school setting. A subjective model may have been employed by a teacher to decide how a unit should be taught; another subjective model may have been employed by a school board to determine educational policy (such as student achievement goals for the school district). The effectiveness of this method of decision making has been limited in part by the accuracy with which the subjective model used by the decision maker has matched reality.

One way to improve upon this method of decision making has been to provide some reality check to the subjective model used by the decision makers and to the conclusions which were reached based upon their subjective models. In this regard, there were two important functions which the author felt could be accomplished by the design and implementation of a computerized decision support system. They were:

1. The DSS could provide analyses based upon a statistically derived model of reality which may, in some cases, be more accurate than the decision maker's heuristically derived normative model. The differences between conclusions based upon the statistically derived model and those based upon the normative model could be important feedback to the decision maker.

2. The process of determining (building) the statistically derived model could add new insights to one's under- 
standing of concepts and relationships which may alter one's mentally held subjective model. In this way one's subjective model could come to better reflect reality.

The research presented here was meant to serve both of the above functions. As Beshers (1972) stated:

Models of the educational process can guide educational research and policy. To see how, we must consider strategic elements in model-building. Efforts to clarify and to formalize alternative assumptions and descriptions of the nature of the educational process must be continually revised in the light of the pragmatic purposes that the model is to serve. Thus basic theory, research strategy, and policy will influence the model-builder as he proceeds. The modelbuilder seeks to make clear the reasonable alternatives that may be posed. (p. 528)

Each of the four concepts of EEO identified by Coleman (see Chapter III) has a corresponding subjective model which could be schematically represented. In this research, these subjective models were represented as schematic diagrams and used as hypotheses which were later compared to a statistically derived preliminary model. As Lave and March (1975) stated in their An Introduction to Models in the Social Sciences,

Since a model has only some of the characteristics of reality, it is natural to have several different models of the same thing, each of which considers a different aspect. (p. 3)

Therefore, the four aspects of EEO dealt with in the Coleman framework were used as the basis for four subjective models of aspects of EEO: (1) EEO Tangible Aspects Subjective Model, (2) EEO Tangible/ Intangible Aspects Subjective Model, (3) EEO Effectiveness Aspects 
Subjective Model, and (4) EEO Achievement Aspects Subjective Model. These four subjective models are discussed in the remainder of this chapter.

EEO Tangible Aspects Subjective Model

Since the enactment of the 13th, 14th and 15th Amendments to the U.S. Constitution, a number of federal and state statutes, court decisions, and educational policies related to the various concepts of educational equity have emerged. In parallel with these events, a large amount of research has been carried out in the various areas concerned with determining equality of educational opportunity. The educational policies and philosophies in effect at a given time influenced the research which was done, and in turn, the research had an impact on the evolution of educational laws and policies.

The Supreme Court has had a number of important cases which affected the concept of educational equity and the application of the provisions of the 14th Amendment to educational policy. The Court's rulings have not been the same over time. And it has not been just changing social attitudes which have led to the different interpretations of the Constitution as evidenced by the Plessy vs. Ferguson (163 US 537 [1895]) decision and the Brown vs. Topeka (349 US 294 [1954 \& 1955]) decision. Rather, the different perspectives and philosophies of the Supreme Court members in 1954 as opposed to those of 1895 led them to different conclusions about the concept of equality of educa- tional opportunity. The research on educational equity may have played an important part in shaping these different perspectives and philosophies. 
During the above mentioned period of time, the concept of EEO has been particularly difficult to define. In their book, On Equality of Educational Opportunity, Mosteller and Moynihan (1972) trace the development of the concept of EEO through the court cases and social reforms of the past century. From Plessy vs. Ferguson (163 US 537 [1895]) to Lau vs. Nichols (414 US 563 [1974]), this country has been in the process of defining and refining these concepts.

Amendments XIII, XIV, and XV to the U.S. Constitution (reproduced in Appendix D) are commonly known as the Reconstruction Amendments, inasmuch as they followed the Civil War and furthered the policy of reconstruction in the South. After the passage of the Reconstruction Amendments, there developed in this country essentially separate educational systems for white persons and for persons of color. In fact, separation extended to almost all major social systems -restaurants, hospitals, hotels, transportation, media, etc. Throughout the country, but perhaps most emphatically in the South, legislation was enacted which permitted localities to deal with the question of access to public facilities to the separate races in their own manner. This period was characterized by a "laissez faire" national policy towards the establishment of equal educational opportunities for minority children. As a result, minority schools were, in general, deprived of basic resources by local policy, and inferior school systems were the norm rather than the exception for minority children.

The Plessy vs. Ferguson Supreme Court decision of 1895 brought to an end the "laissez faire" policy toward EEO in the public schools. In 1896 the United States Supreme Court rendered its "separate-but-equal": 
decision in the Plessy vs. Ferguson case. This was the basis for legally segregated school systems up until the Brown vs. Topeka (347 US 483 [1954 \& 1955]) decision of 1954-55. The main concept to develop out of the "separate-but-equal" ruling with relation to EEO was the concept of equality of tangible resources. Perhaps the most widely shared belief concerning EEO was that all children were entitled to a "fair" (although not necessarily "equal") allocation of tangible resources.

As Kirp and Yudof (1974) noted:

Historically, educational opportunity was defined primarily in resource (or input) terms: its elements included a universally available and free education; a common curriculum; equality of resources - teachers, texts, and the like - within a given school district . . . (p. 532)

The basis for the Plessy decision was the court's interpretation of the 14th Amendment to the Constitution. The 14th Amendment stated that all persons born or naturalized in the United States were citizens of the United States and of the state in which they lived, and that neither the United States Congress nor any state legislature could make or enforce any law which deprived any person of life, liberty, or property without due process. The 14th Amendment also provided for equal protection under the law. The objective of the 14th Amendment had been to establish the equality of all races in the eyes of the law.

The Supreme Court held in the Plessy case that the equal protection clause of the 14th Amendment did not prohibit the State of Louisiana from enacting and enforcing a law which called for the separation of the races in public transportation systems as long as 
this separation did not result in "unequal" services or provisions for any of the races. The particular challenge to the law which was reviewed by the Court referred to separate railroad pullman cars for separate races, but the Court also looked at and applied its logic to separate school systems and separate schools within school systems as well. The Court affirmed that laws providing for separate school systems for separate races and separate schools within a school system did not violate the equal protection clause of the 14th Amendment as long as the separate schools or school systems were "equal."

However, the opinion of the Court was not unanimous in the Plessy case. Mr. Justice Harlan, in a dissenting opinion, argued that the combined effects of the 13th Amendment, (prohibiting slavery), the 14th Amendment (guaranteeing equal protection under the law), and the 15th Amendment (establishing the right to vote for all races) was to make the Constitution "color-blind." He, therefore, argued that no law which drew distinctions between people on the basis of race was constitutional. Justice Harlan's opinion was in the minority in the Court in 1896 in the Plessy case, and again in 1927 in the very similar Gong Lum vs. Rice (275 US 78 [1927]) case, but was the majority opinion of the Court in the 1954 Brown vs. Topeka decision (347 US 483 [1954 \& 1955]).

In the Plessy vs. Ferguson decision of 1895, the U.S. Supreme Court ruled that the railroads could maintain separate facilities for the separate races, so long as the separate facilities were equal in quality. This decision was quickly applied to social systems throughout the country, including the public educational system. "Separatebut-equal" was the buzz word of this concept (or philosophy). Many 
school districts throughout the country which had maintained separate systems of education for Blacks and for whites could easily see that the separate educational systems which they had were not equal when tangible resources were compared. That is to say, throughout the country Black school systems were found to have older, less wellmaintained school buildings, fewer and older textbooks, and much lower salaries for their employees. Since these school systems did not meet the Supreme Court's "separate-but-equal" criterion, they could be challenged in court; and many were. To avoid such challenges, many school systems attempted to upgrade their Black schools to a status equal to that of the White schools. Efforts of this type were particularly strong during the civil rights reform period of the second and third decades of the present century, and again in the post-Second-World-War period of the late forties and early fifties. The "separate-but-equal" philosophy embodied in the Plessy decision and applied to education systems was based upon the assumption (or belief) that equal tangible resources should lead to equal educational achievement. A schematic representation of this philosophy (subjective model) is shown below. 


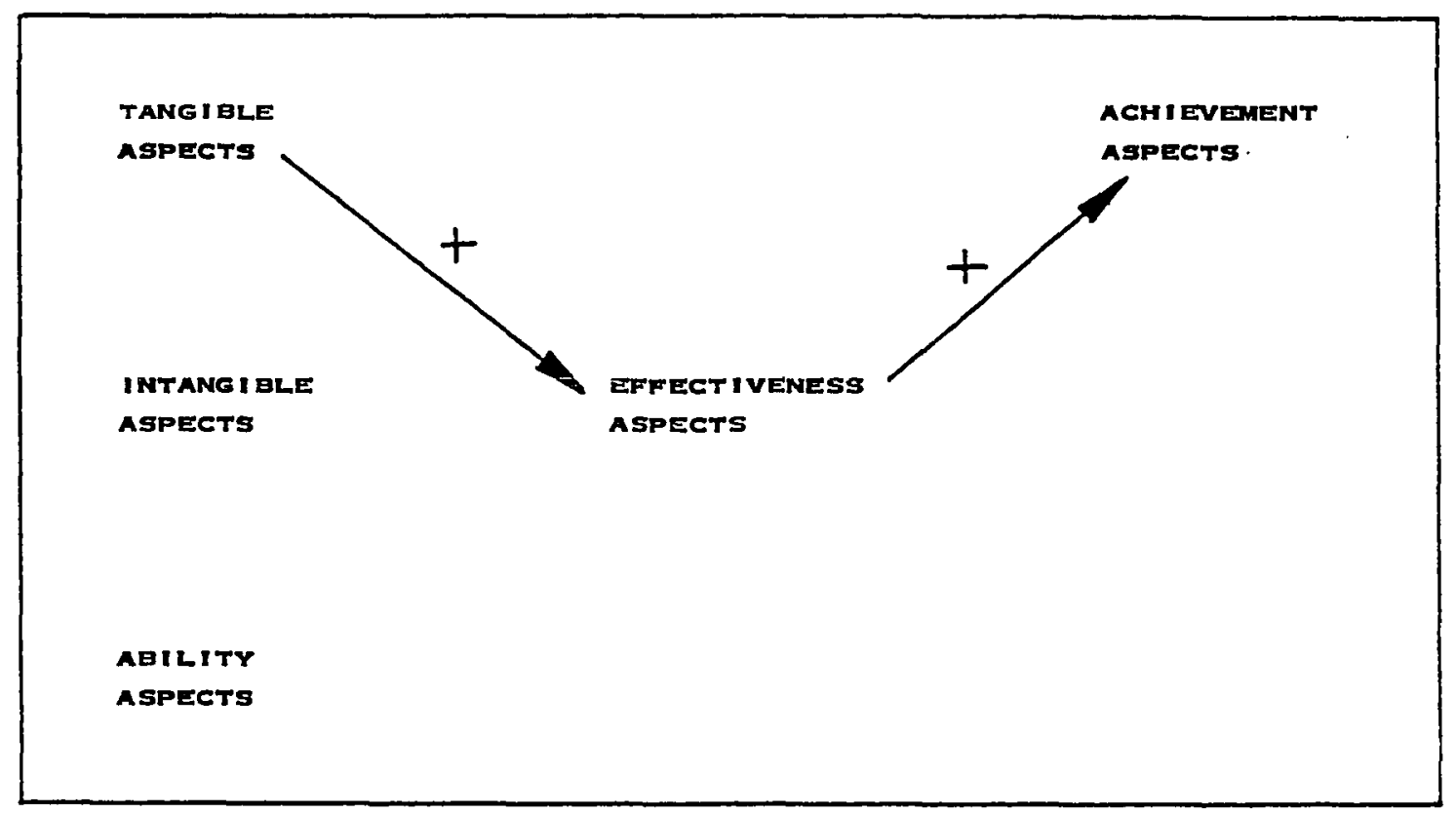

Figure 17: Diagram of the EEO Tangible Aspects Subjective Model

The arrows show direction of impact. The "+" (or "-") sign indicates a positive (or negative) impact. Thus, in this model, Tangible Aspects positively impact Effectiveness Aspects, which in turn positively impact Achievement Aspects. That is to say, equality of tangible aspects, such as resources and curriculum, is assumed to lead to equality of effectiveness aspects, such a learning rate or growth; and equality of effectiveness aspects leads to equality of educational achievement aspects, such as competency. Intangible Aspects and Ability Aspects have no impact in this model. That is to say, equity of intangible aspects and/or ability aspects is not seen as related to equity of the other types of EEO variables. Note that there is no "feedback loop" to this model. Thus, equity of tangible aspects is 
assumed to lead to equity of achievement aspects, but there is no mechanism for ensuring or determining that this is the case.

In this model, tangible aspects, such as identified in this study, COST, FTE, and NCOST, were presumed to lead to educational gains, such as RGAIN, LGAIN, and MGAIN. Thus, lower values for tangible aspects for one group of children would lead to lower values for educational gains for those children. It was this theory (represented in the Tangible Aspects Subjective Model) which led to the upgrading of tangible resources in racially segregated Black schools throughout the country. In this model, intangible aspects (such as M\%, MF\%, and VOTE) were not seen as important factors affecting student education, and achievement aspects (such as GPA, ATT, RIT) were seen as merely the sum of educa- tional gains over time. That is, if students made equal educational gains, then their educational achievement over time would be equal as well.

EEO Tangible/Intangible Aspects Subjective Model

After the Plessy decision, the NAACP challenged the "separatebut-equal" doctrine in a number of court cases. Their efforts were successful in 1947 when the Supreme Court reviewed the case of Sweatt vs. Painter (339 us 629 [1947]). The Sweatt case corisidered the constitutionality of a Texas law which provided for separate law schools for the separate races. The NAACP argued that, although the separate schools might be considered "equal" in terms of tangible resources, there were many intangible resources, such as prestige, faculty reputation, experience, and expectations, which ultimately led to inequitable educational opportunities. The Court affirmed the NAACP 
position and thereby included "intangible resources" in the concept of educational equity. In the words of the Court:

and practice, cannot be effective in isolation from the
individuals and institutions with which the law interacts.
Few students and no one who has practiced law would choose to
study in an academic vacuum, removed from the interplay of
ideas and the exchange of views with which the law is
concerned. The law school to which Texas is willing to admit
petitioner excludes from its student body members of the
racial groups which number 85 percent of the population of
the state and include most of the lawyers, witnesses, jurors,
judges, and other officials with whom petitioner will
inevitably be dealing when he becomes a member of the Texas
bar. (339 us 629 [1947])

The Sweatt case was one of several cases during this period in which the educational policy of equalization of tangible resources was examined in the light of "findings" or "research" related to the impact of "intangible resources."

Very closely related to the concept of equality of educational opportunity, as seen by allocation of resources, and the concept of educational opportunity, as seen by access to intangible resources, was the concept of EEO, as seen by the degree of racial (or another variable, such as handicapping condition or language group) isolation.

Certainly the most definitive and extensive court decision in the area of educational equity during this era was the decision on Brown vs. Topeka Board of Education (347 US 483 [1954]). The plaintiffs were Black elementary school children in Topeka, Kansas. The Topeka school board, acting in compliance with Kansas law which permitted, but did not require, separate schools for Black and White students, had established separate schools for the separate races. The plaintiffs 
contended the segregated schools were not equal simply because they were segregated. After an exhaustive review lasting nearly two years, the Court affirmed the plaintiff's position. In the words of the Court:

Today, education is perhaps the most important function of state and local governments. Compulsory school attendance laws and the great expenditures for education both demonstrate our recognition of the importance of education to our democratic society. It is required in the performance of our most basic public responsibilities, even service in the armed forces. It is the very foundation of good citizenship. Today it is a principal instrument in awakening the child to cultural values, in preparing him for later professional training, and in helping him to adjust normally to his environment. In these days, it is doubtful that any child may reasonably be expected to succeed in life if he is denied the opportunity of an education. Such an opportunity, where the state has undertaken to provide it, is a right which must be made available to all on equal terms.

We come then to the question presented: Does segregation of children in public schools solely on the basis of race, even though the physical facilities and other 'tangible' factors may be equal, deprive the children of the minority group of equal educational opportunities? We believe that it does. (347 US 483 [1954])

The findings which led to the Brown decision were extremely significant. In the first place, the Brown findings were extensive, reviewing most of the arguments of the earlier cases relating the effects of intangible resources on educational equity. In the second place, the Brown findings were buttressed by research from the social sciences: educational research was formally, authoritatively being employed as a basis for legal findings. And finally, the Brown findings were conclusive, ultimately determining that racial isolation was an "intangible" factor which guaranteed that "separate-but-equal" could not be equal. 
Thus, equalization of intangible resources also meant nonseparation.

The impact of intangible resources (such as M\%, MF\%, and VOTE) was documented in the research (Rist [1978], Bullard [1980], Rosenthal [1979]) and now in the courts Sweatt (339 US 629 [1947]), etc.) and shown to have significant influence on the quality of education obtained by students. In the Sweatt decision of 1947, the Supreme Court recognized the role of intangible resources in determining equality of educational opportunity. The Brown decision further established and defined the important influence of intangible resources. A schematic representation of the concept (subjective model) of EEO determined by both tangible and intangible resources is shown below.

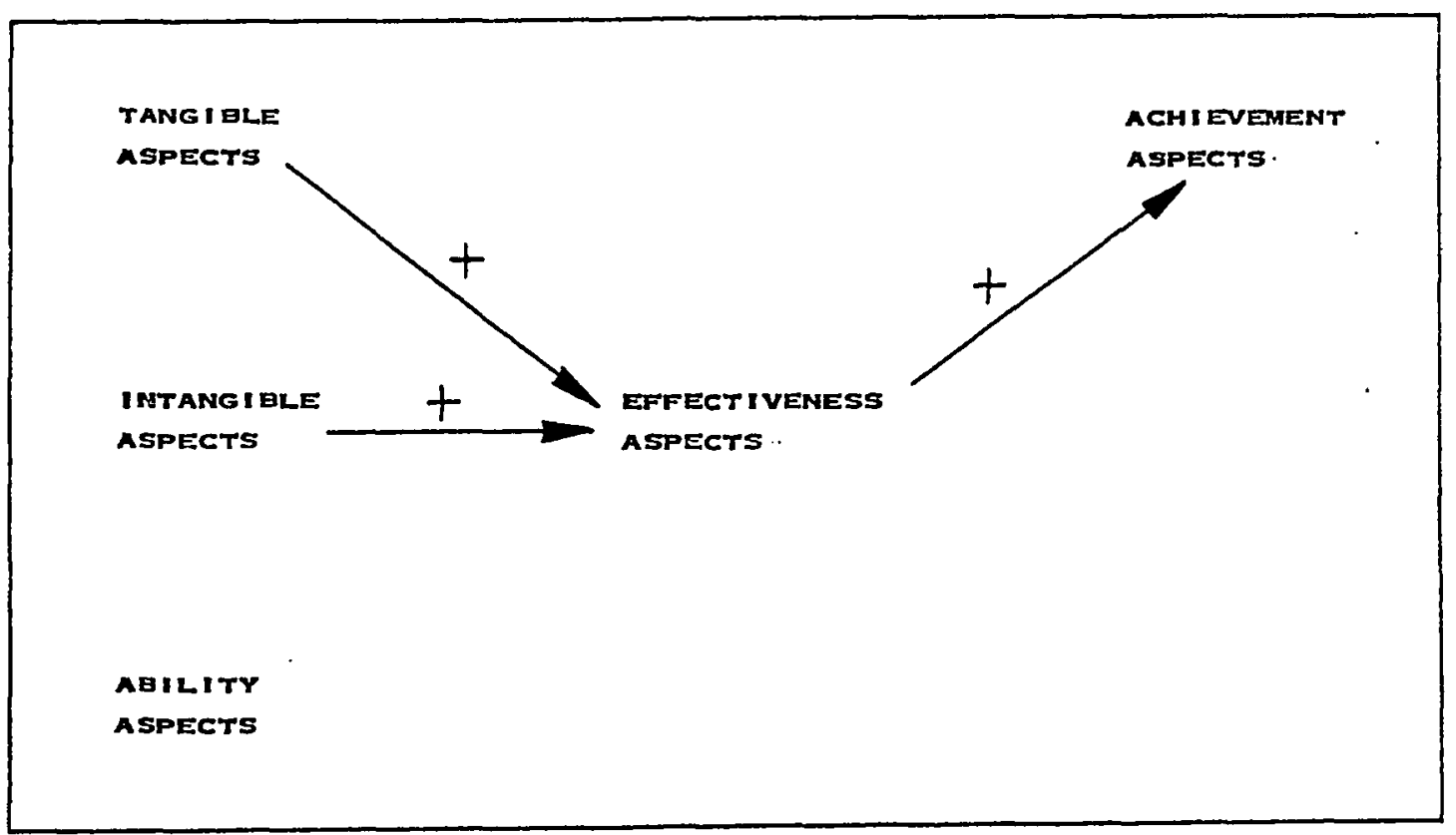

Figure 18: Diagram of the EEO Tangible/Intangible Aspects Subjective Model 
In this subjective model, tangible resources are still seen to have a direct positive impact on educational gains. But in addition, intangible aspects are also seen to have a direct impact on educational gains. This subjective model has been prevalent in much of the research and in educational philosophy and decisions since the time of the Sweatt decision.

In this subjective model, as in the EEO Tangible Aspects Subjective Model, student achievement measures such as GPA, ATT, and RIT were still viewed as simply summations over time of the student educational gains, and thus are not directly employed in the model.

As with the EEO Tangible Aspects Subjective Model, there are no "feedback loops" in the EEO Tangible/Intangible Aspects Subjective Model. Thus, equity in tangible aspects and equity in intangible aspects are assumed to produce equity in achievement, but there is no mechanism within the model for ensuring such equity of achievement.

\section{EEO Effectiveness Aspects Subjective Model}

The Brown vs. Topeka decision established the concept of desegregated school systems as the law, and desegregation as school district policy. The Civil Rights Act of 1964 ( $P L$ 88-452) gave states the authority to see that desegregation plans were implemented, and states have pursued desegregation as a primary goal for EEO ever since.

The Brown decision had broad implications. Nearly every state in the union, having enacted its legislation under the "separate-butequal" doctrine of the Plessy decision, was then in the situation of having to review its laws and practices by a new criterion. To aid the 
Supreme Court issued a second Brown decision, Brown vs. Board of states in this task and to clarify its own position, in 1955 the Education (349 US 294 [1955]), which augmented its first decision and set out what has come to be known as the "Brown Remedies." The "Brown Remedies" were guidelines to the states and local school districts as to how to comply to the original ruling. The key to the "Brown Remedies" was that states and local school districts were to draw up plans for desegregation and implement those plans "with all deliberate speed." All deliberate speed in many instances was more deliberate than speedy. Nine years later, in 1964, the U.S. Congress decided that the local school districts had had enough time and passed the Civil Rights Act of 1964 (PL 88-452), which gave the states authority to withhold funds from school districts which did not show progress towards desegregation. The legislative and administrative rulings which have grown out of the Civil Rights Act provide guidelines to the local school districts. Perhaps the strongest motivation behind the research reported here was the desire to provide a means of helping local school districts to meet these guidelines.

With the Sweatt vs. Painter (339 US 629 [1947]) decision of 1947, the Supreme Court accepted the argument that intangible resources, such as "atmosphere," "program," and "teacher expectations" could legitimately be considered as components of Equality of Educational Opportunity. Research on such intangibles has been slow, often involving case studies rather than statistical analysis. Rist's The Invisible Children: School Integration in American Society (1978), and Bullard and Stoia's The Hardest Lesson (1980) are more recent examples of case 
studies where intangible measures play the key role in examining Equality of Educational Opportunity. Some researchers, who have worked extensively with tangible measures, have come to see the intangibles as the prime concern of EEO.

Rosenthal (1979) documented the impact of "teacher expectation states" on student performance in the classroom, which led to the concept of the "self-fulfilling prophecy" as applied to classroom teachers, and inclusion of "teacher expectation" in the list of key variables. Christopher Jencks, in Inequality (1972), concluded that equal educational achievement was not achievable by the school systems. He cited moral and philosophical arguments for the egalitarian goal of equal achievement, stating that "the net effect would be to make those with the most competence and luck subsidize those with the least competence and luck to a far greater extent than they do today." But he did not feel that the schools could bring this about. He suggested that since the research had shown that schools had very little effect on the attainment of students when they become adults, schools should be measured not by student achievement but by student satisfaction. "Eliminating these differences (immediate effects on students) would not do much to make adults more equal, but it would do a great deal to make the quality of children's (and teachers') lives more equal." (p. 256) Thus, "quality of in-school life" was added to the growing list of intangible variables.

With the Lau vs. Nichols decision of 1974, the Supreme Court added a great deal of support to the concept of effective resources (measured by output) as a measure of Equality of Educational Opportunity. For 
nearly a decade legislation such as the Elementary and Secondary Education Acts had been targeting resources for programs such as Headstart, Title I (of the Elementary and Secondary Education Act of 1965), and Title VII (of the Emergency School Assistance Act of 1972 et. seq.). Research had been done on the effectiveness of these programs (Rossi et al. [1977]), as well as on effectiveness of "in-school variables." Averch et al. (1972), Brown and Dixon (1976), Rutter et al. (1979), and Summers and Wolfe (1977) are just a few of the many studies done during this period to determine the effectiveness of in-school variables on equalizing educational opportunity. All of these studies reached the conclusion that greater equity of educational effectiveness was attainable by control of school variables.

These findings had an impact on the courts. For example, in the case of Green vs. County School Board ( 391 US 430 [1968]) the question before the Court was whether the New Kent County, Virginia, School Board's "freedom-of-choice" desegregation plan met the requirements of the Brown II decision "to achieve a system of determining admission to the public schools on a nonracial basis."

The Supreme Court opinion described the background of the Green case as follows:

Petitioners brought this action in March 1965 seeking injunctive relief against respondent's continued maintenance of an alleged racially segregated school system. New Kent County is a rural county in Eastern Virginia. About one-half of its population of some 4,500 are Negroes. There is no residential segregation in the county; persons of both races reside throughout. The school system has only two schools, the New Kent school on the east side of the county and the George $W$. Watkins school on the west side. In a memorandum filed May 17, 1966, the district court found that the 'school 
system serves approximately 1,300 pupils, of which 740 are Negro and 550 are white. The school board operates one white combined elementary and high school [New Kent], and one Negro combined elementary and high school [George W. Watkins]. There are no attendance zones. Each school serves the entire county.' The record indicates that twenty-one school buses -- eleven serving the Watkins school and ten serving the New Kent school -- travel overlapping routes throughout the county to transport pupils to and from the two schools.

The segregated system was initially established and maintained under the compulsion of Virginia constitutional and statutory provisions mandating racial segregation in public education, Va Const, Art IX, Para 140 (1902); Va Code Para 22-22l (1950). These provisions were held to violate the Federal Constitution in Davis vs. County School Board of Prince Edward County, decided with Brown vs. Board of Education 347 US 483, 487 (Brown I). The respondent school board continued the segregated operation of the system after the Brown decisions, presumably on the authority of several statutes enacted by Virginia in resistance to those decisions. Some of these statutes were held to be unconstitutional on their face or as applied. One statute, the Pupil Placement Act, Va Code Para 22-232.1 et seq. (1961), not repealed until 1966, divested local boards of authority to assign children to particular schools and placed that authority in a state pupil placement board. Under that act children were each year automatically reassigned to the school previously attended unless upon their application the state board assigned them to another school; students seeking enrollment for the first time were also assigned at the discretion of the state board. To September 1964, no Negro pupil had applied for admission to the New Kent school under this statute and no white pupil had applied for admission to the Watkins school.

The school board initially sought dismissal of this suit on the ground that petitioners had failed to apply to the state board for assignment to New Kent school. However on August 2, 1965, five months after the suit was brought, respondent school board, in order to remain eligible for federal financial aid, adopted a 'freedom-of-choice' plan for desegregating the schools. Under that plan, each pupil, except those entering the first and eighth grades, may annually choose between the New Kent and Watkins schools and pupils not making a choice are assigned to the school previously attended; first- and eighth-grade pupils must affirmatively choose a school. After the plan was filed the district court denied petitioners' prayer for an injunction and granted respondent leave to submit an amendment to the plan with respect to employment and assignment of teachers and staff on a racially 
nondiscriminatory basis. The amendment was duly filed and on June $28, .1966$, the district court approved the 'freedom-ofchoice' plan as so amended. The court of Appeals for the Fourth Circuit, en banc, 382 F2d 338, affirmed the district court's approval of the 'freedom-of-choice' provisions of the plan but remanded the case to the district court for entry of an order regarding faculty 'which is much more specific and more comprehensive' and which would incorporate in addition to a 'minimal, objective time table' some of the faculty provisions of the decree entered by the Court of Appeals for the Fifth Circuit in US vs. Jefferson County Board of Education 372 F2d 836, aff'd en banc, 380 F2d 385 (1967). Judges Sobeloff and winter concurred with the remand on the teacher issue but otherwise disagreed, expressing the view "that the district court should be directed . . . also to set up procedures for periodically evaluating the effectiveness of the [board's] 'freedom of choice' [plan] in the elimination of other features of a segregated school system." Bowman vs. County School Board of Charles City County, 382 F2d 326, at 330. We granted certiorari, 389 us 1003.

The pattern of separate "white" and "Negro" schools in the New Kent County school system established under compulsion of state laws is precisely the pattern of segregation to which Brown 1 and Brown 2 were particularly addressed, and which Brown l declared unconstitutionally denied Negro school children equal protection of the laws. Racial identification of the system's schools was complete, extending not just to the composition of student bodies at the two schools but to every facet of school operations -- faculty, staff, transportation, extracurricular activities and facilities. In short, the state, acting through the local school board and school officials, organized and operated a dual system, part "white" and part "Negro." (quoted in Kirp and Yudof, 1974, p. 348-349)

The Green court unanimously found against the New Kent School Board's "freedom-of-choice" plan, and enjoined that "the Board must be required to formulate a new plan and, in light of other courses which appear open to the board, such as zoning, fashion steps which promise realistically to convert promptly to a system without a 'white' school and a 'Negro' school, but just schools." The Green decision supported the EEO policy of desegregation, but it began to give some weight to the concept of EEO as accountability. The Green decision was the 
forerunner of decisions which would mark this shift in EEO policy. The Green decision called upon the early work of the "effective school" research in determining that school districts needed to be responsible for controlling in-school variables related to desegregation.

This shift in policy called for clarification. In 1971, the Supreme Court attempted to clarify its position on school district accountability for desegregation with the opinion reached in Swann vs. Charlotte-Mecklenburg Board of Education (402 US 1 [1971]). In the Swann findings, four separate areas of school district accountability for desegregation were addressed. Those areas, and the Court's firidings, are outlined here.

1. "To what extent racial balance or racial quotas may be used as an implement in a remedial order to correct a previous segregated system." The Court found that racial quotas could be used as "a starting point in the process of shaping a remedy, rather than an inflexible requirement."

2. "Whether every all-Negro and all-white school must be eliminated as an indispensable part of a remedial process of desegregation." The Court concluded that no rule on this could apply to every district. In the Court's words, "No per se rule can adequately embrace all the difficulties of reconciling the competing interests involved; but in a system with a history of segregation the need for remedial criteria of sufficient specificity to 
assure a school authority's compliance with its constitutional duty warrants a presumption against schools that are substantially disproportionate in their racial composition."

3. "What the limits are, if any, on the rearrangement of school districts and attendance zones, as a remedial measure." The Court affirmed that the "pairing and grouping of noncontinuous school zones is a permissible test."

4. "What the limits are, if any, on the use of transportation facilities to correct state-enforced racial school segregation." The Court gave the board latitude in the use of transportation facilities in this area. (quotes from Kirp and Yudof, 1974, p. 364-365)

The overall impact of the Swann decisions was to establish authority of district courts to ensure desegregation policy and accountability of school systems to employ whatever means necessary (within the defined limits) to produce the desired outcome. The Swann decisions established, in this sense, an effectiveness model in relation to desegregation.

The cases of Lau vs. Nichols and California vs. Bakke are two recent Supreme Court cases which have to do with the question of access to educational facilities. However, the findings of these and other 
recent cases have a great deal to do with an analysis of the desegregation policy and the equality of "intangibles" as measures of EEO. The findings of recent cases incorporate research on schooling effectiveness and educational outcomes as basis for a policy analysis of the desegregation policy.

In the case of Kinney Kinmon Lau et al., vs. Alan H. Nichols et al. (414 US 563 [1974]), the San Francisco school system, which had been integrated in 1971 by federal court decree, was challenged for not providing sufficient instruction in Chinese to Chinese-speaking children. The school system then had approximately 2,800 Chinese-speaking youngsters, only 1,000 of whom were given English as a Second Language instruction. Prior to the 1971 decree, separate Chinese language schools had existed for these youngsters. After the decree, these schools were desegregated, and English as a Second Language provided for only 1,000 of the 2,800 Chinese-speaking youngsters.

The school system claimed it simply hadn't the resources to provide ESL instruction for all its Chinese-speaking youngsters, nor to provide bilingual instruction for more than a few of these children. The Supreme Court was unanimous in its decision that, in the opinion of MI. Justice Douglas, "the school system's failure to provide English language instruction denied meaningful participation in the public education program in violation of the Civil Rights Act of 1964." This finding that the school system must provide the education necessary to enable children to take advantage of EEO established a new policy of accountability as EEO policy. 
A similar case is that of the Regents of the University of California vs. Allen Bakke (438 US 265 [1978]). In this case Allen Bakke, a white male applicant to the medical school at the Davis campus of the University of California, challenged the school's "affirmative action" admission policy, which reserved a "quota" of 16 out of 100 positions for entering medical school students for "disadvantaged" minorities. Bakke claimed that this "reserved position" policy denied him access to the program for which he was otherwise qualified, and that the policy thus denied him equal protection under the law as guaranteed by the 14th Amendment. The Supreme Court unanimously upheld the California court's finding that the policy did, indeed, deny Mr. Bakke his rights under this amendment.

In all of the cases discussed in this analysis, the Supreme court was faced with interpreting the meaning of the 14th Amendment. The Amendment provides for individual rights, and in general the difficulty in interpreting the meaning of the Amendment has hung on a debate over the individual rights guaranteed by the Amendment and the rights of government to legislate or otherwise determine policy. In the Bakke findings, government had set policy for implementing the desegregation mandate of the Brown decision, but the court found that the "reserved position" policy (quota system) violation of individual rights overrode in importance the state's obligation to desegregate by such a means. The effect of this decision, as in the case of the Lau decision, was to make the educational system as a whole, and particularly the public educational system, accountable for its output to the extent that it could produce qualified medical school applicants of all races (so that quota 
systems would be unnecessary - since they were unconstitutional). These findings (Lau and Bakke) were based, in part, on the belief that the public educational system could be equal to the task of producing the desired educational outcomes.

This concept of EEO, which is seen in research, in legislation, and in everyday concerns, is the concept of EEO as equality of educational effectiveness. Birley and Dufton (1971) describe this concept of EEO as follows:

To ask for an equal chance for every child is something quite different from seeking the same provision for all. An unreflecting uniformity of treatment may not only ignore precious individual differences and stifle initiative amongst the able but also contribute to the problems of the disadvantaged, who may be ill-equipped to take advantage of what is offered. At the same time, to believe that as long as places in all types of schools are free we have achieved equality of opportunity, or even to imagine that all we need is more of the same, ignores the tremendous weight of environmental handicap that puts some children so far behind others before they even start school, that they may never catch up. (p. 4)

of course, not all researchers who hold to "equal output" as a goal of EEO hold the same view as to what causes the apparent disparity of input in the first place. Leon Kamin (1974) demonstrates the nonobjectivity of the measures commonly used to determine ability and achievement.

In his definition of justice as "fairness," John Rawls (1971) hypothesized a theoretical equal distribution of ability and achievement among groups as an initial state:

In Justice as fairness the original position of equality corresponds to the state of nature in the traditional theory 
of the social contract. This original position is not, of course, thought of as an actual historical state of affairs, much less as a primitive condition of culture. It is understood as a purely hypothetical situation characterized so as to lead to a certain conception of justice. (p. 12)

Differentiations among groups then evolved dependent on each group's culture, values and history. Rawls' theory applied to student achievement and schooling could lead to different EEO policies, depending upon what indicators were chosen to represent "social values." If student achievement was chosen to be the indicator, then an equal distribution of achievement scores would be the goal of EEO. If student growth was taken to be the indicator, then another scale would have to be employed. Kamin pointed out the importance of finding appropriate measures for this type of analysis.

Much research, perhaps culminated by the Coleman Report (1966), demonstrated that not all students could obtain equal educational gains given equal tangible and intangible resources. Some children seemed to have greater "ability" or "capability" or "potential" than others. These differences were attributed to genetic factors (superior or inferior genetic traits, inherited intelligence, etc.) and/or to environmental factors (superior or inferior socioeconomic background, parent training and expectations, etc.). Much of this research was criticized due, primarily, to the difficulty of defining and measuring such factors. Coleman dealt with schooling effects and showed a high correlation between socioeconomic status of students and their families and the students' achievements at school. It was therefore hypothesized that some "ability factors" were also influencing educational 
gains. This hypothesis is illustrated in the diagram of the subjective model of effectiveness aspects shown below.

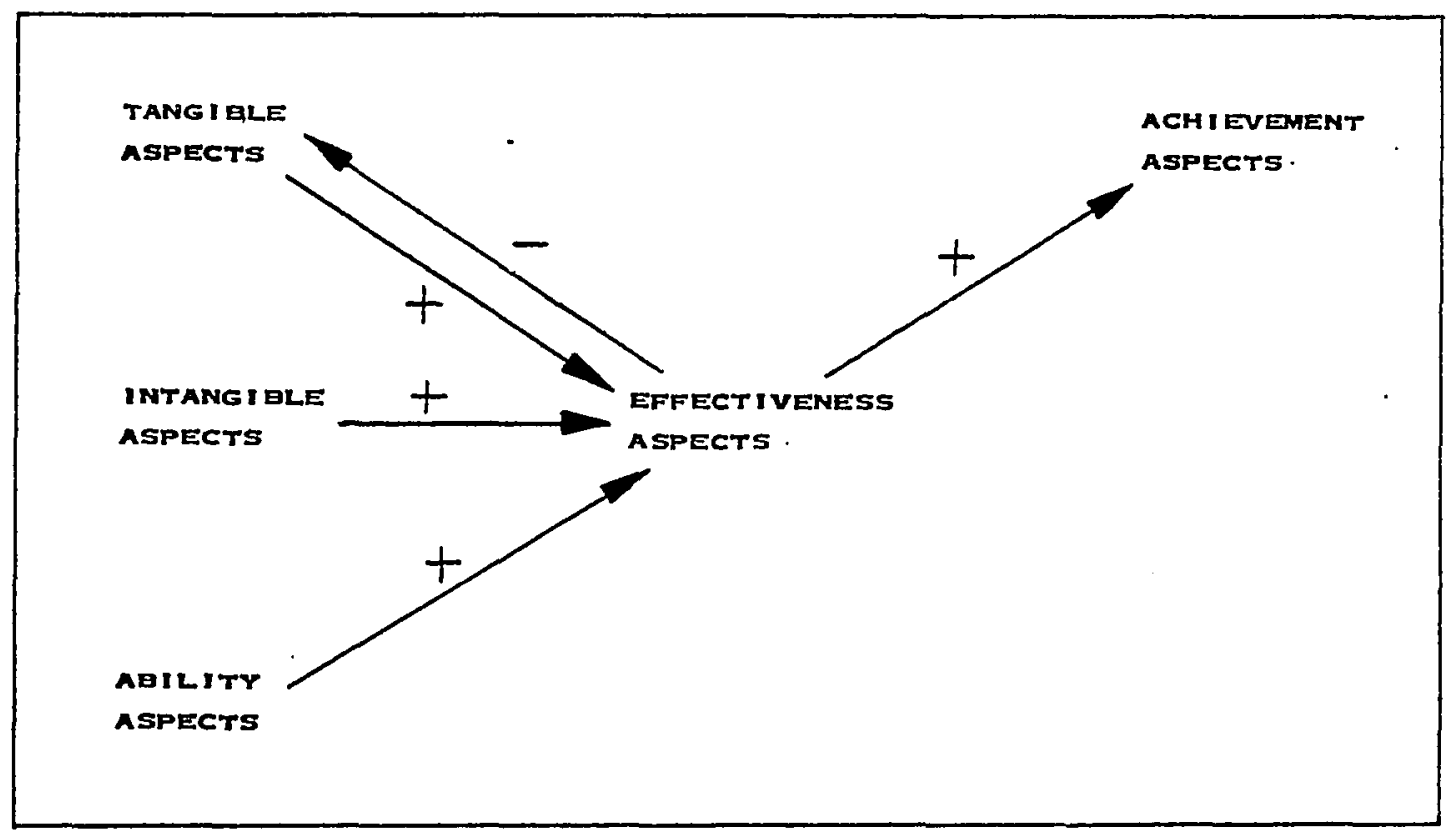

Figure 19: Diagram of the EEO Effectiveness Aspects Subjective Model

In this subjective model, both tangible resources and intangible resources were assumed to positively impact educational gains as seen before in the previous two models. That is to say, equity in tangible aspects and equity in intangible aspects leads to equity in effectiveness aspects. In addition to these relationships was the newly included suspected impact of ability factors on educational gains. Such factors as socio-economic index (SEI) and intelligence quotient (IQ) were suspected of having an impact on educational gains. Among the variables identified for this Dissertation, RIT was taken as a proxy measure of ability for most students. (RIT may not have been 
a good measure of an ability factor for certain students, such as students riewly immigrated into this country for whom English was a second language.)

Note that this subjective model has a "feedback loop" which relates "effectiveness aspects," but none which relates "achievement aspects," back into the system. The desired result of this model would be to optimize equity of "effectiveness aspects," with the assumption that this would lead to equity of achievement. This has been the predominant subjective model of the "effective schools" movement, which has placed a premium on "effectiveness aspects." This illustrates the concept, discussed above, of growing accountability for school effectiveness, which was found in these research findings and court decisions.

In his article "The Measurement of Educational Opportunity," Henry Dyer (1972) proposes such a model for measuring educational opportunity. Titled "Student-Change Model of an Educational System," Dyer's model was based upon the "effective schools" research of Coleman and others, and the then popular "input-output" model structure. Dyer proposed, simply, that expected outcome (student performance on certain measures predicted by conditions at home, community, school, and student characteristics) be compared to actual outcome, and that the difference be taken as a measure of educational opportunity. Dyer's proposal was one of the first formalizations of the EEO Effectiveness Aspects Subjective Model. Dyer summarized the development of measurement of EEO up to that point as follows: 
Probably the oldest and still the commonest method of measuring educational opportunity mistakes means for ends; a more recent one, conversely, mistakes ends for means.

He described the first erroneous method of measuring EEO as follows:

The counting of dollars and cents is still the most commonly used method of measuring educational opportunity. The notion is implicit in the formulas for allocating state aid to local school districts and in state laws that put a floor under teachers' salaries. The theory is very simple, in fact oversimple. It says that equalizing per-pupil expenditure from one school district to another tends to equalize the educational opportunities available to the pupils in each district.

The weakness in this method of measuring educational opportunity is that it rests on two highly questionable assumptions. The first assumption is that there is a one-to-one relationship between the cost of what goes into the running of a school and the quality of the goods and services bought for the purpose. The second is that the quality of the goods and services, thus measured, bears a similar relationship to the effectiveness of the school in meeting the developmental needs of the children.

He described the second erroneous method of measuring EEO in this

way:

The opposite fallacy is just as serious: it rests on the assumption that if certain end results of the educational process are the same for two school systems, the opportunities for learning in both are ipso facto equal, or that any difference in the results constitutes a measure of the degree to which they are unequal. According to this conception, the results of schooling fall into two broad categories: (1) those that have to do with when the pupil leaves school and what happens to him thereafter, and (2) those that rely on standardized achievement tests administered at various points in this school career.

In the first case, it is assumed, for instance, that a school system with a low dropout rate is in some sense better than a school system with a higher dropout rate, or that one with a high percentage of students going on to college is better than one with a lower percentage of students going on. The difficulty with measures like these is that they assume 
the quality of instruction to be perfectly related to retention rate or college-going rate when, as a matter of fact, the relationship may be considerably less than perfect. A student may drop out of school for many reasons that have little or nothing to do with what he has learned there; he may indeed have legitimate aspirations and opportunities that make further formal schooling inadvisable for him. And whether a student goes to college may depend more on his family's status and desire for reflected prestige than on anything the schools may have done or failed to do for him.

The same sorts of considerations apply to achievement test scores. The tendency is to assume that if on a reading test the 6th-grade pupils in a slum school average $X$ points lower than those in a school in white suburbia, then $X$ is the measure of the difference between the two schools in the effectiveness of reading instruction. The case may be quite the opposite: the slum school may be more effective than the suburban school in upgrading reading competence, especially in light of the deficiencies it has had to overcome. Thus, the pupils' level of performance as they emerge from any phase of the educational system tells nothing in itself about how well the system is functioning. One needs to know, in addition, what the pupils have gained during the time they have been under instruction, how much of the gain may be reasonably attributed to the instruction, and how much to factors beyond the reach of the school.

Finally, Dyer described the influence of the Coleman Report on his own model of EEO.

An interesting and important feature of the Coleman study is that it challenges the ends-means confusion in both of these traditional ways of measuring educational opportunity. What Coleman tried to do was to identify those characteristics of schools (plant, facilities, personnel, programs) that bear an empirically determined relationship to pupil achievement and to assess educational opportunity in light of these relationships. Those characteristics having a high relationship to such achievement were to be weighted heavily in the assessment, and those with a low relationship would carry a smaller weight. There is no question in my mind that this general approach is the right one. The main difficulty with the Coleman study is that it, too, oversimplifies the problem. In the search for school correlates, for instance, Coleman settled for measures that, on the face of it, are too gross and insensitive to reflect those characteristics of a school that might actually be having an impact on pupil learning. This grossness of the data is what concerns 
Sheldon White when he suggests that we must look for causal relationships "at a deeper level" than that represented by such items as teacher credentials, number of books in the school library, age of school building, and the like...

Having decided on what the goals of education ought to be and on the measures by which standards of attainment can be defined, one requires some sort of scheme for relating the measures to those variables that characterize an educational system, so as to determine how well the system is doing for its pupils as compared with what it could be doing. For the difference between the is doing and the could be doing is what I regard as the amount of educational opportunity not being provided by a given school or school system . . .

Anyone who examines closely the method I am proposing for assessing the educational opportunities provided by the schools will find plenty of problems in it, some theoretical or technical and some practical. There is not space here to discuss these problems, but I am convinced that, possibly with some modifications in the basic model, they can be solved, and I am even more deeply convinced that, in view of the desperate need for better information about what American education is doing to and for children, they are very much worth trying to solve. (Dyer, 1972, p. 514-526)

As can be seen from the above citations, Dyer's work was a

necessary predecessor to the research presented in this study.

EEO Achievement Aspects Subjective Model

In 1978, George Madaus wrote:

Today, once again, in a time of rising expenditures, accountability, and increased concern about standards, proposals such as that by Congressman Quie and programs such as Michigan's Chapter Three have reunited testing and funding. Now, however, testing is used to indicate where funds for compensatory programs or remedial assistance should be allocated. (p. l)

This movement toward increased educational accountability has been linked to major court decisions over the past twenty-five years. In his work on desegregation policies at Portland Public Schools, Thomas 
(1978) outlined the major court cases dealing with EEO since the first Brown decision (summarized below).

Brown v. Board of Education of Topeka (I) [1954]

Governmentally enforced school segregation violated 14th Amendment.

Brown v. Board of Education of Topeka (II) [1955]

Desegregation standards were broad and timetables were loose. Local school authorities must make a "prompt and reasonable start," and thereafter the court should insure that desegregation proceeds "with all deliberate speed."

Cooper V. Aaron [1958]

The Little Rock Case. Board contended that the tension and violence prevented the implementation of the plan. The court held the actions of the Governor and other State parties responsible and declared that the constitutional rights of Black children could not be yielded or sacrificed because of disorder which officials were bound to quell. The court rejected the notion that the State legislature was not bound by the Brown ruling.

\section{Griffin v. Prince Edward County, Va. School Board [1964]}

Court also ruled that paying of tuition grants to students attending private school was unconstitutional since the public schools had been closed as a last-resort means of preventing desegregation.

Green v. New Kent County, Va. [1968]

Black families choosing freedom of choice were subject to hostility, physical harrassment, and danger. Only 15\% Blacks transferred to White schools and no Whites transferred. Therefore, freedom of choice plans that don't work are not acceptable.

In March 1968 HEW issued Title VI policy statements in which the major change was a shift in responsibility for desegregation from Black parents and students to the school board. 
School boards operating State-compelled dual systems had the duty to convert to a unitary system in which racial discrimination would be eliminated root and branch.

Alexander v. Holmes [1969]

Terminate dual school systems at once. Operate only unitary schools now and hereafter.

Singleton v. Jackson Municipal School District [1970]

The district shall assign the staff so that the ratio of Negro and White teachers to other staff in each school is substantially the same as such ratios are to the teachers in the entire school system.

Swann v. Charlotte-Mecklenburg, N.C. Board of Education [1971]

Altering of attendance zones, pairing, clustering and grouping of schools and busing are approved remedial tools for desegregation. Relying on mathematical ratios, though not an exact racial balance, is a reasonable starting point in shaping a remedy.

Keyes V. Denver School District [1973]

While Denver had never operated a dual system, actions of the Board were sufficient to establish a case de jure segregation. De jure segregation in one part of a school system creates presumption that other segregated schooling in that system is the result of segregative intent. Common sense dictates the conclusion that racially inspired Board actions have an impact beyond the particular schools that are the subject of those actions.

\section{Milliken V. Bradley [1974]}

The Detroit urban-suburban case. Metropolitan-wide or inter-district remedies were inappropriate unless either or all districts concerned had de jure schools or de jure segregation in one district was found to have a racial effect on the other school district or districts. 
Morgan v. Hennigan [1974]

The Boston case. The School Committee knew that its discriminatory feeder patterns, options, open enrollment, controlled transfers, minority teacher and administrator assignments, and dual sub-systems were altogether foreseeable and well-understood by the defendants. Schools to which Black students were channeled changed in racial composition virtually overnight. The day is past when desegregation is to be achieved through the struggle of a handful of pioneering Black students willing to attend a school that is identifiably white.

USA and Webb v. School District of Omaha [1975]

The Omaha Schools and faculties were segregated. Segregated housing in the city and suburbs resulted from discriminatory State and private actions. Faced with other choices, the school district's actions in faculty assignments, student transfers, optional zones, school construction and the deterioration of Tech. High gave sufficient proof to trigger the presumption of segregative intent. This violates the Constitution and must be "eliminated root and branch."

These and other recent Supreme Court decisions have tended to bring about the formation of the latest EEO policy, that of accountability of school systems for educational outcomes.

Burbules, Lord, and Sherman (1982) noted that:

While several authors have written quite lucidly on certain aspects of the issue of equal opportunity for education, there has not been a thorough and comprehensive philosophical analysis and critique of the concepts of "equity" and "equal opportunity" and related issues in education. (p. 169)

They, therefore, undertook their theoretical analysis of the major conceptual issues concerning equal educational opportunity. They concluded that: 
An equitable opportunity is an opportunity that is distributed to persons in a fair and equal manner based on their possession of certain relevant characteristics. The criteria of access for the opportunity should be identical to these relevant characteristics, and it is this identity that makes the opportunity equitable. (p. 178)

Although the concept of accountability (equity of results) did not fall under their formal definition of "equitable opportunity," they did recognize the development of the accountability concept, citing Coleman and Bakke.

Their definition of "equitable opportunity" focused, instead, on equitable process. They then went on to discuss two strategies for providing more equitable opportunity: (1) elimination of irrelevant access criteria and (2) compensation.

Federal legislation PL 94-142 (the Handicapped Child Education Act) further applied the concept of effective resources as determined by output to handicapped students. A general statement of this concept might be that each student was entitled to that allocation of resources which most effectively met his needs, within the limits of the available resources of the system. Although in many cases funding has been provided to help with more expensive resources, there has also been a shifting of the distribution of resources within school systems. This concept of EEO amounts to a maximization-of-resource allocation problem, and technical studies and experimental efforts to solve this problem have abounded.

A good example of implementation of the philosophy of EEO as accountability for educational achievement is the development of the accountability model for the Florida public school system. 
Equal educational opportunity in the constitutional sense says that the quality of a student's education must not be dependent on the local wealth or lack of wealth of school districts. Most legal authorities believe that the Florida funding formula which funds individual students according to need and nullifies local wealth, can withstand a legal test of equal educational opportunity. The corollary is that if the funding formula can stand the test of equity interdistrict, it can stand the test of equity intradistrict if the district flows through to schools a pro rata share of the base student dollar receipt from the finance program in the manner that tracks the State funding formula. This in effect is school-based budgeting, in which a school's budget is determined by the unique mix of a student body and funds flow to match that mix. (McFatter, 1982, p. 360)

The Florida story illustrates the implementation of the accountability concept of EEO at a state-wide level. This accountability concept leads to a fourth subjective model of EEO, described here as the EEO Achievement Aspects Subjective Model.

The philosophy which led to the subjective model for the Intangible Aspects concept followed in time and simply added on to the previous concept shown by the Subjective Model of Tangible Aspects. The concept illustrated by the EEO Effectiveness Aspects Subjective Model followed in time those illustrated by the earlier models, but its schematic representation did not simply add on to the previous subjective models. Instead, there was a distinct difference in the structure of the model brought about by the addition of a feedback loop which impacted future allocation of tangible resources. The EEO Achievement Aspects Subjective Model expands upon this important concept of feedback. Feedback loops in the model imply accountability responsibilities within the system. Feedback loops of this type, with an odd number of negative impact relationships, are known as "regula- 
tors." They cause the system to tend towards equilibrium, and in this sense define the accountability of the system. In this Dissertation, the term "EEO Accountability" is used to describe the relationships illustrated by the feedback loops in the EEO Achievement Aspects Subjective Model which tend to bring about equilibrium of the achievement variables within the system.

The EEO Achievement Aspects Subjective Model was based upon the (abstract, moral) goal of equality of educational achievement. It placed a new kind of accountability on the educational system. Whereas with each of the three previous subjective models the focus was on the process of education, the EEO Achievement Aspects Subjective Model focused on the product. Therefore, the EEO Effectiveness Aspects Subjective Model might have its chief advocates among the ranks of educators and educational researchers concerned with the process and effectiveness of education. The EEO Achievement Aspects Subjective Model might have as its chief advocates social scientists and political scientists (and practitioners) who were primarily concerned with the outcomes of the educational system.

In the EEO Achievement Aspects Subjective Model, the Effectiveness Aspects and the Intangible Aspects were seen as factors which impacted the allocation of tangible resources in such a way as to bring about the resulting equitable Educational Achievement. A diagram of this subjective model is shown below. 


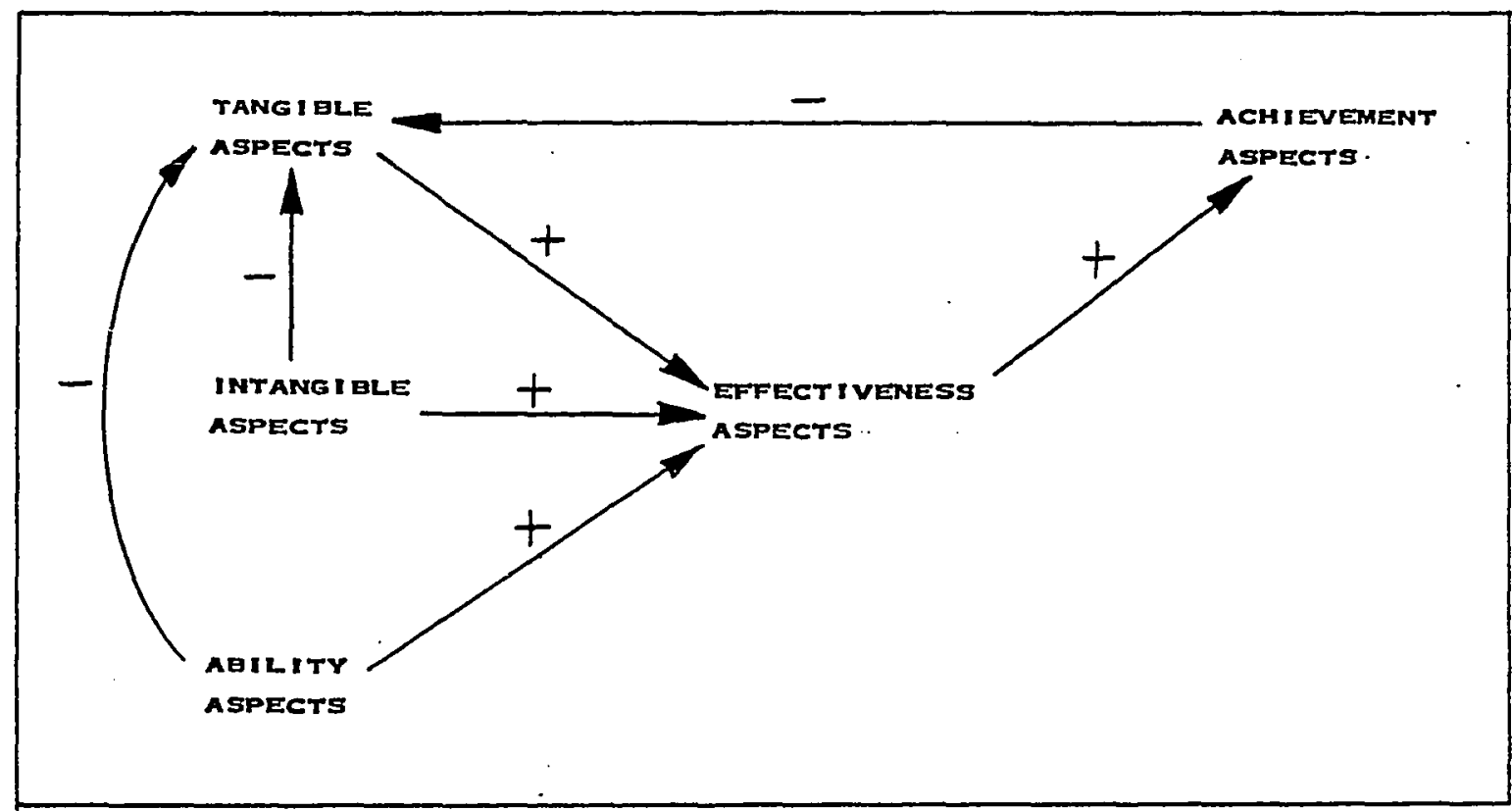

Figure 20: Diagram of the EEO Achievement Aspects Subjective Model The difference between the EEO Effectiveness Aspects Subjective Model and the EEO Achievement Aspects Subjective Model was essentially one of accountability for equitable student achievement. In the EEO Effectiveness Aspects Subjective Model, the accountability for student achievement was shared by factors within and outside of tile educational system, with the educational system acountable only for student progress. In the EEO Achievement Aspects Subjective Model, the educational system was held solely accountable for the achievement of its students. The Supreme Court's Lau decision of 1973 placed a good deal of this accountability on the public school system. 
In fact, it was the major finding of the author's literature review that current school policy on a national level can be classified as being in an era of accountability. (A similar conclusion is reached by both Gordon (1972) and Wise (1980)). Given this finding, one would expect that the EEO Achievement Aspects Subjective Model, constructed on the basis of educational accountability, would be reflected in any valid "computerized" or "mathematical" model. It is, in fact, this expectation which underlies the approach used in this study to identify the subjective models reflected in the literature and to analyze the policy reflected by the subjective model in effect. The hypothesis of this research is that a computerized model can be constructed which adequately reflects the reality of current policy. Thus, one check on the validity of the derived (computer) model of EEO will be its congruence with the EEO Achievement Aspects Subjective Model. That is to say, statistical relationships between the identified variables are predicted by the literature analysis as illustrated by the EEO Achievement Aspects Subjective Model. This is the reality check needed to tie the computer model, and thus the eventual Decision Support System, to the real world.

The foregoing literature search led the author to the hypothesis that the identified key variables presented in the preceding chapter may provide an adequate basis for building a computerized model of EEO. These variables were grouped according to an outline extracted from Coleman. These groups of variables have been included, in this chapter, in four hypothetical subjective models. It is further hypothesized that one of these models, the EEO Achievement Aspects 
Subjective Model, which encompasses current concepts of accountability and feedback, should most closely represent the real world situation, and will be demonstrated by analysis of actual data. The experimental research described in the following chapter is designed to empirically determine the adequacy of the selected variables to provide a basis for a computerized representation of such a subjective model to be used in a Decision Support System centered on the concept of Equal Educational Opportunity. 
CHAPTER $V$

COMPUTER SIMULATION OF SUBJECTIVE MODELS

\section{Computer Simulation and Analysis}

The next step in the DSS design methodology adopted for this Dissertation was computer simulation of models. Any model is an abstraction, a simplified representation, of the reality it purports to represent. Any time a model is built, its purpose is to provide a proxy for the reality it represents, adequate to the context of its intended use. A general method of "computer simulation of models" is that representations of subjective models such as those developed in Chapter IV are programmed in some computer simulation language and the computer program is run. The computer program reads in data descriptive of the variables included in the model at some point or points in time and prints out values for the variables at a later point or points in time. The output values are then compared to actual, measured values for those variables at the designated times, and the model is "validated" and/or "calibrated" so that the output matches (as closely as possible) reality. This method is used primarily for simulation models which compute projections over time. (For a particularly relevant example, see Beshers, 1972.)

Another method for computer simulation of models, the method selected for this research, is not to project values of variables over time, but rather to compute values of relationships at a given time, given specific input values. A general method for this type of "computer simulation of models" is to run a computer program which 
carries out some multi-variate statistical analysis on the input data, and produces, as an output, coefficients or equations which describe the relationships of interest. (See, for example, Smith, 1972.) Validation of this type of "computer simulation" is generally accomplished by running similar analyses of more data and looking for similar results. The simplest and most basic multi-variate statistical analysis which can be used in this way is correlation analysis, and therefore correlation analysis was chosen as a starting point for this activity. Several additional computer methods, including sub-group correlation analysis and graphic analysis, are then used to validate the original findings.

Based upon the research outlined in the last chapter, it is hypothesized that analysis by computer simulation will demonstrate that, of the four subjective models represented, the Achievement Aspects Subjective Model most closely accounts for the relationships found in the data. The results reported in this chapter verify that hypothesis.

\section{Correlation Analysis}

A primary goal of this portion of the research was to discover relationships among the identified key variables using a statistical analysis approach. The strategy was to use the resulting statistically derived relationships to either confirm or disprove aspects of the hypothesized subjective models. If the subjective and statisticallyderived models corroborated one another, they would then be installed as part of the DSS and thus available to the EEO decision maker. 
One assumption implicit in the choice of the identified key variables was that they do, indeed, fall into the categories used in the subjective models. A test of this was to do a correlation analysis on each of the thirteen variables with each of the other variables and see if indeed the real-world data bore out the assumptions. The hypothesis stipulates that there would be a stronger correlation between variables within categories than between variables of different categories. Further, the literature suggested four subjective models (represented in Chapter IV) which could be used as hypotheses for a potential statistically-derived model relating these categories of variables. It was concluded that of the four subjective models, the EEO Achievement Aspects Subjective Model due to its feedback and accountability features, should most closely correspond to the statistically derived model. In order to test these hypotheses, a Pearson correlation analysis was performed on the identified key variables. The correlation coefficients computed were used to determine the validity of the relationships and groupings among the variables as hypothesized in the subjective models.

There are many statistical analyses which can be used to determine relationships in the data of many variables. These analyses are often referred to collectively as "multi-variate statistics," and include such sophisticated techniques as factor analysis, analysis of variance, and multiple linear regression. All of these multi-variate techniques, however, are founded upon the basic concept of correlation. A simple correlation analysis is therefore the starting point of any such inter/intra variable analysis. Correlation, in general, is the 
calculation of the quantifiable degree to which values of one variable are related to values of another variable.

The Pearson correlation analysis subprogram of the Statistical Package for the Social Sciences (SPSS) was used for this part of the investigation. Pearson correlation computes product-moment correlation coefficients for pairs of interval-level variables.

According to Nie et al. (1975), several social science methodologists argue that the Pearson correlation coefficients may be used even if the data satisfy only the assumptions of ordinal-level measurement.

Of the EEO variables identified for this study, all were interval-level variables except SUSP. (Some researchers feel that GPA is not an interval-level variable either.) for this reason, and because of the small number of suspensions, the SUSP variable was not analyzed using the Pearson correlation technique.

The SPSS program for Pearson Correlation did a pairwise comparison of the values of each of two variables for each case considered. In this study a case represented a student's record which contained values for each of the defined EEO variables. The program dealt with missing data by pairwise deletion.

With pairwise deletion, a case is omitted from the computation of a given coefficient if the value of either of the two variables being considered is missing. Pairwise deletion has the advantage of utilizing as much of the data as possible ii: $t$ ise computation of each coefficient. It has the disadvantage, however, of producing coefficients which are based on different number of cases and perhaps on even quite different subpopulations of the file. (Nie, et al., 1975, p. 283.) 
The value of $N$ (number of cases) in this analysis ranged up to 4000 , depending on the amount of pairwise deletion. Values of correlation coefficients run from -1 to +1 . A coefficient value near -1 indicates a high, negative correlation. A coefficient value near +1 indicates a high, positive correlation. A coefficient value near 0 indicates a low correlation. Also reported by the Pearson correlation program is a significance value, $P$, which is the probability that the correlation coefficient found is due to chance distribution of variable values. Thus, the lower the value of $P$, the higher the reliability of the coefficient.

Table A-I (Appendix A) shows a matrix of Pearson correlation coefficients, the number of pairs of variables used in each correlation, and the probability that the calculated coefficient was due to chance for the twelve interval-level variables examined. The following table shows all pairs of variables for which the Pearson correlation coefficient was greater than 0.1 . 
TABLE I

SUMMARY OF SIGNIFICANT CORRELATIONS FOUND

$\underline{\text { Variable } 1 \text { Variable } 2 \text { Coefficient }} \underline{\underline{\text { Significance }(P)}}$

$\begin{array}{llll}\text { COST } & \text { FTE } & .9702 & .000 \\ & \text { NCOST } & .9877 & .000 \\ & \text { M\% } & .6755 & .000 \\ & \text { MF\% } & .4847 & .000 \\ & \text { VOTE } & -.2727 & .000 \\ \text { FTE } & \text { RIT } & -.1602 & .000 \\ & \text { NCOST } & .9204 & .000 \\ & \text { M\% } & .6849 & .000 \\ & \text { MF\% } & .3846 & .000 \\ & \text { VOTE } & -.2413 & .000 \\ \text { NCOST } & \text { RIT } & -.1597 & .000 \\ & \text { M\% } & .6443 & .000 \\ & \text { MF\% } & .5800 & .000 \\ & \text { VOTE } & -.2840 & .000 \\ \text { M\% } & \text { RIT } & -.1537 & .000 \\ & \text { MF\% } & .5313 & .000 \\ & \text { VOTE } & -.1308 & .000 \\ \text { MF\% } & \text { RIT } & -.2519 & .000 \\ & \text { VOTE } & -.2431 & .000 \\ \text { VOTE } & \text { RIT } & -.2285 & .000 \\ \text { RGAIN } & \text { RIT } & .2647 & .000 \\ \text { RIT } & \text { RIT } & -.1146 & .000 \\ & \text { GPA } & .1064 & .000 \\ \text { GPA } & \text { ATT } & .1071 & .000 \\ & \text { ATT } & .3939 & .000\end{array}$

Table B-I (Appendix B) is a simplification of Table A-I which only displays a "+" or "-" sign in those positions where the correlation coefficient exceeds .I and the significance level exceeds .1 (i.e., the probability that the correlation is due to chance is less than .1).

This correlation analysis led to the following general conclusions:

1. The variables COST, FTE, and NCOST all showed high positive correlation among themselves and a small 
negative correlation with VOTE and RIT. These variables could be considered to form a group.

2. The variables $M \%$ and $M F \%$ showed positive correlation between themselves and with the first group of COST, FTE, and NCOST. These variables also showed a small negative correlation with VOTE and RIT and could be grouped as above.

3. The variables GPA and ATT showed positive correlation and could be grouped.

4. The variable VOTE had a negative correlation with the first two groups (COST, FTE, NCOST, M\%, and MF\%) and a positive correlation with RIT.

5. The variable RIT had a small negative correlation to the first group, a small positive correlation to the second group, and a positive correlation to VOTE.

6. The variables RGAIN, MGAIN, and LGAIN showed no significant correlations with the other variables.

The following figure is a schematic representation of the relationships between these twelve variables implied by the analysis. 


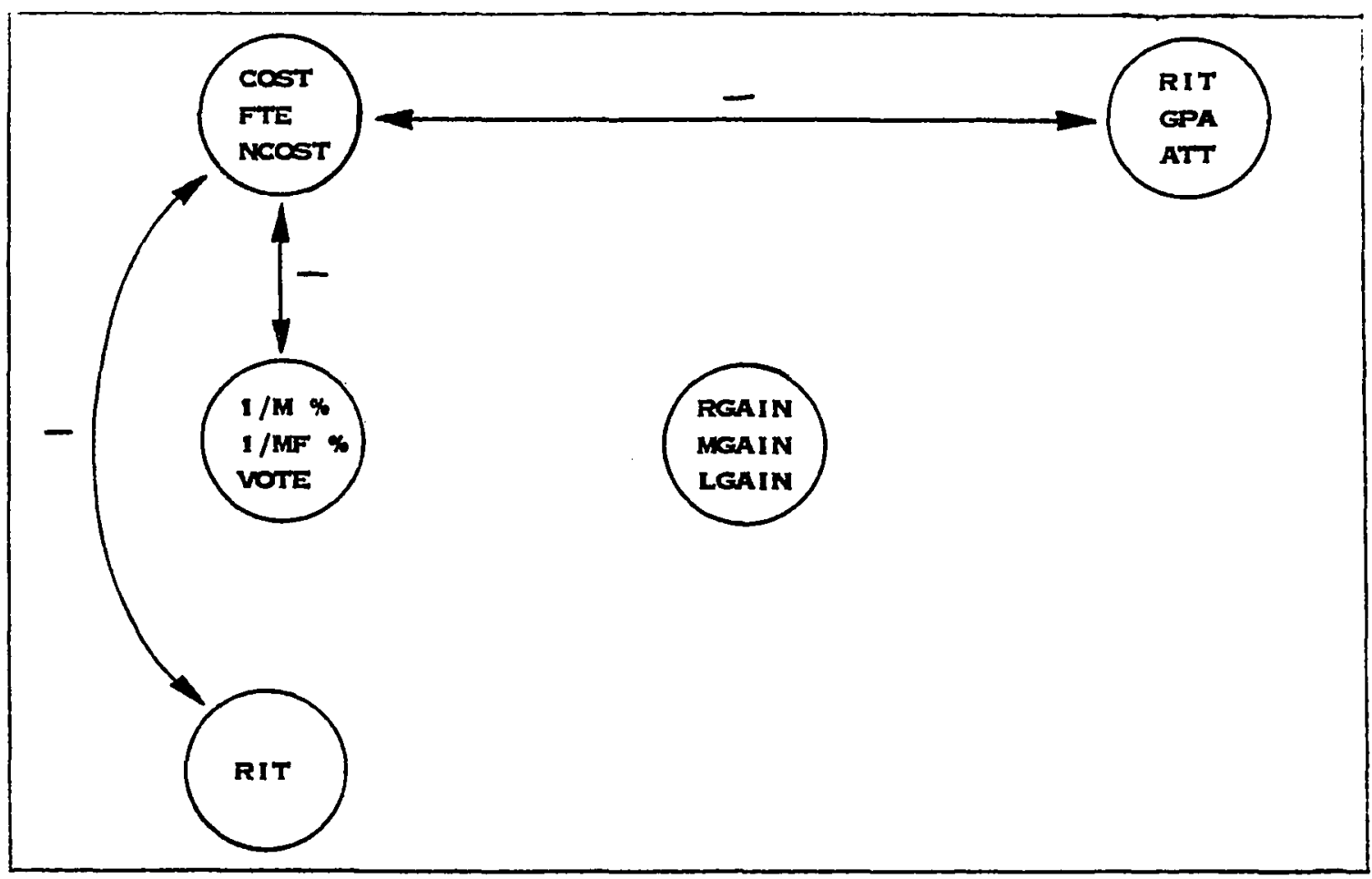

Figure 21: Diagram of EEO Variable Relationships Determined by Correlation Analysis

The "-" signs in the above diagram refer to negative correlation between the variables. The arrows point in both directions, since the Pearson correlation coefficient does not indicate direction of impact. Variables in circles were seen to have higher positive correlations among themselves than with the other variables.

These relationships can be expressed in the following generalizations about the student data examined:

1. Students who attended class regularly had a tendency to achieve higher grades than students who did not. 
2. Students with higher reauting scores had a slight tendency to attend class more regularly and to achieve higher grades than students with lower reading scores.

3. Students with lower reading scores had a slight tendency to attend schools with higher costs per student, higher FTE per student, and higher nonsalary costs per student. That is, the system spent more on students with lower reading scores.

4. Students at schools with higher minority percentages of students had slightly lower reading scores and received slightly more resources than students at schools with lower minority percentages.

5. Voter support was slightly higher in areas of schools with lower costs and minority percentages than for areas of schools with higher costs and minority percentages.

6. Gains in reading, mathematics and lainguage usage test scores did not directly correlate to the other variables in this study.

These findings from the correlation analysis were compared with the proposed subjective models (i.e., the philosophies underlying the four major concepts of EEO) developed in Chapter IV. The main observations from this comparison are as follows: 
1. In the statistical analysis, there was a direct relationship between the tangible variables and the intangible variables. This was true of the EEO Achievement Aspects Subjective Model but of none of the other subjective models and is indicative of a system of accountability for allocation of tangible resources.

2. In the statistical analysis, there was a direct relationship between RIT, an ability and/or achievement factor, and the Intangible Aspects variables. Again, the only subjective model which displayed this characteristic was the EEO Achievement Aspects Subjective Model.

3. In the statistical analysis, there was no direct relationship between the Intangible Aspects variables and the Effectiveness Aspects variables. Again, this resembled the EEO Achievement Aspects Subjective Model more than any of the other subjective models, since the feedback loops of this model would tend to minimize such a correlation.

4. The relationship between Ability Aspects variables and Effectiveness Aspects variables which was present in the EEO Effectiveness Aspects Subjective Model was not found in the statisticaliy : mivar model. Again; the feedback loops of the EEO Achievement Aspects Subjective Model would tend to diminish such a correlaticn. 
5. In the statistical analysis, there was no direct relationship between the Tangible Aspects variables and the Effectivenss Aspects variables. This resembled the expected outcome from the EEO Achievement Aspects Subjective Model and the EEO Effectiveness Aspects Subjective Model more than the other two subjective models, since their feedback loops would both tend to minimize such a correlation.

In all of the above five cases, the statistical analysis seemed to support the EEO Achievement Aspects Subjective Model (Figure 20) more than any of the other subjective models. This confirmed and validated the hypothesis of the last chapter and strengthened the credibility of the statistical findings.

Figure 22 below shows the EEO Achievement Aspects Subjective Model with the average correlation coefficients discovered by the statistical analysis. This diagram represents a preliminary model of EEO accountability which can be used in a computerized Decision Support System. The term accountability is used here, as in Chapter IV, to indicate the presence of feedback loops which have the affect of bringing about equilibrium of the achievement variables within the system. 


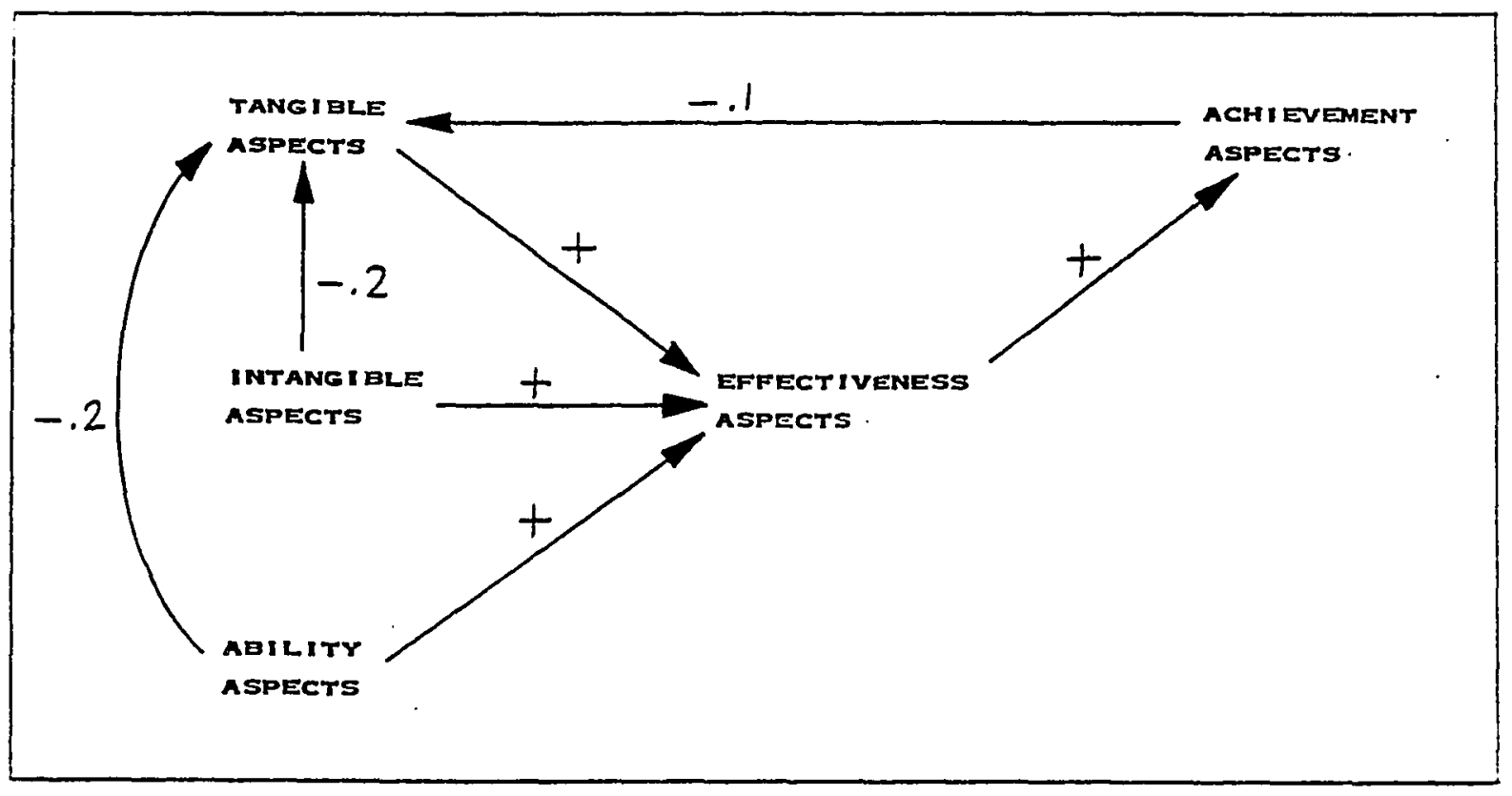

Figure 22: Preliminary Statistical Model of EEO Accountability

The relationships represented in the EEO Achievement Aspects Subjective Model appear to have been confirmed by this research, although a number of the relationships remain to be quantified.

It is clear that the process of building the statistical model has led to a clearer understanding of the EEO context. The selection of EEO variables, the derivation of their relationships, the interpretation of these relationships in the form of a statistical model, and the comparison of the statistical model to several subjective models led to the rejection of a number of hypotheses previously put forward in the subjective models. 
Subgroup Analysis

Novick (1982) refers to the phenomenon known as "Simpson's Paradox," which demonstrates that characteristics which may be true for a given population may not be true for any subpopulation, depending upon how the subpopulations are defined. Novick refers to the earlier work by Campbell and Stanley (1963), which stresses the need for appropriate sub-group analysis to validate the findings of an analysis of a larger group. Therefore, in order to determine the general applicability of the relationships found in the correlation analysis of the entire set of ninth grade students, similar analyses were performed on subsets of this student population. Appendix A contains the Pearson correlation coefficient matrices obtained by these additional analyses. Pearson correlation coefficient matrices are presented for:

All Groups Ethnic Group 1 Ethnic Group 2 Ethnic Group 3 Ethnic Group 4 Ethnic Group 5 Females Males
Tab.le A-I

Table A-II

Table A-III

Table A-IV

Table A-V

Table A-VI

Table A-VII

Table A-VIII

Simplified matrices representing the correlation coefficient matrices are presented in Appendix $\mathrm{B}$ for:
Al1 Groups
Ethnic Group 2
Ethnic Group 3
Ethnic Group 4
Females
Males

Table B-I

Table B-II

Table B-III

Table B-IV

Table B-V

Table B-VI 
Simplified matrices were not prepared for Ethnic Groups 1 and 5; the small number of students in these subsets rendered the correlations found in these two analyses statistically insignificant.

The subgroup analyses in Appendix $A$ showed many of the same relationships as found in the analysis of the full set of data. The following general group relationships were very similar for each student subset:

1. COST, FTE, and NCOST were highly positively correlated;

2. $M \%$ and MF\% were positively correlated with themselves and with COST, FTE, and NCOST;

3. VOTE was negatively correlated to the first set of variables; and

4. GPA and ATT were highly positively correlated.

These general groupings showed up in each of the ethnic and sexual subsets examined, as well as in the overall analysis of the data.

of interest to administrators in the school system were differences in the matrices in Appendix $A$. The interest and usefulness of these observations illustrates the potential usefulness of the DSS to be developed from this research. For instance, for females there was a positive correlation between RIT and GPA; for males, there was not. This implied that males were not achieving (in terms of GPA) at their potential to the same extent that females were. Perhaps some aspect of the educational program could address this discrepency. 
There were a number of this type of sex-specific or ethnicspecific characteristics which could be starting points for significant educational research. Some further examples are given here.

1. Ethnic Group 4 showed a negative correlation between RGAIN and the group of variables COST, FTE, NCOST, M\%, and MF\%, and a negative correlation between MG̈ÂIiv and the group COST, FTE, NCOST, M\%, and MF\%. Also, RGAIN and MGAIN were positively correlated. of particular significance in the interpretation of these relationships for Ethnic Group 4 was the fact that many of these students were new immigrants into this country for whom English was not their native language.

2. Ethnic Group 4 showed a positive correlation between LGAIN and GPA not seen with other ethnic groups.

3. Ethnic Group 3 showed a positive correlation between ATT and VOTE not seen with other ethnic groups.

4. Ethnic Group 4 showed a positive correlation between RGAIN and NCOST, between RGAIN and M\%, and between RGAIN and MF\%.

However, the general finding of the additional correlation analyses was the confirmation of the relationships described in the above first approximation model for a DSS. Since the relationships which had been hypothesized between these variables were demonstrated 
based on the Pearson correlation analysis, it was not felt necessary to subject this data to any of the more complex multi-varite analysis techniques.

The next sections of this chapter discuss other methods of verifying these findings.

Graphic Analysis

Lendaris and Stanley (1970) and Fukunaga and Olsen (1971) introduced a methodology of representing data as "signatures" (normally visually represented) in a computer-graphic, pattern-recognition research environment to discover groupings of data with similar characteristics. The signatures were manipulated in various ways via (computerized) transformations and graphing techniques, and studied by the investigator to discover patterns in the signatures. These patterns were then investigated for possible interpretations in the original problem context.

To apply this analysis method to the present study, hereafter called graphic analysis, mean values of the EEO variables for each ethnic group and for the entire group were calculated. These values were then normalized by determining for each ethnic group mean value its difference from the entire group mean in standard deviations. The "tic marks" on the horizontal axis were arbitrariiy assigned to represent the five ethnic groups. Then, the values for each group were entered on the graph as points, and the points were connected with straight lines, thus creating the "signatures" to be studied. This was all done using a computerized graphics system. 
Chapter III contains signatures obtained in this manner for each of the thirteen defined EEO variables.

The first signatures examined were those for the variables COST, FTE, and NCOST. These signatures are shown in Chapter III as Figures 3, 4, and 5. The exciting discovery made in this research was to note that each of the signatures in these three figures resembled a letter "W." In fact, the signatures for all these three variables were almost identical. This served to confirm the grouping of these variables derived in Chapter $V$ and represented in Figures 21 and 22.

Interestingly, SUSP, which could not be analyzed by Pearson correlation analysis, also showed a "W" signature (see figure 15). This could indicate that the SUSP variable was closely associated with this group.

The next signatures examined were those for $M \%$ and MF\% (see Figures 6 and 7). These variables were sometimes classified as "desegregation variables," sometimes as "intangible variables." In the correlation analysis, a high correlation between these variables and the tangible variables of COST, NCOST and FTE was found.

The signatures of these graphs looked like modified "W's," similar to the signatures of the first group but sharing similar differences. These two signatures ( $M \%$ and $M F \%$ ) were almost identical. This coincided with the correlation analysis findings that these variables were very closely related to each other and closely related to the first group.

A third group of variables examined by this graphic technique consisted of RIT, GPA, and ATT (see Figures 12, 13, and 14). This group had shown somewhat less correlation under the Pearson analysis 
than had the first two groups. Here, their signatures all resembled the letter "M," although they were not nearly so identical with each other as were signatures in the first two groups. This correspondence in signatures supported the grouping of these variables.

The four variables remaining to be examined graphically were RGAIN, MGAIN, LGAIN and VOTE. One hypothesis was that the gain measures, RGAIN, MGAIN and LGAIN, would form a statistical grouping. The Pearson correlation analysis did not show correlations high enough to confirm this hypothesis. However, the signatures of these three graphs were very similar (see Figures 9, 10, and 11). The graphs began to look like a straight horizontal line with value zero on the vertical axis. The points on these three signatures were, on the average, within .l standard deviations of the norm. The points on the previous nine graphs averaged more than .2 standard deviations from the norm. Although these three signatures did not form as distinctive a group as some of the previous groups of signatures, they did show enough similarity to suggest a relationship between these variables.

The final signature analyzed, the one for the variable VOTE, did not appear to be related to any of the other variables in a noticeable way (see Figure 8 ).

It was important to realize that the arbitrary ordering of the ethnic groups across the horizontal axis did not change the groupings validated by this signature analysis technique. Changing the order of the ethnic groups along the horizontal axis produced different signatures, but signatures for related variables still resembled one another. For example, if the points for the ethnic group values were 
spaced along the horizontal axis in the order Ethnic Group 2, Group 4, Group 1, Group 3, Group 5, signatures for the group COST, FTE, NCOST, and SUSP looked like this:

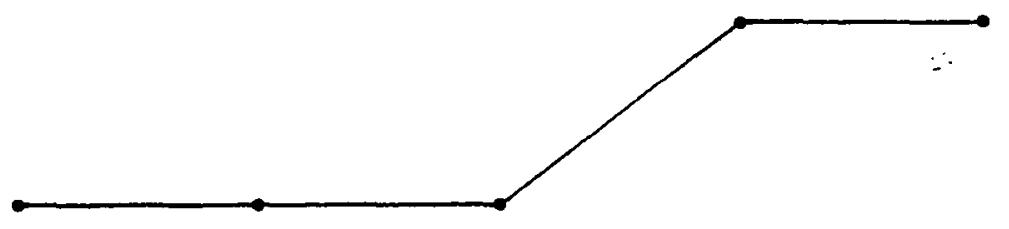

and signatures for the group RIT, GPA, and ATT looked like this:

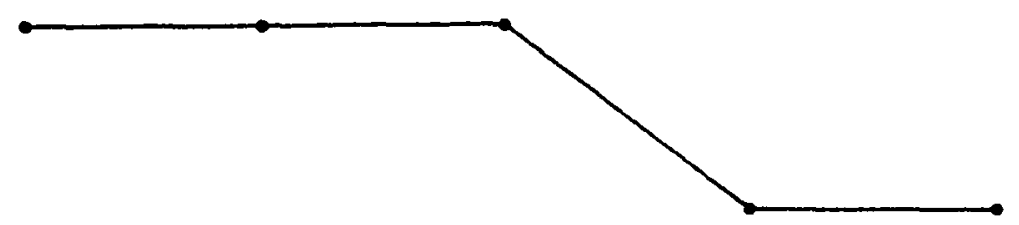

Although the shape of the signature was therefore arbitrary, depending on the sequence of the values along the horizontal axis, the groupings of the variables by their signatures was significant.

Using this graphic analysis technique, each of the EEO variables was graphed and a signature produced. The similarities and differences among these signatures confirmed and added to the findings of relationships using the Pearson correlation technique.

Phenomena Explanation

A fourth method which contributed to validating the findings was an examination of the ability for the findings to help account for observed phenomena.

A good example of this method was seen in the relationship between the signatures of COST (Figure 3) and RGAIN (Figure 9), the signature for RIT (Figure 12), and the observed phenomena of remedial and special 
education. It is a general practice of most school systems that the proportionately largest amounts of school system funds are spent on the education of those students with the greatest (most expensive) educational needs. This greater educational need is often demonstrated by poor performance on academic achievement measures. Thus, students who were performing less well on such indicators as the district's reading, math or language usage tests were often the same students on whom a larger proportion of funds were being spent for remediation, tutorial help, special education, etc. The fact that in this research the expenditure of funds was very disproportionate across ethnic categories (a "W" signature for COST), and that the test score gains were very evenly distributed across ethnic categories (a nearly straight line signature for RGAIN, MGAIN and LGAIN) helped to account for the educational gains attributed to remedial and special programs.

The signature for RIT showed that the RIT scores for students in Ethnic Groups 2 and 4 were relatively high, for Groups 1, 3, and 5 relatively low. The signature for COST showed that the expenditure per child was highest for Ethnic Groups 1, 3, and 5 - those groups whose RIT scores were the lowest. That is, funds were being spent most where need was most indicated. The straight line signature for RGAIN showed that Group 1, 3, and 5 students were making gains in their RIT scores equal to the gains made by the (higher scoring) Group 2 and Group 4 students. In this respect, it appeared that the increased funding for Ethnic Group 1, 3, and 5 students may have contributed in a causative way to the equality of the Reading RIT gains made by these students as compared to Group 2 and 4 students. 
A second example of the ability of the findings to account for observed phenomena was found in the relationship of the SUSP variable (Figure 15) to $M \%$ (Figure 6) and FTE (Figure 4). This school district, like many urban school districts, had a history of higher suspension rates among minority students than among nonminority students. This could be seen by the identical signatures of SUSP and $M \%$ in the variable graphs in Chapter III. In order to provide additional assistance to students who might potentially be suspended, counseling FTE was added to specific schools where $M \%$ was high. This contributed to higher FTE at schools with higher minority percentages. The similarities of the M\%, SUSP, and FTE signatures confirmed and further illustrated this phenomenon.

Finally, the strongest validation of the statistically derived model was its strong congruence with the subjective model derived from an analysis of the literature. This method of validation is somewhat unique to this Dissertation and adcis considerably to the methodology for validating computer models in the present application area.

\section{Suggestions for Further Research}

The research thus far has consisted of the identification of key EEO variables, the hypothesis of four subjective models of EEO based upon educational research and legal precedent, and an analysis of the data of one school district's ninth grade class to see how well the proposed subjective models represent the relationships found in the data. The analysis techniques employed have been: (I) correlation 
analysis, (2) sub-group correlation analysis, (3) graphic analysis, and (4) phenomena explanation.

Perhaps the most important method for further validation of these results, and for obtaining further results, is further research. It must be remembered that the findings of this analysis are based upon only the ninth grade students in one school district and on a limited set of variables for those students.

Four main avenues of future research are indicated from this beginning: (1) further multi-variate analyses of the original data, (2) research with other grade levels of students, (3) research with other school districts, and (4) research with other EEO variables. The methodology set forth in this analysis should be useful in each of these avenues of future research. Not only that, the methods used here, along with the derived model of EEO, are the essential ingredients for a useful Decision Support Systen. The implementation and refinement of the DSS will lead to a much more precise and comprehensive EEO model. Similarly, the improved model will augment the usefulness of the Decision Support System.

This preliminary analysis has, nonetheless, provided sufficient results for the general validation of the Achievement Aspects Subjective Model and for the quantification of the relationship between key variables in a computer simulation model for a Decision Support System. The next chapter describes this computer simulation model, here named an EEO Accountability Model, and its primary output, an EEO Accountability Index. 


\title{
CHAPTER VI
}

\author{
PROUULT OF THIS RESEARCH: AN EEO ACCOUNTABILITY INDEX
}

Chapter II reviewed the general concepts of information systems and their applications, and the design and use of specific Decision Support Systems was introduced. In Chapter III, a specific information system was created and used to gather and analyze data for this Dissertation. In Chapter IV, subjective models of EEO were developed. In Chapter V, a preliminary computer simulation model was developed, as per the steps identified by Clemson and expanded as required by this particular application. But the question remains, how can school district information be made useful to that school system for decision support in the area of EEO? In this chapter, the usefulness of the proposed Decision Support System is explained.

Need for an EEO Accountability Model

Standard evaluation techniques, particularly those evaluation techniques developed during the "effective schools movement," tend to relate effectiveness aspects to tangible and intangible aspects. However, these techniques often do not provide sufficient analysis to aia decisions concerning allocations of tangible and intangible resources to more than one budgetary or educational area at a time. For instance, standard evaluation techniques may show that a particular program at a specific cost is very effective at decreasing high school oropout rates, and that another program at some other cost is particularly successful at teaching mathematics. But standard 
techniques do not assist in determining whether the dropout program or the mathematics program is more effective (or necessary) for bringing about the overall school system goals (of EED).

Similarly, standard desegregation monitoring techniques, such as calculation of a "desegregation index" (see Pugh and Krasnakevich, 1971), assist in evaluating the school system's effectiveness in desegregation, but not in relating this effectiveness to the school system's overall effectiveness at educational equity.

Clearly, there is a need for some method to assist in determining the overall equity and effectiveness of the school system.

One version of the goal of the "accountability movement" implicit in the EEO Achievement Aspects Subjective Model (Chapter IV) would be an equal attainment of achievement measures by the various ethnic groups. (That is, scores on achievement measures would be approximately equal for all ethnic categories.) Given this goal, a simple measure of the composite variance from the norm for achievement measures by the various ethnic groups could be used as a measure of school system effectiveness in EEO. However, this simple measure has at least three distinct drawbacks:

1. Not everyone agrees on the above specific goal as the general goal of the "accountability movement." Some people, for example, place a larger emphasis on the relationship between ability measures and achievement measures, as opposed to looking solely at the achievement measures. 
2. This simple measure of composite variance would not distinguish between school systems with uniformly low achievement measures and systems with uniformly high achievement measures.

3. This simple measure of composite variance would not account for the variety of inputs into various school systems.

Clearly, this simple measure of composite variance would not meet the described need. What has a better chance of meeting the need would be a model of how a school syste: a lould work. Given such a model, the actual and projected functionings of a school system could be compared to the model. A suggested EEO Acountability MOdel, as derived from this research and described in the next section, providies such a candidate model.

Suggested EEO Accountability Model

In Chapter IV, subjective models of EEO were developed. The Achievement Aspects Subjective Model was shown to differ from others due to the inclusion of "feedback loops" which would bring about system accountability for student achievement. In Chapter $v$, a preliminary statistical model confirmed and quantified these feedback relationships based on the empirical data for a group of students in a given school district. It should be emphasized that the grouping of the variables and the negative feedback relationships were primarily established by the analysis of the aata, while the positive impact relationships were 
primarily established by the review of the literature. The following aiagram illustrates these "feeaback" relation- ships which were thus confirmed. Since these relationships describe the "accountability" of the system for producing equitable student achievement (as described in Chapter IV), this model is categorized as a suggested EEO Accountability Model. Again, it is the particular quality of having an odd number of negative impact relationships in the feedback loops which causes these loops to act as regulators which bring about

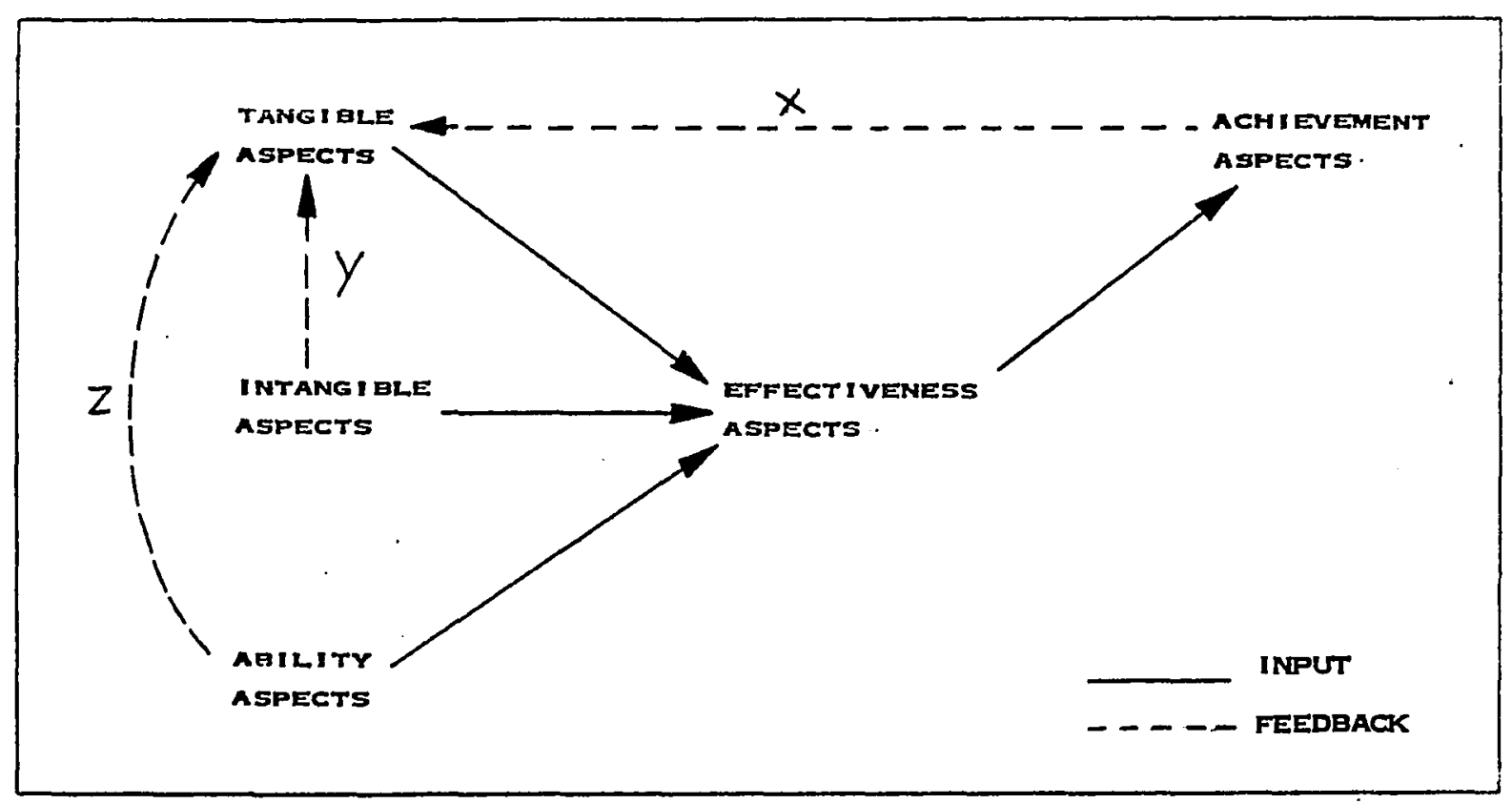

Figure 23: Suggested EEO Accountability Model

In this diagram the values of the feedback relationships (used here to mean negative impact relationships within a loop) are labeled with the letters $\underline{x}, \underline{y}$, and $\underline{z}$. In Chapter $v$, these values were defined 
as average Pearson correlation coefficients between variables in the different classifications of EEO aspects. For the data examined in this study, the value of $\underline{x}$ was approximately $-.1 ; \underline{y}$, approximately -.2 ; and $\underline{z}$, approximately -.2. However, Pearson correlation is not the only measure of variable relationship which can be used in such a model. For whatever set of data is selected within a given DSS, a correlation analysis, a regression analysis, or a factor analysis can be run which will more exactly determine these values for the particular application. Indeed, calculation of the values of such relationships as can be determined by the equations derived from factor analysis and other multi-variate statistics is one of the more useful "spin-offs" of the development of such a Decision Support System. Once the data gathering and analysis components of the DSS are in place, any number of such analyses can be run on the various sub-sets of data available. These types of analyses can tell the researcher a great deal about the particular data under study, and in many cases these particular conclusions can be generalized to larger bodies of data. For the particular school district involved in this research effort, this seconcary application of multi-variate statistical analysis has already begun to prove a useful application of the developing Decision Support System. However, results of such analysis (on such specific data) have been specific to the particular students and school district examined, and therefore are not reported in this dissertation, which attempts to deal with concepts and conclusions of a more general nature.

As stated above, Figure 23 represents a model of the accountability for EEO of a school system, where accountability is 
aefined as the functioning of the system to regulate (and thus equalize) the various measures of EEO aspects. This model can be characterized by a single measure, termed an EEO Accountability Index, explained in the next section.

Suggested EEO Accountability Index

In order to calculate the suggested EEO Accountability Index, the values of the coefficients $\underline{x}, \underline{y}$, and $\underline{z}$ have first to be "normalized" (1) to avoid a zero factor (since correlation coefficients run from -l to +1 ) and (2) to account for the sign of the coefficient. Normalized coefficients are thus defined as follows:

$$
\begin{aligned}
& x^{\prime}=-x+1 \\
& y^{\prime}=-y+1 \\
& z^{\prime}=-z+1
\end{aligned}
$$

Values of $\underline{x}^{\prime}, y^{\prime}$, and $\underline{z^{\prime}}$ defined in this way will range from .01 to 1.99 for any set of data from a given school system. The stronger the feeaback relationship, the higher will be the value of the coefficient calculated for that relationship. A combined value for the three feedback circuits can be calculated by summing some factor of each of the three normalized feedback coefficients. This summation defines the suggested EEO Accountability Index, as follows:

EEO Accountability Index $=a x^{\prime}+b y^{\prime}+c z^{\prime}$

where $\underline{a}, \underline{b}$, and $\underline{c}$ are weighting factors and $\underline{x}^{\prime}, \underline{y}^{\prime}$, and $\underline{z^{\prime}}$ are normalized average values of the feedback coefficients. 
This suggested EEO Accountability Index is a measure of the degree to which the school system is functioning as per the accountability model. The weighting factors $\underline{a}, \underline{b}$, and $\underline{c}$ allow the decision maker to determine, before calculation of the index, the relative value of each feeaback variable. Thus, if the decision maker felt that it was very important that tangiole resources be allocated to students with low ability factors, weight $\subseteq$ (weighting variable $\underline{z^{\prime}}$, the normalized coefficient between Tangible Aspects and Ability Aspects) might be high. If the decision maker felt that the relationship between Achievement Aspects and Tangible Aspects was more important, weighting factor a (which weights variable $\underline{x}^{\prime}$, the normalized coefficient between Achievement Aspects and Tangible Aspects) could be increased. The assj.gnment of weights $\underline{a}$, $\underline{b}$, and $\underline{c}$ reflects the value system of the decision maker. These values need to be set before calculation of the suggested EEO Accountability Index and need to remain fixed throughout the calculation. This ability to set the values into the Decision Support System makes such a system extremely versatile. In school systems, where different members of the Board of Education or different administrators or different members of the public have different values and different value assumptions, such values can be identified and incorporated into the Decision Support System calculations. This makes the output of the DSS (values of the suggested EEO Accountability Index) much more likely to be used by the decision maker. 
Use of the Suggested EEO Accountability Index

In the discussion of need for an EEO model, it was brought out that there was a need for a method which could determine the overall equity and effectiveness of a school system. Some examples may illustrate how the use of the suggested EEO Accountability Index can provide such a method.

The simplest example would be the use of the suggested EEO Accountability Index in the choice between two alternatives. Let us return to the example of the choice between implementing an effective "ciropout" program or an effective mathematics program, as put forth in the first section of this chapter. For each of those two alternatives, the computerized decision support system could make the appropriate changes in the tangible (ana intangible) aspect variables of the students to be affected, correlation coefficients and normalized coefficients could be calculated, and weighting factors to reflect values of the decision makers could be assigned. Then an EEO accountability index could be calculated and reported. Thus, there would be an accountability index, measuring the overall system EEO accountability and reflecting the values of the decision maker, for each alternative considered. The alternative with the higher EEO Accountability Index would best meet the overall EEO goals of the school system, within the context of the given value system.

It is most useful to find a single index to accomplish such a feat. And yet, the choice between two alternatives is perhaps the least impressive potential use of the suggested EEO Accountability Index. One can imagine a school district contemplating perhaps dozens 
of buagets, each reflecting different overall plans for the delivery of services to students, each with different priorities and approaches. For each contemplated budget, a systemwide accountability index could be calculated. School district planning/budgeting functions could thus become more comprehensive, drawn together by the unifying goal of EEO accountability.

Within the school district which supported the research reported here, just such an application of the suggested EEO accountability index is being considered. The district has been examining a number of proposals as to how staff should be allocated to individual schools. Some proposals call for increasing teacher support personnel, thereby Ieoucing the burden on teachers to accomplish many different tasks. Other proposals call for allocation of more teachers (and therefore fewer support personnel, since total numbers of staff is limited by budget restrictions), thus reducing class size and the burden on teachers to handle more students. A number of proposals have varying degrees of teaching and support staff allocations. It is possible to calculate thie allocation to each school under each proposal. With the application of the developing DSS and the suggested EEO accountability index, it will soon be possible to calculate an EEO accountability index for each proposal. Values of the School Board, of the administration, of teachers, or of any other group, could be incorporated into the calculation of the indices by adjustments to the weighting factors. Thus, EEO accountability indices can be calculated for each proposal for each identified value system. These indices could then be used to support a decision on how to allocate staff 
within the district.

Decision support based upon the EEO Accountability Index need not be restricted to individual school aistrict use. State and federal agencies, such as the Office of Civil Rights, could use such an index to monitor and compare school system progress in EEO accountability in determining their own actions.

The potential usefulness of such an index, one based on a fully developed EEO accountability model and computerized decision support system, seems extremely valuable at this time. 
CHAPTER VII

SUMMARY AND CONCLUSIONS

Summary

One of the major goals of public education has been the provision of an equal educational opportunity (EEO) for all students. This goal has been strongly reaffirmed by legislation and by the courts.

In order to pursue this goal, school systems have needed adequate means of determining the equity of the educational opportunities offered their students. Two main stumbling blocks have stood in the way of school systems in determining this equity: (1) the insufficiency of readily available information for such a determination, and (2) differences in philosophies and understandings of the concept.s of equal educational opportunity.

It has been here suggested that a computerized decision support system (DSS), based on a model incorporating key variables associated with EEO, and with the capacity for producing a measure of the system's accountability for EEO, could help to meet school systems' information requirements. The process itself of developing the model(s) used within such a DSS could also prove beneficial, by clarifying and perhaps either confirming or denying some of the assumptions underlying philosophical differences concerning EEO concepts.

Although there are many "software packages" available which provide computer support for decision making, there are, to date, no packages for specific Decision Support Systems aimed at meeting the needs of school districts for support in the area of EEO. The field of 
EEO has proved to be too complex, and school district needs too ill-defined, for such a product to have been developed commercially at this time. Therefore, in order to obtain such computer support, a school district would have to develop such a system on its own. The efforts described in this Dissertation were undertaken to accomplish this desirable but heretofore unattained objective of developing such a system.

A review of the literature concerning the development of computerized Decision Support Systems led to the following outline for DSS development, attributed to Clemson (1978):

1. identification of key variables;

2. subjective model building;

3. computer simulation of models; and

4. continuous management involvement.

In order to insure "continuous management involvement," a task-group of key administrators of the school district was organized. With the cooperation and support of the superintendent, a key group of assistant superintendents and department directors directly concerned with EEO policy and practice was assembled for this task-group. This task-group assisted in defining the need for such a DSS, and outlining the research required to complete the steps identified by Clemson for the design of the DSS. The author has carried out this research as discussed in this Dissertation, all the while remaining in contact with this group of school district administrators who have direct interest and involvement with school district policy and practice in EEO. 
The first step in this research undertaken by the author was the identification of key EEO variables.

A synthesis of the EEO literature reviewed yielded five major potential categories of EEO variables; those dealing with:

1. Tangible aspects - including school system resources;

2. Intangible aspects - dealing with the gestalt of the educational environment;

3. Effectiveness aspects - which were generally measures of student progress;

4. Achievement aspects - which tended to apply student achievement measures as prima facie evidence of EEO; and

5. Ability aspects - which refer to the student's potential for achievement in school and elsewhere.

A preliminary computerized information system was designed and implemented to gather, store, and analyze a set of thirteen defined EEO variables for a given school district which were chosen to provide an easily obtainable value in each of the above five categories. The values of the thirteen variables were collected for all ninth grade students during the 1980-81 school year, in addition to student identification variables such as ethnic category and sex. The EEO variables thus defined were: 
Tangible Aspects

1. Cost per Student per School (COST)

2. Full Time Equivalency per Student per School (FTE)

3. Non-FTE Cost per Student per School (NCOST)

Intangible Aspects

1. Minority Percentage per School (M\%)

2. Minority Faculty Percentage per School (MF\%)

3. Voter Support (VOTE)

Effectiveness Aspects

1. Reading RIT Gain (RGAIN)

2. Math RIT Gain (MGAIN)

3. Language Usage RIT Gain (LGAIN)

Achievement Aspects

1. Reading RIT Score (RIT)

2. Grade Point Average (GPA)

3. Attendance (ATT)

4. Suspensions (SUSP)

Reading RIT Score (RIT) was also used as a proxy for an Ability Aspect variable.

The next step taken by the author in the development of the DSS was to develop subjective models. Four hypothetical subjective models were derived which reflected the assumptions and values incorporated in the four main concepts of EEO discovered in the literature. A subjective model labeled the EEO Achievement Aspects Subjective Model seemed to correspond most closely with current policy and theory 
towards EEO. A hypothesis was set up to test whether this was indeed the case.

A correlation analysis was performed on the data for a group of nearly 4,000 ninth grade students, and for subgroups of these students as identified by ethnic and sex variables. The findings of the correlational analysis confirmed many of the hypothesized relationships. A separate technique, that of signature analysis, was employed to confirm the findings of the correlation analysis, and the correlation analysis findings were confirmed. Also, it was demonstrated that some of the relationships found by these analyses helped to explain certain educational system phenomena, such as the disproportionate expenditure of school system funds on students with higher demonstrated need in order to increase educational gains.

Specifically, the groupings of the variables, and the negative feedback loops of the model, were confirmed by the preliminary analysis of the data. The positive impacts of groups of variables on one another, hypothesized in the models from evidence in the literature, were not confirmed by the preliminary analysis of the data, presumedly because of the regulating effect of the feedback loops. These Ielationships remain to be more precisely defined in the model by further research.

The relationships determined by this research were iliustrated in Figure 22, repeated here: 


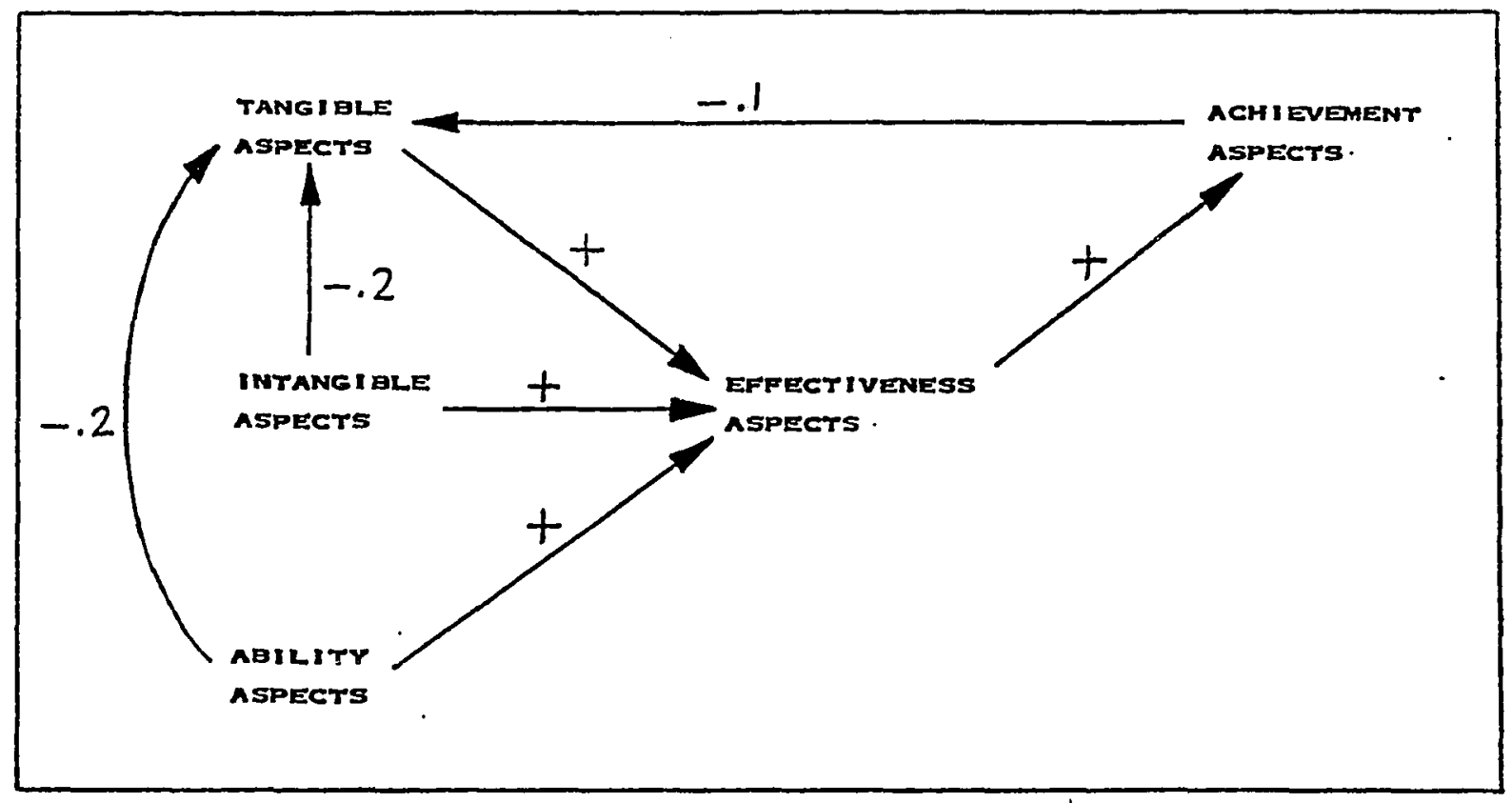

Figure 22: Preliminary Statistical Model of EEO Accountability

This schematic diagram could be used as a first-order approximation of a model of EEO accountability for a computerized decision support system, where the word accountability refers to the functioning of the system to regulate the values of the measures of each of these aspects of EEO. Further research was suggested to validate these findings and to refine and improve the suggested model.

The relationships illustrated in Figure 22 were expressed in the following generalizations about the student data examined:

1. Students who attended class regularly had a tendency to achieve higher grade point averages than students who did not. 
2. Students with higher reading scores had a slight tendency to attend class more regularly and to achieve higher grade point averages than students with lower reading scores.

3. Students with lower reading scores had a slight tendency to attend schools with higher costs per student, higher FTE per student, and higher nonsalary costs per student. That is, the system spent more on students with lower reading scores.

4. Students at schools with higher minority percentages of students had slightly lower reading scores and received slightly more resources than students at schools with lower minority percentages.

5. Voter support was slightly higher in areas of schools with lower costs and minority percentages than for areas of schools with higher costs and minority percentages.

6. Gains in reading, mathematics and language-usage test scores did not directly correlate to the other variables in this study.

These findings from the correlation analysis were compared with the proposed subjective models of the philosophies of the four major concepts of EEO. Some of the major observations from this comparison were as follows: 
1. In the statistical analysis, there was a direct relationship between the tangible aspects and the intangible aspects. This was true of the EEO Achievement Aspects Subjective Model, but of none of the other subjective models, and is indicative of a system of accountability for allocation of resources, which would have such a feedback relationship.

2. In the statistical analysis, there was a direct relationship between RIT, an ability and/or achievement factor, and the Intangible Aspects variables. Again, the only subjective model which displayed this characteristic was the EEO Achievement Aspects Subjective Model.

3. In the statistical analysis, there was no direct relationship between the Intangible Aspects and the Effectiveness Aspects. Again, this resembled the EEO Achievement Aspects Subjective Model more than any of the other subjective models, since the feedback loops of this model would tend to minimize such a correlation.

4. The relationship between Ability Aspects and Effectiveness Aspects which was seen in the EEO Effectiveness Aspects Subjective Model was not found in the statistical model. Again, the feedback loops of the EEO Achievement Aspects Subjective Model would tend to diminish such a correlation. 
5. In the statistical analysis, there was no direct relationship between the Tangible Aspects and the Effectiveness Aspects. This resembled the expected outcome from the EEO Achievement Aspects Subjective Model and the EEO Effectiveness Aspects Subjective Model more than the other two subjective models, since their feedback loops would both tend to minimize such a correlation.

In all of the above five observations, the statistical analysis seemed to support the EEO Achievement Aspects Subjective Model (Figure 20) more than any of the other subjective models. This confirmed and validated the hypothesis of Chapter IV and strengthened the credibility of the statistical findings.

Finally, the third step in the DSS development process, "computer simulation of models," was undertaken by the author. This led to the development of a suggested "EEO Accountability Index," a DSS output measure purported to measure the degree to which the school system was accountable for EEO given the set of data examined and the values assigned to different aspects of EEO. It is envisioned that such an index could be extremely useful to school systems and other educational agents, and some such uses of the index are suggested.

\section{Conclusions}

This research has led to the identification of some key EEO variables and to some preliminary understandings of the relationships of these variables. Based on these relationships, a tentative model of 
EEO accountability in a public school system has been put forth.

One goal of defining such a model was its incorporation into the design of a computerized Decision Support System. Such a computerized system could be of great assistance to school districts in meeting the demands of attempting to provide equality of educational opportunity. Given a particular set of assumptions or definitions, such a system could help in evaluating existing practices and proposed decisions.

A second goal of defining such a model was to gain a better understanding of what has come to be called the "educational system." Thomas Green (1980) has given a general overview of the educational enterprise as a system in Predicting the Behavior of the Educational System. An endeavor of this Dissertation has been to describe in more detail one aspect of that system. It is important to note that this is only an emerging approach to understanding the educational enterprise. Almost all previous studies of education either have been of the case-study genre or have been statistical analyses of particular aspects (generally input or output variables) of the educational system. The emergence of studies of the educational enterprise as a system can help resolve the differences of people's conceptions of equity and of EEO, which depend so heavily on one's definitions and assumptions. A system's perspective allows the inquirer to evaluate the system somewhat more independently from a priori assumptions than does a more traditional statistical analysis $\pi$ pijicy anaiysis approach. One can still ask the question "How well does this educational system meet this particular EEO concern?" from a particular perspective, but one can also begin to ask the more general 
question "How well is this educational system meeting all of the various concerns (or definitions) of EED?" The development of an EEO Decision Support System, based on a model of EEO accountability, is seen as a step in this direction.

Thus, there were two important functions which could be accomplished by the design and implementation of this computerized decision support system. They were:

1. The DSS could provide analyses based upon a statistically derived model of reality which, in some cases, could be more accurate than the decision maker's heuristically derived subjective model, and in some cases could be less accurate. In either case, differences between conclusions based upon the statistically derived model and those based upon the subjective model could be important decision support to the decision maker.

2. The process of determining (building) the statistically derived model could add new insights to one's understanding which may alter one's mentally held subjective model. In this way, one's subjective model could come to better reflect reality.

The research reported here was meant to serve both of the above functions. Accordingly, the audience for this Dissertation might be (1) information specialists responsible for the design of Decision 
Support Systems, (2) school district board members, superintendents, and decision makers, and (3) other academicians interested in developing a better understanding of the concepts of EEO and the implications of those concepts for educational decision making.

\section{Afterword}

The stated purpose of this research was to lay the groundwork for building a computerized model of Equal Educational Opportunity to be used in a Decision Support System. The extent to which that was accomplished remains to be seen, as the DSS is more fully developed and used by this and perhaps other school systems.

The specific hypothesis tested by this research was that the thirteen key variables identified in this study would be related to each other in such a way as to form the basis for a computer model of EEO accountability. The relationships discovered were sufficient to form the basis of a first-approximation model, a model adequate for preliminary use in a decision support system. Development of the concept of an EEO Accountability Index further added to the potential usefulness of this approach.

Other than the general success of the research in this regard, there were a number of specific accomplishments made by this research.

1. When the recommended procedure for determining information system specification - (interviewing potential users and experts) - proved inadequate, a second method - (extensive, purposeful literature research) was successfully substituted. This method is 
potentially very useful to systems designers dealing with unstructured tasks in a number of fields both inside and outside of public education. This Dissertation is thus a case illustration of an alternative systems design technique.

2. The four hypothesized "subjective models," and the first-approximation derived model, can be very useful as tools for understanding and studying the key concepts associated with Equal Educational Opportunity. The use of "schematic representations of subjective models," and the comparison of these representations to schematic representations of derived models, is a second innovative method which could find usage both inside and outside of this particular application area.

In this research, a particular subjective model derived from the literature was hypothesized to embody the key school system relationships which represented a realistic representation of EEO accountability. Statistical relationships were then analyzed between identified variables in order to construct a computer model of reality. The "reality check" between the hypothesized subjective model and the mathematically derived model served as a first-order validation criterion. This is similarly a promising method to be used in the design of computerized decision support systems. 
3. Similarly, the use of graphic analysis techniques (associated with pattern recognition) in a social science application of validating results obtained from correlational analysis is a method introduced in this Dissertation which could have a wide range of applications.

4. The computer programs written for this Dissertaton have been useful to the involved school district in monitoring, reporting, and evaluating student data. A preliminary information system, the precursor of a Decision Support System, has been established.

5. Specific findings of this research, as reported in Chapter V and Chapter VI, have been of particular interest to educators in the involved school district.

6. This research has laid the groundwork for building a computerized model of Equal Educational Opportunity accountability to be used in a Decision Support System. This research may ultimately prove useful to school districts and to all educators in their efforts to ensure an equal opportunity to every child for a quality educational experience.

In addition to the above specific accomplishments of this study, there is the general accomplishment which is common to every study, and that is the contribution made to the researcher's own education and 
understanding. For the support, challenge, guidance, and instruction provided by the Dissertation Committee and by Portland State University, the researcher is eternally grateful. 


\section{REFERENCES}

Alter, Steven L., 1976. "How Effective Managers Use Information Systems," Harvard Business Review, Nov.-Dec.

Alter, Steven L., 1980. Decision Support Systems: Current Practice and Continuing Challenges, Reading, Mass.: Addison-Wesley.

Arnovick, George N., 1978. "Design and Evaluation of Information Systems," Information Processing and Management, Vol. 14.

Averch, H. A., ed., 1972. How Effective Is Schooling? A Critical Review and Synthesis of Research Findings, Santa Monica, California: The Rand Corporation.

Axelrod, Joel, 1970. "14 Rules for Building an MIS," Journal of Advertising Research, June.

Bearly, William, 1980. "Squeezing More from D. P.," Datamation, January.

Bertalanffy, Ludwig von, 1968. General System Theory, New York: George Braziller, Inc.

Beshers, James M., 1972. "Models of the Educational Process: A Sociologist's Perspective," in Mosteller, Frederick and Moynihan, Daniel P., On Equality of Educational Opportunity, New York: Random House.

Bess, James L., 1979. "Classroom and Management Decisions Using Student Data: Designing an Information System," Journal of Higher Education, May-June.

Birley, Derek, and Anne Dufton, 1971. An Equal Chance, London: Routledge and $\mathrm{K}$. Paul.

Boyan, Norman J., 1981. "Follow the Leader: Commentary on Research in Educational Administration," Educational Researcher, February.

Braddock, Jomills Henry, 1980. The Perpetuation of Segregation Across Levels of Education: A Behavioral Assessment of the Contact Hypothesis, Baltimore, Maryland: Center for Social Organization of Schools, John' Hopkins University.

Bridge, Jane, 1977. Beginning Model Theory, London: Oxford University Press.

Brown, F., and J. Dixon, 1976. "Characteristics of Outstanding Programs," The Journal of Negro Education, June. 
Brown, Jerry W., 1979. "Enrollment Decline and Institutional Size: Using Management Information to Ask the Right Questions," Cause/Effect, September.

Bullard, Pamela, and Judith Stoia, 1980. The Hardest Lesson: Personal Stories of a School Desegregation Crisis, New York: Little.

Burbules, Nicholas C., and Brian T. Lord and Ann L. Sherman, 1982. "Equity, Equal Opportunity, and Education," Educational Evaluation and Policy Analysis, Vol. 4, No. 2, Summer.

Campbell, D. T. and Stanley, J. C., 1963. Experimental and Quasi-Experimental Designs for Research, Chicago: Rand McNally College Publishing.

City Club of Portland, 1980. Racial Integration-Desegregation Issues in the Portland Public Schools, Portland, Oregon.

Clark, Kenneth B., 1972. A Possible Reality: A Design for the Attainment of High Academic Achievement for Inner-City Students, New York: Emerson Hall.

Claycamp, Henry J. and Lucien E. Liddy, 1969. "Prediction of New Product Performance: An Analytical Approach," Journal of Marketing Research, Vol. VI, November.

Clemson, Barry, 1977. "Information Systems as Adaptive Processes," Proceedings of Advanced Information Systems Development Technology Symposium, College Park, Md.: University of Maryland Press.

Clemson, Barry, 1978. "Beyond Management Information Systems," Educational Administration Quarterly, Fall.

Coleman, James, ed., 1966. Equality of Educational Opportunity, Washington, D.C.: U. S. Government Printing Office.

Coleman, James, 1967. "The Concept of Equality of Educational Opportunity," Harvard Educational Review, May-June.

Davisson, William and John Uhram, 1977. A Primer for Ndtran, South Bend, Indiana: University of Notre Dame.

Dyer, Henry S., 1972. "The Measurement of Educational Opportunity," in Mosteller, Frederick and Moynihan, Daniel P., On Equality of Educational Opportunity, New York: Random House.

Ein-Dor, Phillip, 1978. "Strategic Planning for Management Information Systems," Management Science, November. 
Elias, Maurice J., et al., 1979. "The Use of Computerized Management Information in Evaluation," Administration in Mental Health, winter.

Forrester, J. W., 1968. System Simulation Workbooks, Boston, Mass.: MIT Press.

Fukunaga, Keinosuke, and D. R. Olsen, 1971. "A Two-Dimensional Display for the Classification of Multivariate Data," IEEE Transactions on Computers, Vol. C-20, No. 8, August.

Gordon, E. W. and J. Koutrebakos, 1971. Utilizing Available Information from Compensatory Education and Surveys, June.

Gordion, Edmund W., 1972. "Toward Defining Equality of Educational Opportunity," in Mosteller, Frederick, and Moynihan, Daniel P., On Equality of Educational Opportunity, New York: Random House.

Graybill, Franklin A., 1976. Theory and Application of the Linear Model, North Scitutate, Massachusetts: Duxbury Press, Colorado State University.

Green, T. J., 1980. Predicting the Behavior of the Educational System, New York: Syracuse University Press.

Hall, Arthur U., 1969. "Three-Dimensional Morphology of Systems Engineering," IEEE Transactions of Systems Science and Cybernetics, vol. SSC-5, No. 2, April.

Hathaway, Walter E., 1980. "Toward a Revised and Renewed City-Wide Annual School Studies and Profile Program," Portland, Oregon: Portland Public Schools, July. (unpublished)

Hayman, J. F., Jr., 1974. "Educational Management Information Systems for the Seventies," Educational Administration Quarterly, Winter.

Heflin, John F., 1975. "Preliminary Thoughts About Oregon Department of Education Activities with Implications for the Education of Black Youth," Corvallis, Oregon: Cal-Max Symposium of the Status of Blacks in Oregon.

Heflin, John F., 1976. Equal Educational Opportunity Resource Handbook, Salem, Oregon: Oregon Department of Education.

Heflin, John F., 1979. "Perspectives on Educational Policy Research (An AERA Pre-Session Training Workshop)," San Francisco, California: American Educational Research Association.

Heflin, John F., 1981, "Leadership Training for Integrated Education: Final Report (A Staff Development Project to Supplement Portland Public School District Comprehensive Desegregation Plan)," Portland, Oregon: Portland Public Schools. (unpublished) 
Heflin, John, and Marcia Douglas, 1980. "School Desegregation: Portland Style," Boston, Massachusetts: American Educational Research Association, April 10.

Holland, Robert, 1980. "DBMS: Developing User Views, "Datamation," February.

Howe, Harold, 1966. Report on Equality of Educational Opportunity, Washington: U.S. Government Printing Office. Document Catalog No. FS 5.238: 38000

Irvine, D. J., 1976. Studying School Processes Through the Analysis of School District Data, San Francisco: American Educational Research Association, April.

Jencks, Christopher, et al., 1972. Inequality, New York: Basic Books, Inc.

Jones, Charles 0., 1977. An Introduction to the Study of Public Policy, North Scitutate, Massacinusetts: Duxbury Press.

Kamin, Leon, 1974. The Science and Politics of I.Q., New York: Halsted Press.

Kaufman, R., 1972. Educatioral System Planning, Englewood Cliffs, N.J.: Prentice-Hall.

Keen, Peter G. W., 1976. "'Interactive' Computer Systems for Managers: A Modest Proposal," Sloan Management Review, Fall.

Keen, Peter, and Michael Scott Morton, 1978. Decision Support Systems: an Organizational Perspective, Reading, Mass.: Addison-Wesley.

Kentron, Inc., 1979. C.A.R.S. Computer Assisted Reassignment System, Massachusetts: Ketron, Inc.

Kieseling, H. J., 1977. Multivariate Analysis of Schools and Eaucational Policy, Santa Monica, California: The Rand Corporation.

Kirp, David L., and Mark G. Yudof, 1974. Educational Policy and the Law, Berkeley, California: McCutchan Publishing Corporation.

Kunn, Thomas, 1962. The Structure of Scientific Revolutions, Chicago: University of Chicago Press.

Lave, Charles, and March, James G., 1975. An Introduction to Models in the Social Sciences, New York: Harper \& Row.

Lendaris, G. G., and G. L. Stanley, 1970. "Diffraction Pattern Sampling for Pattern Recognition," Proceedings of the IEEE, Vol. 58, February. 
Levin, Henry M., 1972. "A Conceptual Framework for Accountability in Education," An Uccasional Paper in the Economics and Politics of Education, Stanford, California: Stanford University Press.

Madaus, George, 1978. "Testing and Funding: Measurement and Policy Issues," in Schrader, William B., ed., Measurement and Educational Policy, San Francisco: Jossey-Bass, Inc.

Madaus, George, 1980. Schooling Effectiveness: A Reassessment of the Evidence, New York: McGraw.

Maher, Charles A., 1979. "Special Education Management Information Systems: Nature, Scope, and Guidelines for System Design," Journal of the International Association of Pupil Personnel Workers, June.

Martin, James, 1976. Principles of Data-Base Management, Englewood Cliffs, N. J.: Prentice-Hall.

McFatler, William, 1982. "A Superintendent's Perspective on Management Information Sustems, " Proceedings, Association for Educational Data Systems, Washington, D.C.: Library of Congress ISSN 0147-9296.

Mellor, W. L., 1977. "Dynamic Information Systems in an Educational Environment," Educational Administration Quarterly, Spring.

McLaughlin, D. H., 1977. TITLE I, 1965-1975: A Synthesis of the Findings of Federal Studies, Palo Alto, California: American Institute for Research.

McLeod, Raymond, 1979. Management Information Systems, New York: Science Research Associates.

McPherson-Turner, Cherry, and James E. Eisele, 1979. "The Design of a Management Information System (MIS) for a Development Project," Educational Technology, September.

Mosteller, Frederick, and Daniel Moynihan, (eds.), 1972. On Equality of Educational Opportunity, New York: Random House.

Mumford, L., 1967. The Myth of the Machine, New York: Harcourt, Bruce.

Nevo, David, and Daniel Stufflebean, 1976. "The Availability and Importance of Evaluative Information within the School," Studies in Educational Evaluation, 2.

Neuburger, Wayne F., 1980. "A Model for Testing Support of Instructional Decisions Using Computers," Oregon Association for Educational Data Systems, October. (unpublished) 
Nie, Norman H., et al., 1975. Statistical Package for the Social Sciences, New York: McGraw-Hill Co.

Novick, Melvin R., 1982. "Educational Testing: Inferences In Relevant Subpopulations," Educational Researcher, Vol. 11, No. 8, October.

Oregon Department of Education, 1975. Equal Educational Opportunities, A Suggested Policy Guide for School Districts, Salem, Oregon: Oregon Department of Education.

Oregon State Board of Equcation, 1974. Guidelines for the Prevention, Reduction and Elimination of Racial Imbalance in Public Schools, Salem, Oregon. (Oregon State Board of Education Policy Number 4171, March 22, 1974.)

Owen, John D., 1974. School Inequality and the Welfare State, Baltimore, Maryland: Johns' Hopkins University Press.

Penrod, James I., 1978. "Thinking New Systems? Some Action Items," Cause/Effect, September.

Pettigrew, Thomas F., and Green, Robert L., 1976. "School Desgregation in Large Cities: A Critique of the Coleman 'White Flight' Thesis," Harvard Educational Review, February.

Pugh, George E., and John Krasnakevich, 1971. School Desegregation with Minimum Busing, Arlington, Virginia: Lambaa Corporation.

Rawls, John, 1971. A Theory of Justice, Boston: Harvard University Press.

Rist, Ray C., 1978. The Invisible Children: School Integration in American Society, Boston: Harvaro University Press.

Rosenthal, Davio, Putnam, Barbara, and Hansen, James., 1979. "Racially Different Adolescents; Self-Concepts and Vocational Attitudes," Urban Education January.

Rosenthal, Rovert, and Lenore Jacobson, 1968. Pygmalion in the Classroom: Teacher Expectation and Pupils Intellectual Development, New York: Holt, Rinehart and Winston.

Rossi, R. J., ed., 1977. Summaries of Major Title I Evaluations: 1966-1976, Palo Alto, California: American Institutes for Research, July.

Rutter, Michael, ed., 1979. Fifteen Thousand Hours, Boston: Harvard University Press.

Sammon, John W., Jr., 1970. "Interactive Pattern Analysis and Classification," IEEE Transactions on Computers, July. 
Schwab, Herbert, ed., 1964. Race and Equal Educational Opportunity in Portland's Public Schools, Portland: Portland Public Schools.

Smith, Marshall S., 1972. "Equality of Educational Opportunity: The Basic Findings Reconsidered," in Mosteller, Frederick and Moynihan, Daniel P., On Equality of Educational Opportunity, New York: Random House.

Stufflebean, D. L., ed., 1971. Educational Evaluation and Decision-Making, Itasca, Ill.: Peacock.

Summers, A. A., and B. L. Wolfe, 1977. "Do Schools Make a Difference?" American Economic Review, September.

Thomas, Clint, 1978. Racial Isolation and School Desegregation Court Decisions - State Law - State Board of Equcation Policy School District Policy, Portland, Oregon: Portland Public Schools. (unpublished)

U.S. Commission on Civil Rights, 1967. Racial Isolation in the Public Schools, Washington, D.C.: U.S. Government Printing Office.

United States Congress, 1964. Economic Opportunity Act, PL 88-452.

United States Congress, 1977. Handicapped Child Act. PL 94-142.

United States Supreme Court. Supreme Court Reporter, St. Paul, Minn: West Publishing Co.

Plessy vs. Ferguson (163 US 537 [1895])

Gong Lum vs. Rice (275 US 78 [1927])

Sweatt vs. Painter (339 US 629 [1947])

Brown vs. Topeka (349 US 294 [1954 \& 1955])

Green vs. New Kent County (391 US 430 [1968])

Swann vs. Charlotte-Mecklenburg (402 US 1 [1971])

Lau vs. Nichols (414 US 563 [1974])

California vs. Bakke (438 US 265 [1978])

Wiorkowski, Gabrielle, and John Wiorkowski, 1978. "Does a Data Base Management System Pay Off?", Datamation, April.

Wirt, Frederick M., 1980. "Comparing Educational Policies: Theory, Units of Analysis, and Research Strategies," Comparative Equcation Review, June.

Wise, Arthur, 1980. Legislated Learning: The Bureaucratization of the American Classroom, Berkeley, California: University of California Press. 
APPENDIX A

CORRELAT IONAL ANALYSES 


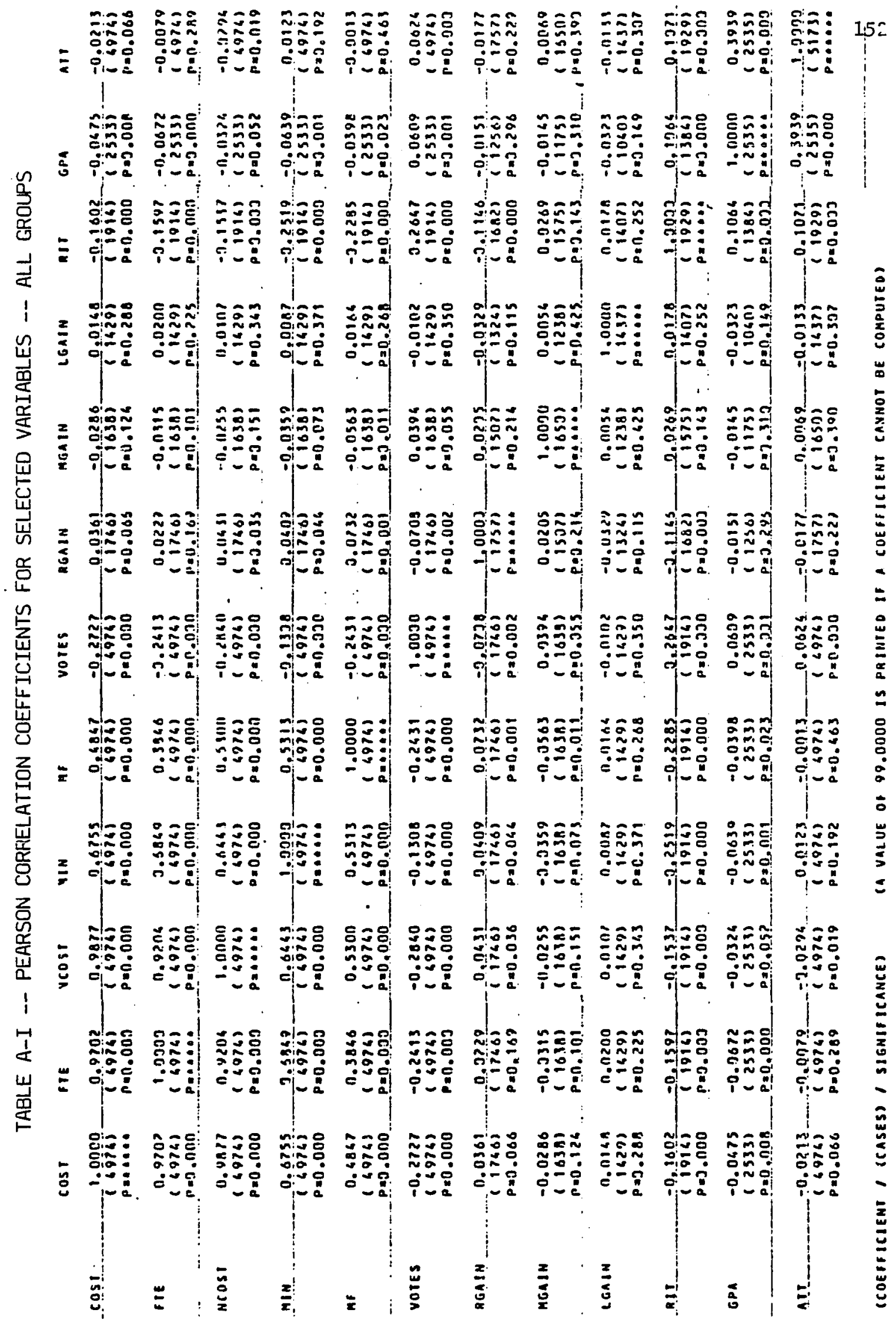


TABLE A-II -- PEARSON CORRELATION COEFFICIENTS FOR SELECTED VARIABLES -- ETHNIC GROUP 1

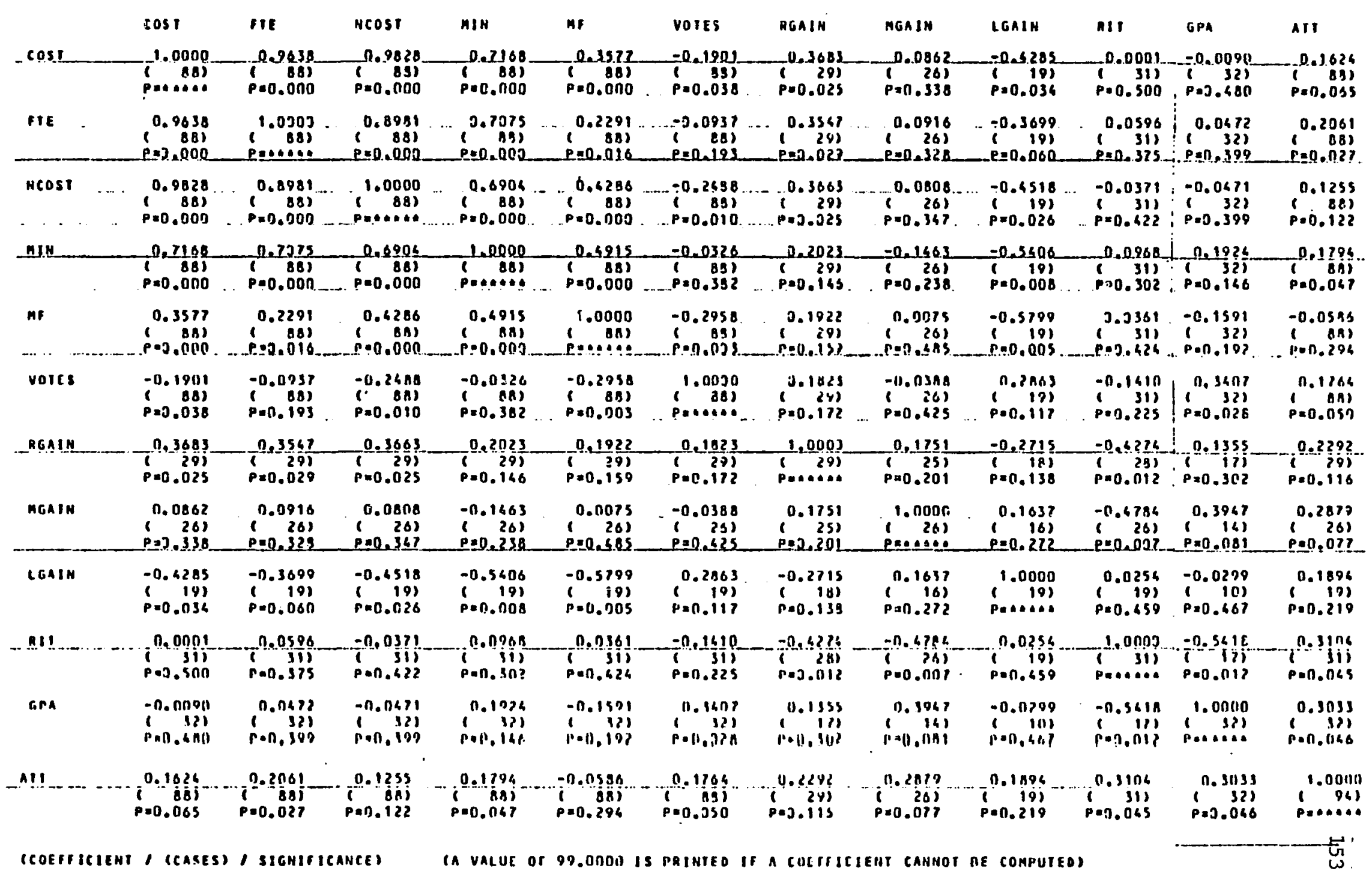


TABLE A-III -- PEARSON CORRELATION COEFFICIENTS FOR SELECTED VARIABLES -- ETHNIC GROUP 2

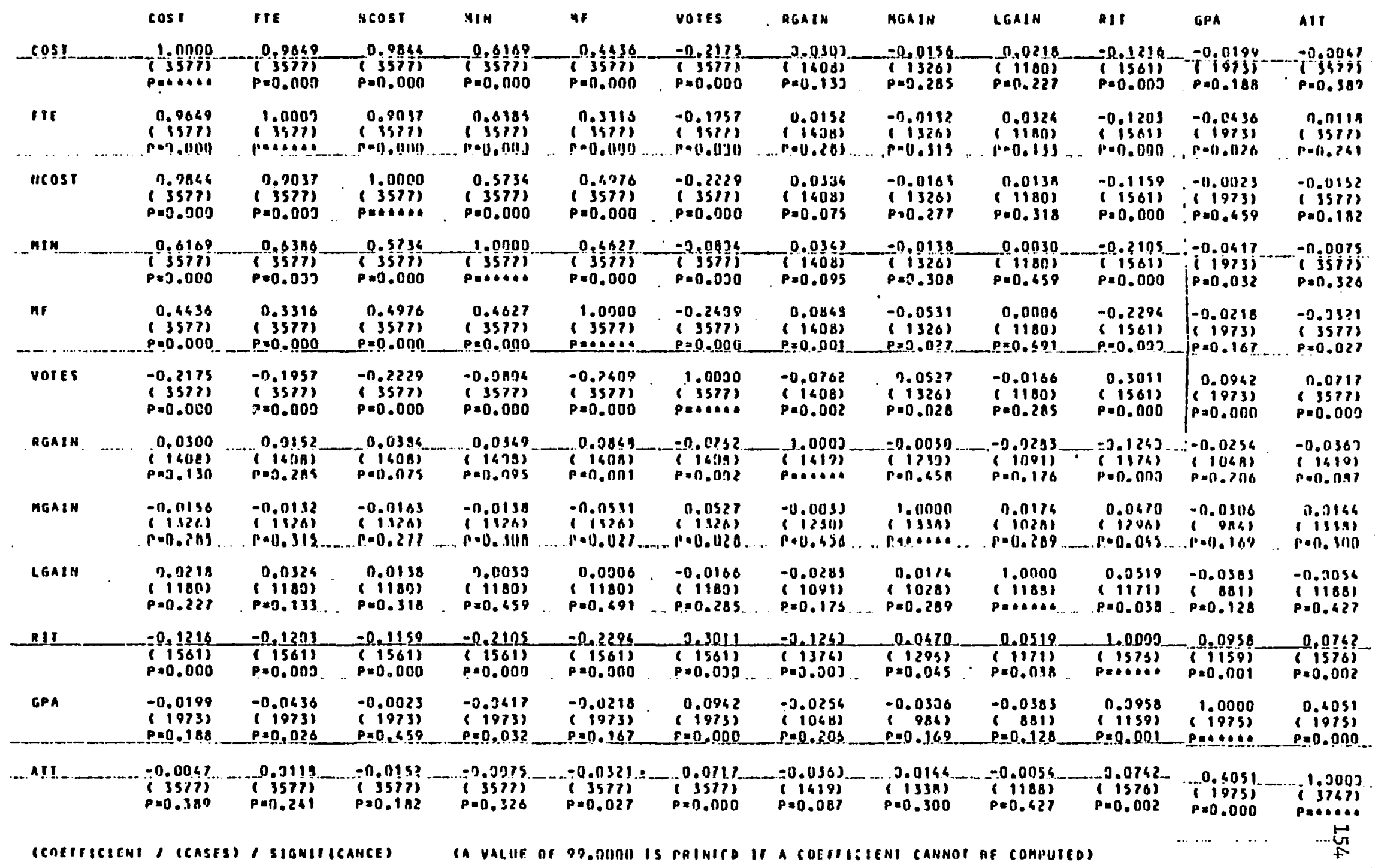




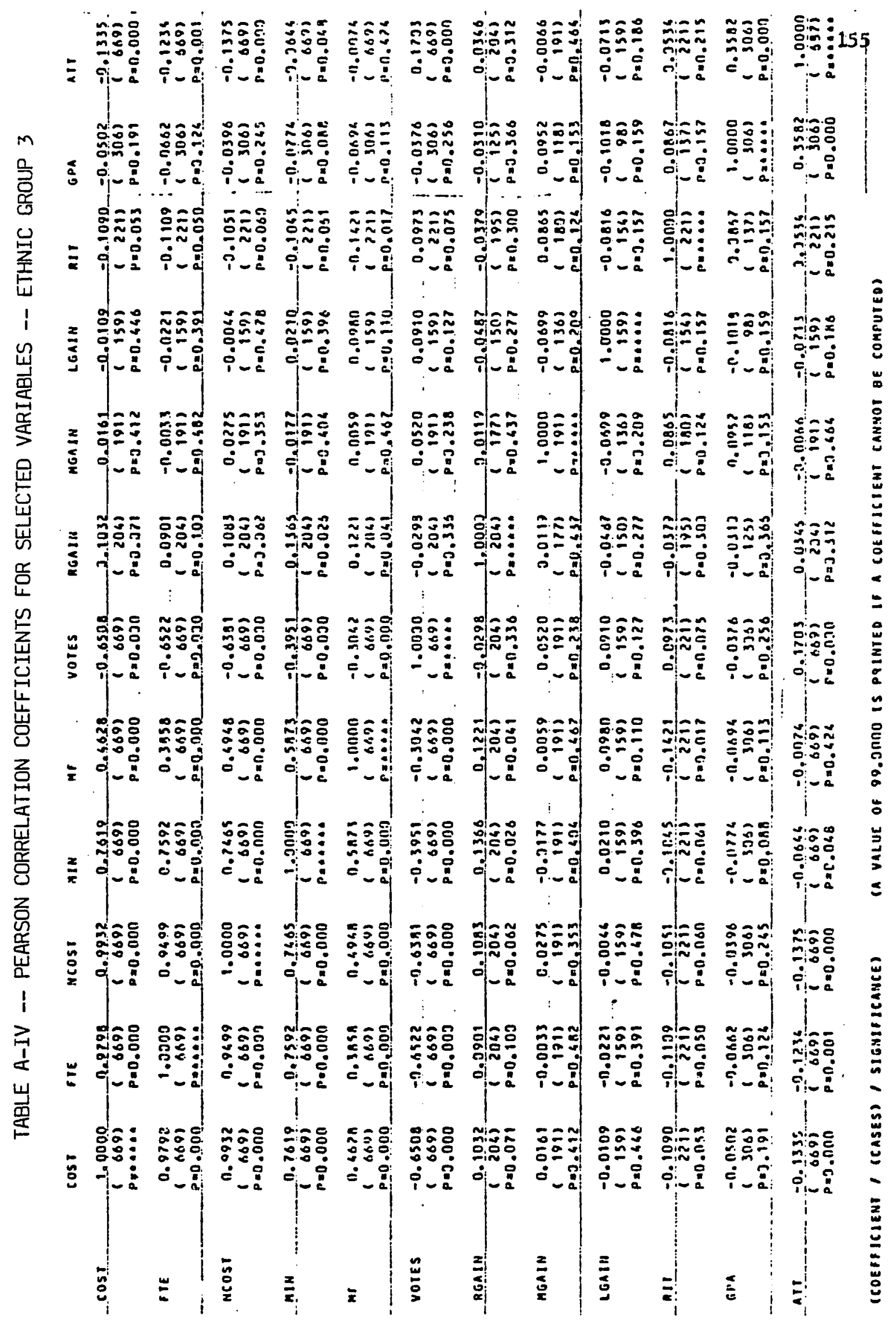




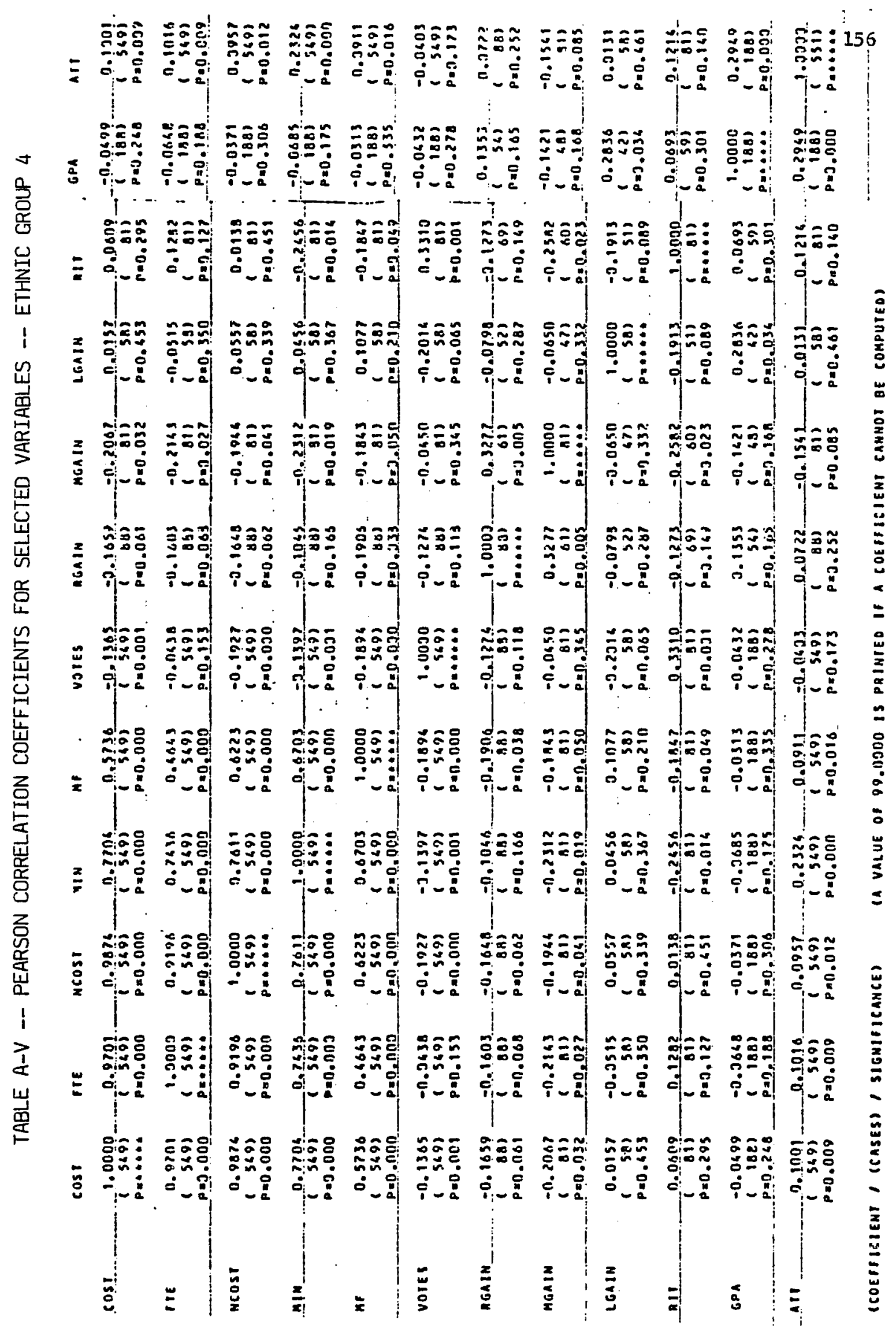




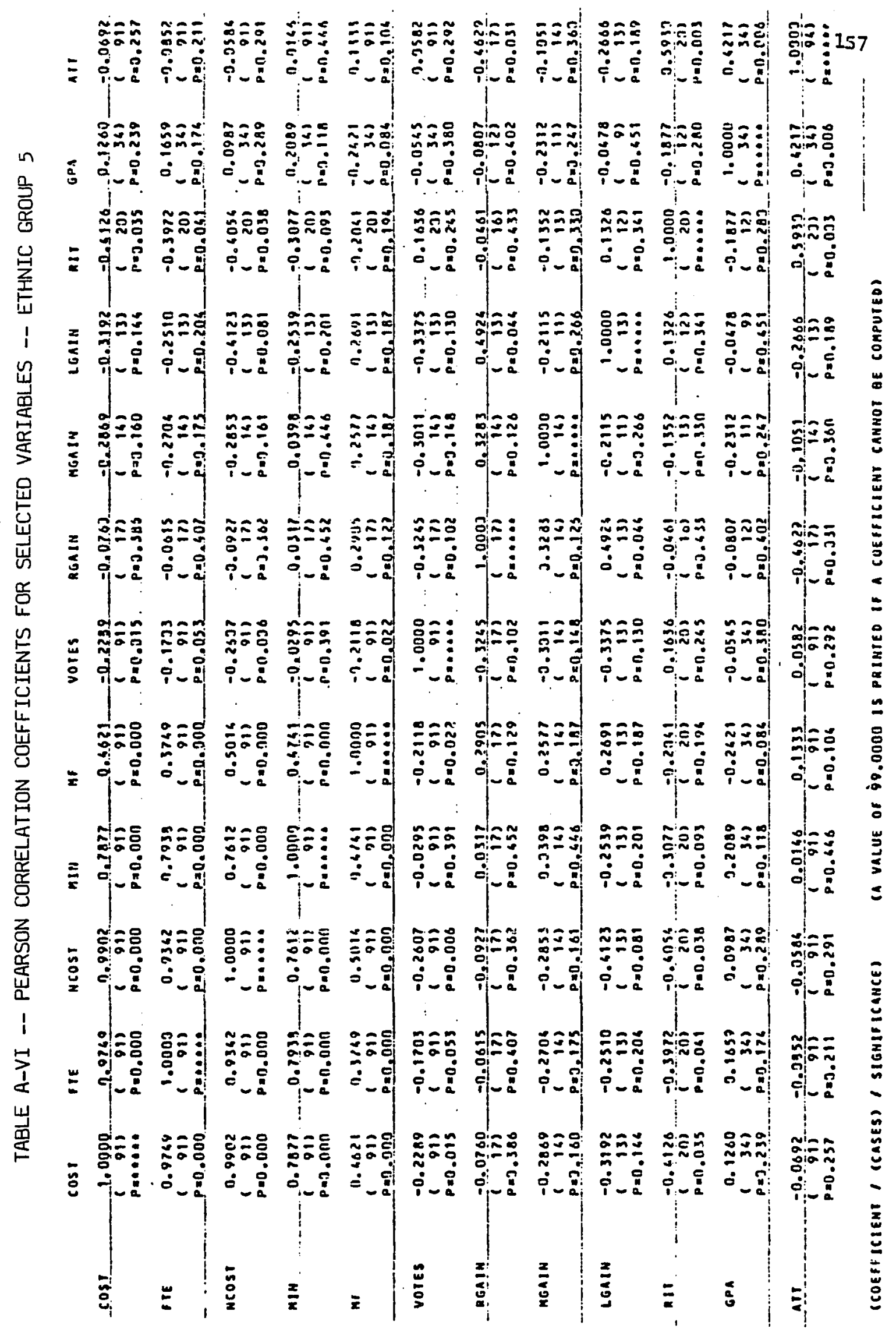


TABLE A-VII -- PEARSON CORRELATION COEFFICIENTS FOR SELECTED VARIABLES -- FEMALE

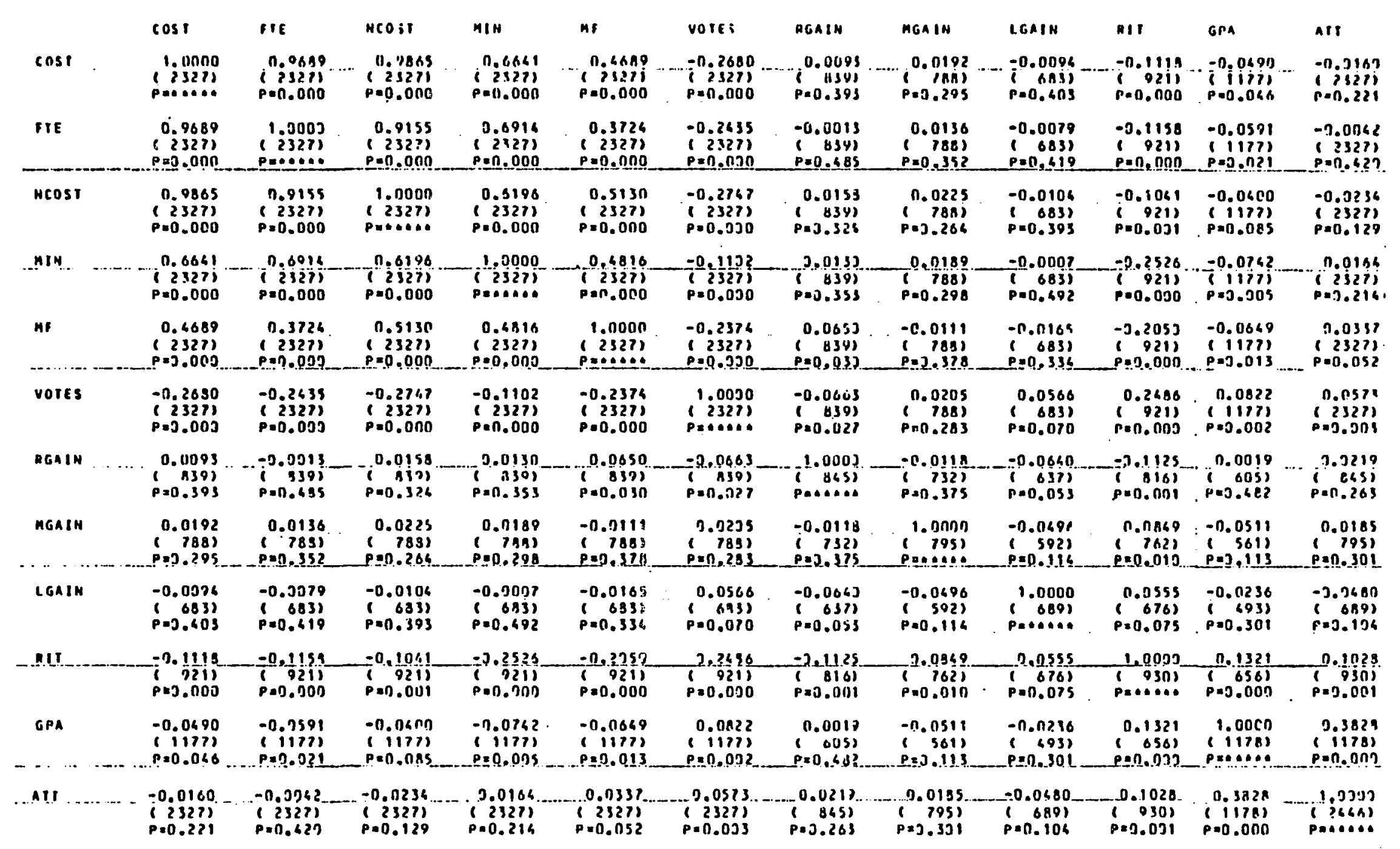

(COEMICIEMT / (CASES) , SIGNIFICANCE) 


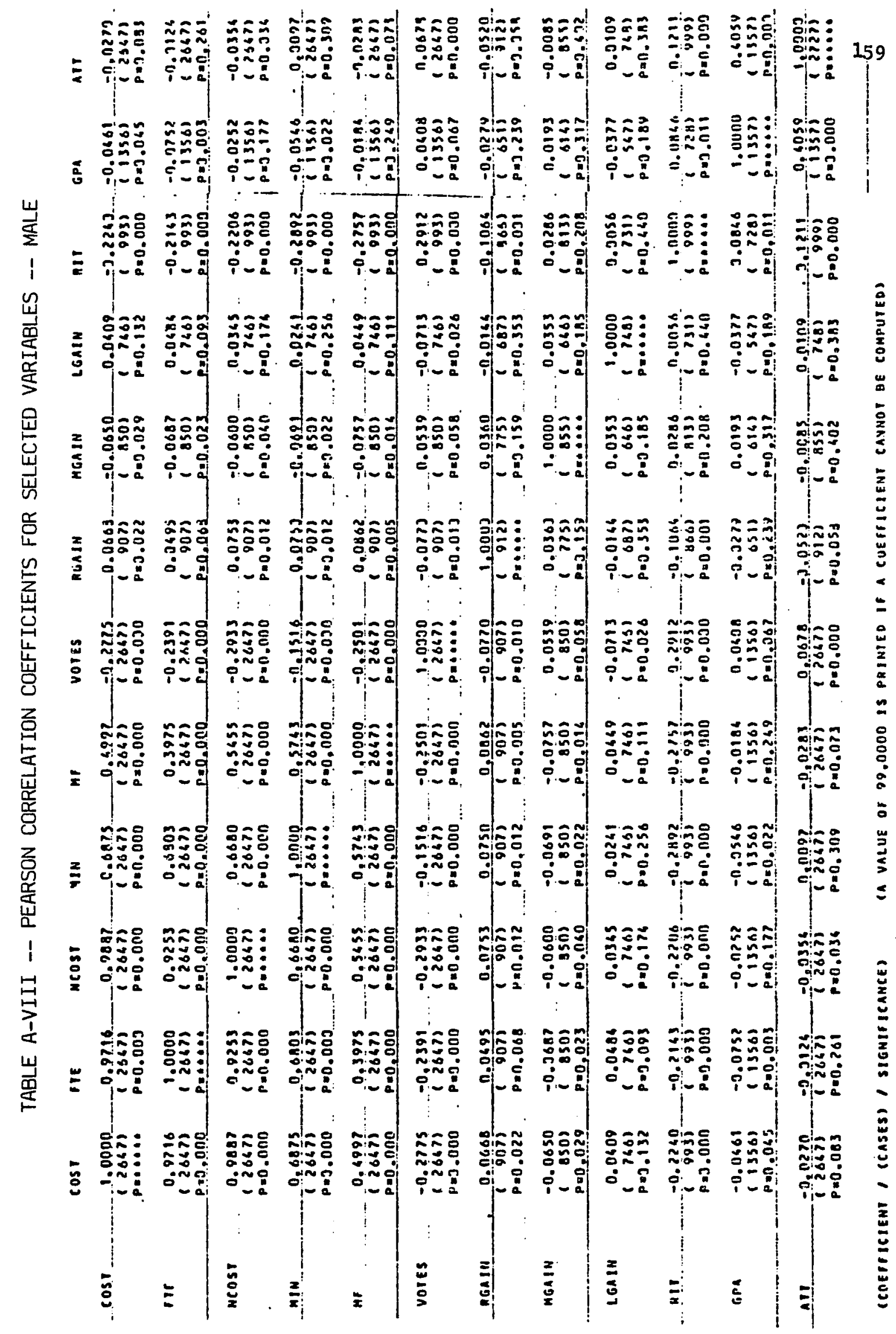


APPENDIX B

SIMPLIFIED REPRESENTATIONS

OF CORRELATION ANALYSES 
TABLE B-I

SIMPLIFIED CORRELATION MATRIX

ALL GROUPS

\begin{tabular}{|c|c|c|c|c|c|c|c|c|c|c|c|c|}
\hline & COST & FTE & NCOST & $M \%$ & MF\% & VOTE & RGAIN & MGAIN & LGAIN & RIT & GPA & ATT \\
\hline COST & & + & + & + & + & - & & & & - & & \\
\hline FTE & + & & + & + & + & - & & & & - & & \\
\hline NCOST & + & + & & + & + & - & & & & - & & \\
\hline$M \%$ & + & + & + & & + & - & & & & - & & \\
\hline MF\% & + & + & + & + & & - & & & & - & & \\
\hline VOTE & - & - & - & - & - & & & & & + & & \\
\hline RGAIN & & & & & & & & & & - & & \\
\hline MGAIN & & & & & & & & & & & & \\
\hline LGAIN & & & & & & & & & & & & \\
\hline RIT & - & - & - & - & - & + & - & & & & + & + \\
\hline GPA & & & & & & & & & & + & & + \\
\hline ATT & & & & & & & & & & + & + & \\
\hline
\end{tabular}


TABLE B-II

SIMPLIFIED CORRELATION MATRIX

ETHNIC GROUP 2

\begin{tabular}{|c|c|c|c|c|c|c|c|c|c|c|c|c|}
\hline & COST & FTE & NCOST & M\% & MF\% & VOTE & RGAIN & MGAIN & LGAIN & RIT & GPA & ATT \\
\hline COST & & + & + & + & + & - & & & & - & & \\
\hline FTE & + & & + & + & + & - & & & & - & & \\
\hline NCOST & + & + & & + & + & - & & & & - & & \\
\hline M\% & + & + & + & & + & & & & & - & & \\
\hline MF\% & + & + & + & + & & - & & & & - & & \\
\hline VOTE & - & - & - & & - & & & & & + & & \\
\hline RGAIN & & & & & & & & & & - & & \\
\hline \multicolumn{13}{|l|}{ MGAIN } \\
\hline \multicolumn{13}{|l|}{ LGAIN } \\
\hline RIT & - & - & - & - & - & + & - & & & & & \\
\hline GPA & & & & & & & & & & & & + \\
\hline ATT & & & & & & & & & & & + & \\
\hline
\end{tabular}


TABLE B-III

SIMPLIFIED CORRELATION MATRIX ETHNIC GROUP 3

\begin{tabular}{|c|c|c|c|c|c|c|c|c|c|c|c|c|}
\hline & COST & FTE & NCOST & M\% & MF\% & VOTE & RGAIN & MGAIN & LGAIN & RIT & GPA & ATT \\
\hline COST & & + & + & + & + & - & & & & - & & - \\
\hline FTE & + & & + & + & + & - & & & & - & & - \\
\hline NCOST & + & + & & & + & - & + & & & - & & - \\
\hline$M \%$ & + & + & + & & + & - & + & & & - & & \\
\hline MF\% & + & + & + & + & & - & + & & & - & & \\
\hline VOTE & - & - & - & - & - & & & & & & & + \\
\hline RGAIN & & & + & + & + & & & & & & & \\
\hline \multicolumn{13}{|l|}{ MGAIN } \\
\hline \multicolumn{13}{|l|}{ LGAIN } \\
\hline RIT & - & - & - & - & - & & & & & & & \\
\hline GPA & & & & & & & & & & & & + \\
\hline ATT & - & - & - & & & + & & & . & & + & \\
\hline
\end{tabular}


TABLE B-IV

SIMPLIFIED CORRELATION MATRIX

ETHNIC GROUP 4

\begin{tabular}{|c|c|c|c|c|c|c|c|c|c|c|c|c|}
\hline & COST & FTE & NCOST & M\% & MF\% & VOTE & RGAIN & MGAIN & LGAIN & RIT & GPA & ATT \\
\hline COST & & + & + & + & + & - & - & - & & & & + \\
\hline FTE & + & & + & + & + & & - & - & & & & + \\
\hline NCOST & + & + & & + & + & - & - & - & & & & \\
\hline$M \%$ & + & + & + & & + & - & & - & & - & & + \\
\hline$M F \%$ & + & + & + & + & & - & - & - & & - & & \\
\hline VOTE & - & & - & - & - & & & & - & + & & \\
\hline RGAIN & - & - & - & & - & & & + & & & & \\
\hline MGAIN & - & - & - & - & - & & + & & & - & & - \\
\hline LGAIN & & & & & & - & & & & - & + & \\
\hline RIT & & & & - & - & + & & - & - & & & \\
\hline GPA & & & & & & & & & + & & & + \\
\hline ATT & + & + & & + & & & & - & & & + & \\
\hline
\end{tabular}


TABLE B-V

SIMPLIF IED CORRELATION MATRIX

FEMALE

\begin{tabular}{|c|c|c|c|c|c|c|c|c|c|c|c|c|}
\hline & $\operatorname{COST}$ & FTE & NCOST & M\% & MF\% & VOTE & RGAIN & MGAIN & LGAIN & RIT & GPA & ATT \\
\hline COST & & + & + & + & + & - & & & & - & & \\
\hline FTE & + & & + & + & + & - & & & & - & & \\
\hline NCOST & + & + & & + & + & - & & & & - & & \\
\hline M\% & + & + & + & & + & - & & & & - & & \\
\hline MF\% & + & + & + & + & & - & & & & - & & \\
\hline VOTE & - & - & - & - & - & & & & & + & & \\
\hline RGAIN & & & & & & & & & & - & & \\
\hline \multicolumn{13}{|l|}{ MGAIN } \\
\hline \multicolumn{13}{|l|}{ LGAIN } \\
\hline RIT & - & - & - & - & - & + & - & & & & + & + \\
\hline GPA & & & & & & & & & & + & & + \\
\hline ATT & & & & & & & & & & + & + & \\
\hline
\end{tabular}


TABLE B-VI

SIMPLIFIED CORRELATION MATRIX

MALE

\begin{tabular}{|c|c|c|c|c|c|c|c|c|c|c|c|c|}
\hline & COST & FTE & NCOST & M\% & MF\% & VOTE & RGAIN & MGAIN & LGAIN & RIT & GPA & ATT \\
\hline COST & & + & + & + & + & - & & & & - & & \\
\hline FTE & + & & + & + & + & - & & & & - & & \\
\hline NCOST & + & + & & + & + & - & & & & - & & \\
\hline M\% & + & + & + & & + & - & & & & - & & \\
\hline MF\% & + & + & + & + & & - & & & & - & & \\
\hline VOTE & - & - & - & - & - & & & & & + & & \\
\hline RGAIN & & & & & & & & & & - & & \\
\hline \multicolumn{13}{|l|}{ MGAIN } \\
\hline \multicolumn{13}{|l|}{ LGAIN } \\
\hline R.LT & - & - & - & - & - & + & - & & & & & + \\
\hline GPA & & & & & & & & & & & & + \\
\hline ATT & & & & & & & & & & + & + & \\
\hline
\end{tabular}


APPENDIX C

GLOSSARY OF ABBREVIATIONS AND ACRONYMS 


\section{GLOSSARY OF ABBREVIATIONS AND ACRONYMS}

ATT Attendance. A computed variable, the number of classes attended in a given term by a student.

CARS Computer Assisted Reassignment System. A computer software system for determining school attendance boundaries.

COST Cost. A computed variable, the cost per student per school.

DSS Decision Support System. A computerized information system designed to aid in decision making.

EEO Equality of Educational Opportunity. The concept that each public school student is entitled to an equal opportunity for a quality education.

FTE Full Time Equivalency. A computed variable, a measure of the full time equivalent faculty per student per school.

GPA Grade Point Average. A computed variable, a measure of a student's average grades in a given term.

IQ Intelligence Quotient. A measure, often a test score, sometimes used to estimate a student's potential for educational achievement.

IS Information System. A system (in this Dissertation, a computerized system) which stores data and is able to manipulate the data in such a way as to provide information within a given context.

LGAIN Language Usage RIT Gain. A computed variable, measuring the gain from fall to spring on the Language Usage test.

M\% Minority Percentage per School. A computed variable, measuring the percentage of minority students at a school.

MF\% Minority Faculty Percentage per School. A computed variable, measuring the percentage of minority faculty at a school.

MGAIN Math RIT Gain. A computed variable, mesuring the gain from fall to spring on the Math test.

MIS Management Information System. A computerized information system which provides information for management.

NAACP National Associaton for the Advancement of Colored People. 
NDTRAN Notre Dame Dynamic Fortran. A continuous simulation computer Ianguage developed at the University of Notre Dame.

NCOST Non-FTE Cost per Student per School. A computed variable, measuring the cost per student per school for all expenditures except personnel.

PL Public Law. Used in reference to Public Law 88-452 and Public Law 94-152, federal legislation.

RGAIN Reading RIT Gain. A computed variable, measuring the gain from fall to spring on the Reading test.

RIT Reading Rasch Unit Score. A measure of the student's reading achievement level in units which can be compared to all other students.

SEI Socioeconomic Index. A computed variable, measuring a student's social and economic background.

SPSS Statistical Package for the Social Sciences. A package of computer software which performs various statistical analyses.

SUSP Suspensions. A computed variable, measuring the incidence of suspension for each student.

US United States. Used in referencing United States Supreme Court decisions.

VOTE Voter Support. A computed variable, measuring the percentage of voters residing within the attendance area of any school who voted in favor of the school district's latest tax measure. 
APPENDIX D

CONSTITUTION OF THE UNITED STATES

AMENDMENTS $V, X I I I, X I V, X V$ 
AMENDMENT $V$

Provisions concerning prosecution. Trial and punishment--private property not to be taken for public use without compensation.

No person shall be held to answer for a capital, or otherwise infamous crime, unless on a presentment or indictment of a Grand Jury, except in cases arising in the land or naval forces, or in the militia, when in actual service in time of war or public danger; nor shall any person be subject for the same offense to be twice put in jeopardy of life or limb; nor shall be compelled in any criminal case to be a witness against himself, not be deprived of life, liberty, or property, without due process of law; nor shall private property be taken for public use without just compensation. 
(Proposed by Congress January 31, 1865; ratification completed December 18, 1865. The amendment, when first proposed by a resolution in Congress, was passed by the Senate, 38 to 6 , on April 8, 1864, but was defeated in the House, 95 to 66 , on June 15, 1864. On reconsideration by the House on January 31, 1865, the resolution passed, 119 to 56. It was approved by President Lincoln on February 1, 1865, although the Supreme Court had decided in 1798 that the President has nothing to do with the proposing. of amendments to the Constitution, or their adoption.)

1. Neither slavery nor involuntary servitude, except as a punishment for crime whereof the party shall have been duly convicted, shall exist within the United States or any place subject to their jurisdiction.

2. Congress shall have power to enforce this article by appropriate legislation. 
AMENDMENT XIV

Citizenship Rights Not to be Abridged

(The following amendment was proposed to the Legislatures of the several states by the 39th Congress, June 13, 1866, and was declared to have been ratified in a proclamation by the Secretary of State, July 28, 1868.)

(The 14th amendment was adopted only by virtue of ratification subsequent to earlier rejections. Newly constituted legislatures in both North Carolina and South Carolina [respectively July 4 and 9, 1868], ratified the proposed amendment, although earlier legislatures had rejected the proposal. The Secretary of State issued a proclamation, which, though doubtful as to the effect of attempted withdrawals by Ohio and New Jersey, entertained no doubt as to the validity of the ratification by North and South Carclina. The following day [July 21, 1868], Congress passed a resolution which declared the 14th Amendment to be a part of the Constitution and directed the Secretary of State so to promulgate it. The Secretary waited, however, until the newly constituted Legislature of Georgia had ratified the amendment, subsequent to an earlier rejection, before the promulagation of the ratification of the new amendment.)

1. All persons born or naturalized in the United States, and subject to the jurisdiction thereof, are citizens of the United States and of the State wherein they reside. No State shall make or enforce any law which shall abridge the privileges or immunities of citizens of the United States; nor shall any State deprive any person of life, liberty, or property, without due process of law; nor deny to any person within its jurisdiction the equal protection of the laws.

2. Representatives shall be apportioned among the several States according to their respective numbers, counting the whole number of persons in each State, excluding Indians not taxed. But when the right to vote at any election for the choice of Electors for President and VicePresident of the United States, Representatives in Congress, the executive and judicial officers of a State, or the members of the Legislature thereof, is denied to any of the male inhabitants of such State, being twentyone years of age, and, citizens of the United States, or in any way abridged, except for participation in rebellion, or other crime, the 
basis of representation therein shall be reduced in the proportion which the number of such male citizens shall bear to the whole number of male citizens twenty-one years of age in such State.

3. No person shall be a Senator or Representative in Congress, or Elector of President and Vice-President, or hold any office, civil or military, under the lnited states, or under any State, who, having previously taken an oath, as a member of Congress, or as an officer of the United States, or as a member of any State Legislature, or as an executive or judicial officer of any State, to support the Constitution of the United States, shall have engaged in insurrection or rebellion against the same, or given aid or comfort to the enemies thereof. But Congress may by a vote of two-thirds of each House, remove such disability.

4. The validity of the public debt of the United States, authorized by law, including debts incurred for payment of pensions and bounties for services in suppressing insurrection or rebellion, shall not be questioned. But neither the United States nor any State shall assume or pay any debt or obligation incurred in aid of insurrection or rebellion against the United States, or any claim for the loss or emancipation of any slave; but all such debts, obligations and claims, shall be held illegal and void.

5. The Congress shall have power to enforce, by appropriate legislation, the provisions of this article. 
AMENDMENT XV

Race No Bar to Voting Rights

(The following amendment was proposed to the legislatures of the several States by the 40th Congress, February 26, 1869, and was declared to have been ratified in a proclamation by the Secretary of State, March 30, 1870.)

1. The right of citizens of the United States to vote shall not be denied or abridged by the United States or by any State on account of race, color, or previous condition of servitude.

2. The Congress shall have power to enforce this article by appropriate legislation. 


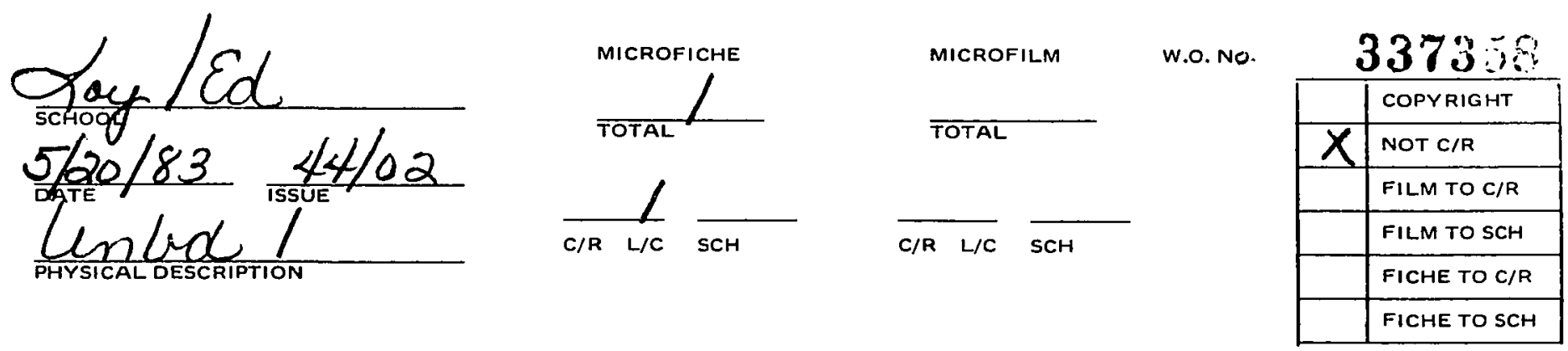

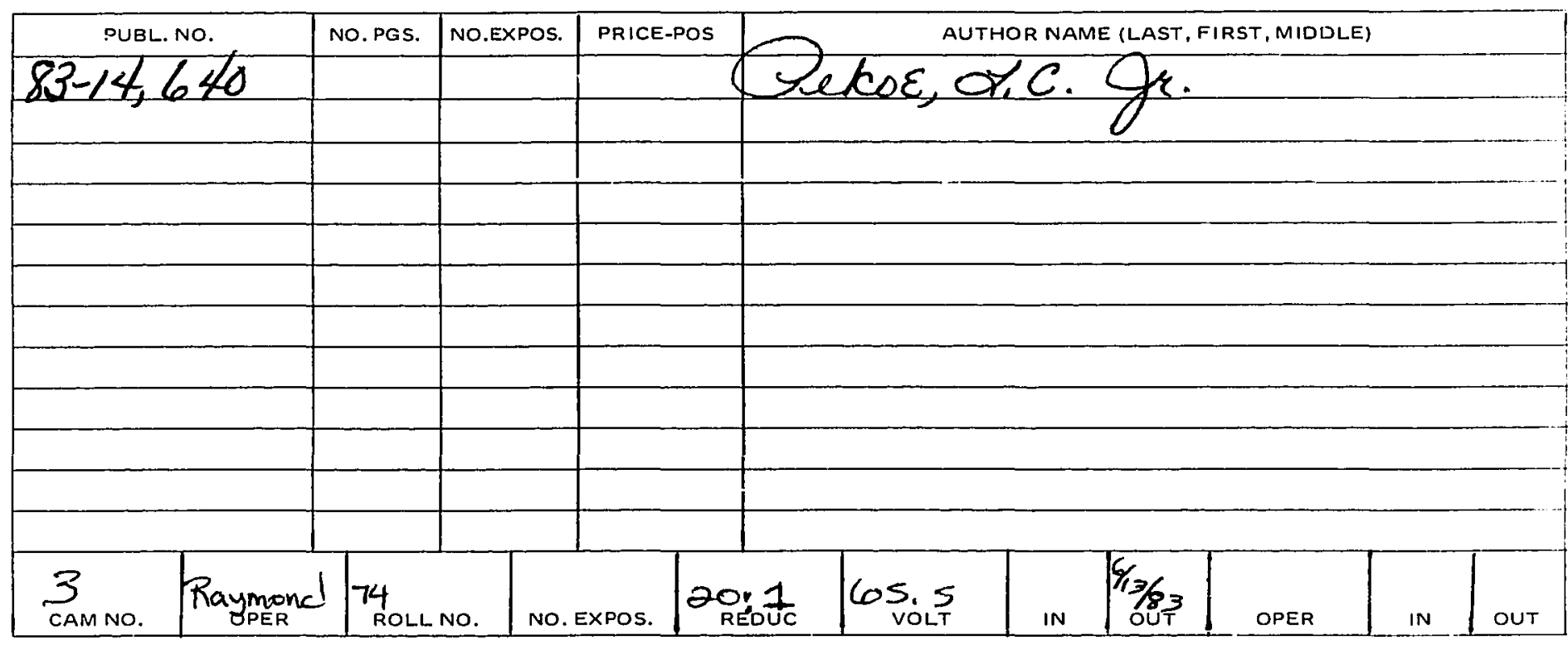

Em 263

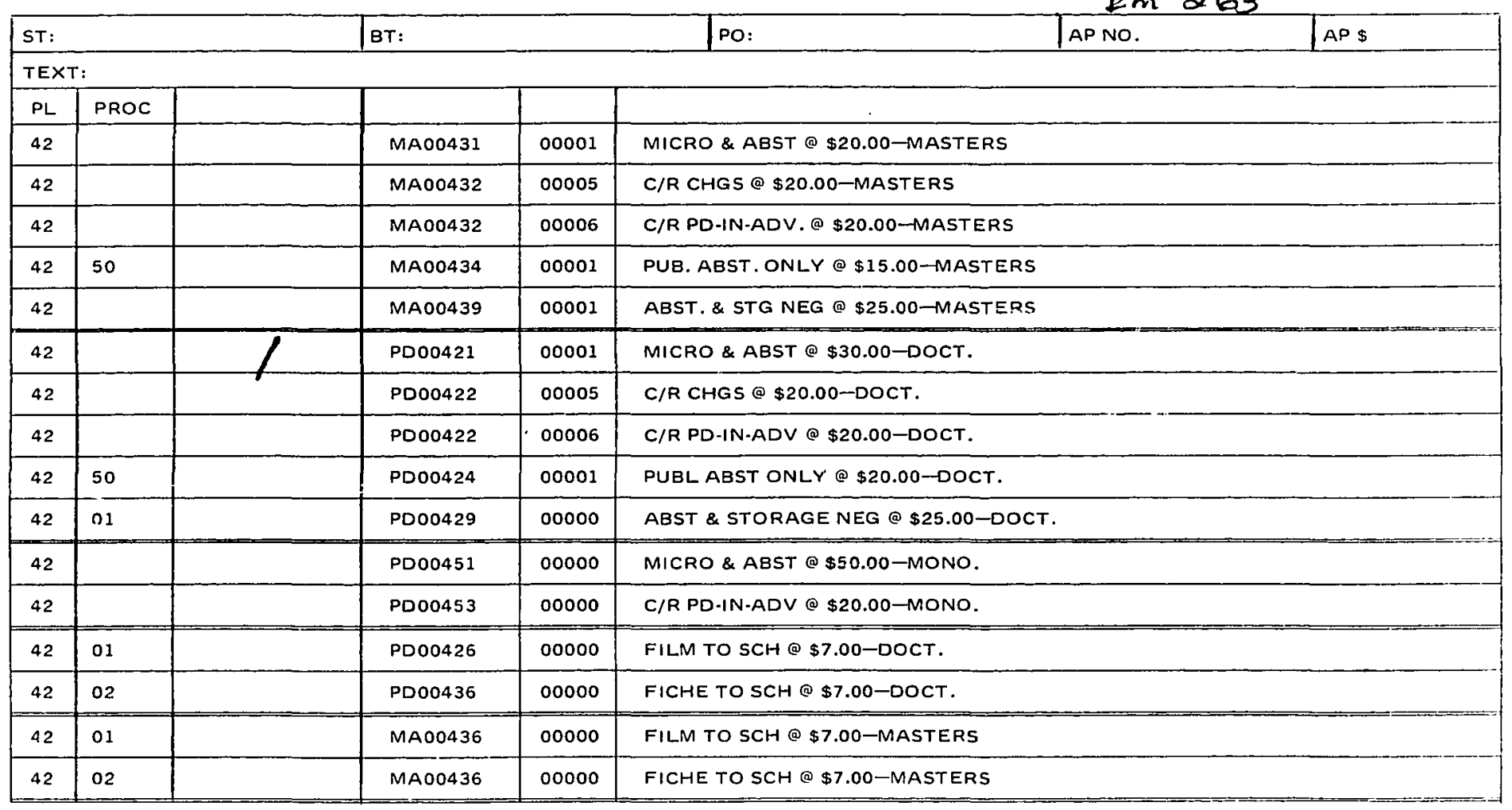

FORM 33 